Gustavo Voltani von Atzingen

\title{
DESENVOLVIMENTO DE UM EQUIPAMENTO PARA CAPTAÇÃO DO EFEITO CORONA EM ALIMENTOS
}

\author{
Versão Revisada
}

Dissertação apresentada à Faculdade de Zootecnia e Engenharia de Alimentos da Universidade de São Paulo, como parte dos requisitos para a obtenção do Título de Mestre em Engenharia de Alimentos.

Área de Concentração: Ciências da Engenharia de Alimentos

Orientador: Prof. Dr. Ernane José Xavier Costa 
Dados Internacionais de Catalogação na Publicação

Serviço de Biblioteca e Informação da Faculdade de Zootecnia e Engenharia de Alimentos da Universidade de São Paulo

\section{Atzingen, Gustavo Voltani von}

A887d Desenvolvimento de um equipamento para captação do

efeito corona em alimentos / Gustavo Voltani von

Atzingen -- Pirassununga, 2013.

$100 \mathrm{f}$.

Dissertação (Mestrado) -- Faculdade de Zootecnia e Engenharia

Alimentos - Universidade de São Paulo.

Departamento de Engenharia de Alimentos.

Área de Concentração: Ciências da Engenharia de

Alimentos.

Orientador: Prof. Dr. Ernane José Xavier Costa.

1. Simulação computacional 2. Algoritmo genético

3. Campo elétrico 4. Propriedades reológicas 5. Kirlian

I. Título. 
“Se, a princípio, a ideia não é absurda, então não há esperança para ela"

Albert Einstein 


\section{AGRADECIMENTOS}

A meu Pai e minha mãe, agradecimento eterno por todas as oportunidades que me proporcionaram.

A minha Esposa, que deu todo o suporte necessário para a conclusão deste trabalho.

Ao Prof. Dr. Ernane José Xavier Costa, pela contribuição à minha formação acadêmica, por sua Amizade e por acreditar neste projeto.

Ao Especialista em Laboratório, Aldo Ivan Céspedes Arce, pelo auxílio no desenvolvimento do projeto e por tudo que me ensinou neste período.

Ao Professor Dr. Adriano Rogério Bruno Tech e Dra. Ana Carolina de Souza Silva, por ajudar no desenvolvimento deste trabalho.

Aos alunos de Graduação e Pós-Graduação do LAFAC, por todos os momentos que passamos juntos, com muito trabalho, mas também descontração e brincadeiras.

À Faculdade de Zootecnia e Engenharia de Alimentos, pela oportunidade de realização deste trabalho. 
A todos aqueles que, de uma forma ou de outra, contribuíram para a realização deste trabalho. 


\section{RESUMO}

\section{Atzingen, G. V. v. Desenvolvimento de um equipamento para captação do}

efeito corona em alimentos. 2013. 100 f. Dissertação (Mestrado) Faculdade de Zootecnia e Engenharia de Alimentos, Universidade de São Paulo, Pirassununga, 2013.

O presente trabalho teve como objetivo o desenvolvimento de um equipamento capaz de gerar e captar o efeito corona em alimentos de forma automatizada e instantânea. Para isto, foi desenvolvido um gerador de alta tensão e alta frequência, um sistema de captação com eletrodo e câmera digital e um software de gerenciamento do sistema, que recebe e trata os dados coletados através da câmera digital. Para comprovar a eficiência do sistema, foram feitos vários testes com frutas (maçã, limão, ameixa, uva e pera) e os resultados obtidos foram comparados com imagens geradas por um sistema kirlian e com simulações computacionais através de algoritmo genético e elementos finitos e permitem assim, concluir que o sistema proposto foi capaz de captar imagens que contém informações das características físico-químicas do alimento.

Palavras-chave: Kirlian, simulação computacional, algoritmo genético, Campo Elétrico, Propriedades Reológicas. 


\begin{abstract}
Atzingen, G.V.v. Development of a device for acquiring the corona effect on food . 2013. 100 f. Dissertation (Master's degree) - Faculdade de Zootecnia e Engenharia de Alimentos, Universidade de São Paulo, Pirassununga, 2013.

This study aimed to develop a device capable of generating and acquiring the corona effect on food automatically and instantaneously. In order to make it possible, a high voltage and high frequency generator was developed, with a system with electrodes and digital camera controlled by a software that receives and handles incoming data from a digital camera. To test de system, experiments where made with fruits (apples, lemons, plums, grapes and pears) and the results where compared to a standard system and with computational simulation made with Genetic Algorithm and Finite Elements and it was conclude that the system is able to acquire images that contain information on the physical-chemical proprieties of the material.
\end{abstract}

Key-words: Kirlian, Computational Simulation, Genetic Algorithm, Electric Field, Rheology. 


\section{LISTA DE ILUSTRAÇÕES}

Figura 1 - circuito elétrico equivalente a uma célula. Arnold, Harker e Bauchot

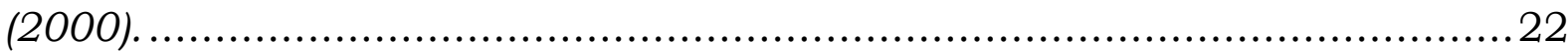

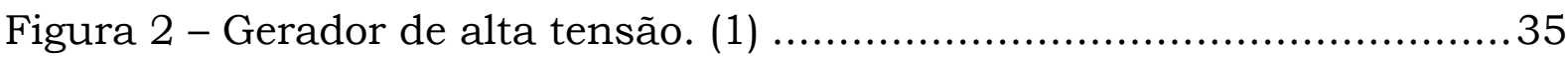

Figura 3 - Esquema elétrico do circuito gerador dos pulsos de alta

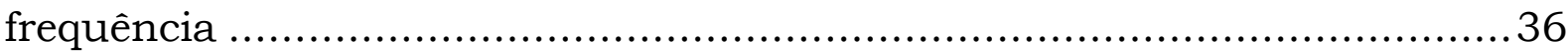

Figura 4 - Circuito para impressão e confecção na placa de fenolite e cobre.

Figura 5 - Sistema de aquisição, com gerador de alta tensão, Sistema de captação da imagem e sistema computacional ..................................38

Figura 6 - Eletrodo com placas de vidro e solução Sal + Água. .................38

Figura 7 - Equipamento em MDF fechado (7.1) e aberto (7.2) .................39

Figura 8 - Pistão que aplica a alta tensão na amostra. .........................40

Figura 9 - Interface do software de controle. ............................... 42

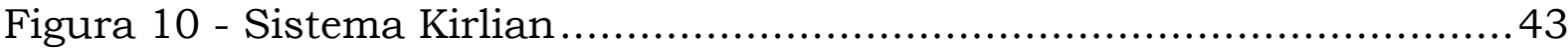

Figura 11 - Tipos de frutas utilizadas no teste do aparelho (adicionar uva e pera cortada). .................................................................... 44

Figura 12 - Fluxograma do algoritmo...................................... 47

Figura 13 - Equipamento gerador de alta tensão ..............................48

Figura 14 - Tensão Lida no Osciloscópio...................................... 49

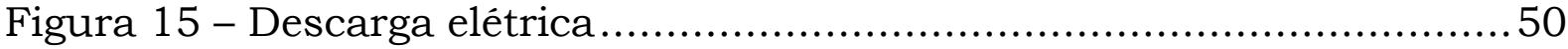

Figura $16-$ Uva Inteira ........................................................... 51

Figura 17- Uva Cortada. (a) imagem processada. (b) imagem não processada. 52

Figura 18 - Maçã............................................................. 53

Figura 19 - Limão........................................................... 53

Figura 20 - Ameixa ............................................................. 54

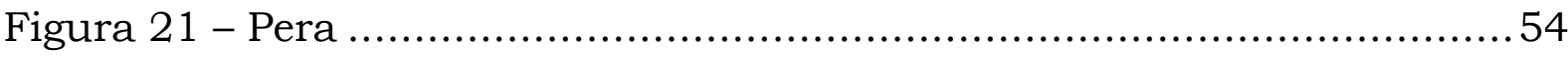

Figura 22 - Imagens captadas separadamente de 3 uvas inteiras.............55 
Figura 23 - maçã. (a) imagem da maçã com marca. (b) imagem da maçã sem problema aparente. (c) Efeito corona na maçã com marca. (d) Efeito corona na maçã sem problema aparente.

Figura 24 - limão. (a) imagem do limão com marca. (b) imagem do limão sem problema aparente. (c) Efeito corona no limão com marca. (d) Efeito corona no limão sem problema aparente.

Figura 25 - Ameixa. (a) imagem da ameixa com marca. (b) imagem da ameixa sem problema aparente. (c) Efeito corona na ameixa com marca. (d) Efeito corona na ameixa sem problema aparente. .58

Figura 26 - Ameixa. .59

Figura 27 - Limão .59

Figura 28- Maçã 60

Figura 29 - Pera cortada. 60

Figura 30 - Uva inteira. 61

Figura 31 - Densidade de cargas em superficie circular. 62

Figura 32 - Densidade de cargas em superficie quadrada.

Figura 33 - Teste do algoritmo com 4 cargas. (a) Cargas na amostra. (b) Energia total do sistema em função do número de iterações. (c) Potencial elétrico na amostra. (d) Densidade de cargas na amostra. .64 Figura 34 - 50 indivíduos, 500 cargas, 5000 iterações. (a) Cargas na amostra. (b) Energia total do sistema em função do número de iterações. (c) Potencial elétrico na amostra. (d) Densidade de cargas na amostra. 65 Figura 35 - 2 constantes dielétricas, 50 indivíduos, 500 cargas, 5000 iterações. (a) Cargas na amostra. (b) Energia total do sistema em função do número de iterações. (c) Potencial elétrico na amostra. (d) Densidade de cargas na amostra. 66

Figura 36 - Comparação entre o Potencial elétrico simulado com 2 constantes dielétricas (a) e efeito corona em uma pera com poupa escura na parte superior (b). 


\section{LISTA DE ABREVIATURAS E SIGLAS}

$\mathrm{AC}=$ corrente alternada, do inglês, "alternating current"

$\mathrm{A} / \mathrm{D}$ = analógico/digital

APPCC = Análise de Perigos e Pontos Criticos de Controle

$\mathrm{BPF}=$ Boas práticas de fabricação

$\mathrm{CCD}=$ Dispositivo de Carga Acoplada

DC = corrente contínua, do inglês, "direct current"

EIS = Espectroscopia de Impedância Complexa, do inglês, "Electric Impedance Spectroscopy"

GUI $=$ Grafical User Interface

GDV = Visualização da descarga em um gás, do inglês, "Gas Discharge Visualization"

MP = Megapixels

PCR $=$ Polymerase Chain Reaction 
PPHO = Procedimento Padrão de Higiene Operacional

u.d.a = Unidade de distância Adimensional

MDF = Medium density fiberboard 


\section{LISTA DE SÍMBOLOS}

Atm $=1$ atmosfera ou $101325 \mathrm{~Pa}($ Pascal)

$\mathrm{h}=$ hora

$\mathrm{Hz}=$ Hert $z$, unidade de medida de freqüência.

$\mathrm{k}=\mathrm{x} 10^{3}$, "kilo".

$\mathrm{m}=$ metros.

$\mathrm{M}=\mathrm{x} 10^{6}$, "mega".

$\mathrm{s}=$ segundo

$\mathrm{V}=$ Volts, unidade de medida para potencial elétrico.

$v=$ Frequência

$\lambda=$ Comprimento de Onda 


\title{
SUMÁRIO
}

\author{
RESUMO
}

ABSTRACT

LISTA DE ILUSTRAÇÕES

LISTA DE ABREVIATURAS E SIGLAS

LISTA DE SÍMBOLOS

RESUMO

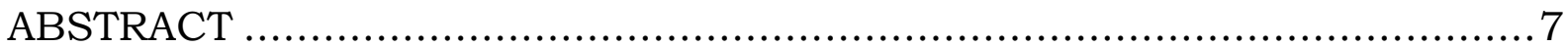

LISTA DE ILUSTRAÇÕES ......................................................

LISTA DE ABREVIATURAS E SIGLAS ......................................... 10

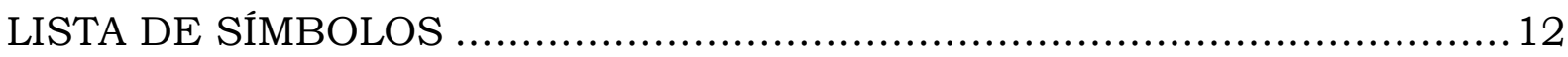

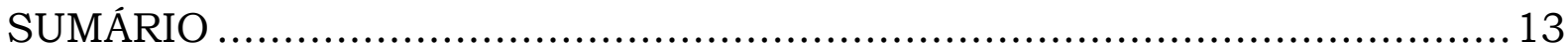

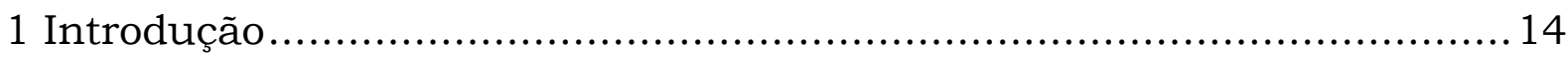

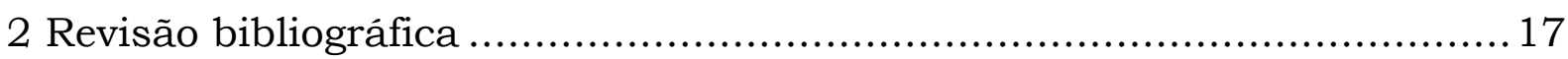

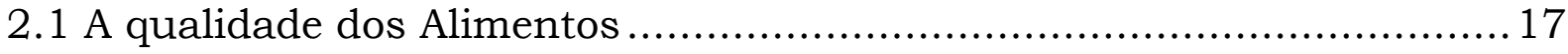

2.2 Espectroscopia de Impedância Complexa .......................................20

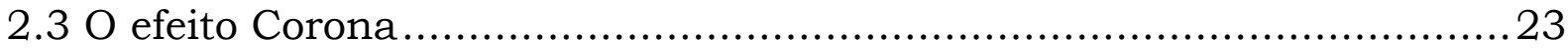

2.3.1 Visualização da descarga elétrica...................................24

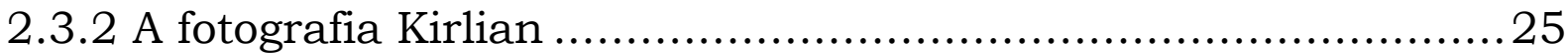

2.3.3 Aplicações em geral .............................................. 27

2.3.4 Aplicações em alimentos ...........................................29

2.4 Modelagem e Simulação na engenharia de alimentos .......................31

2.4.1 Algoritmo Genético ............................................. 32

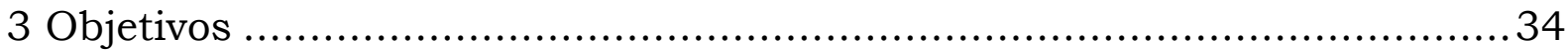

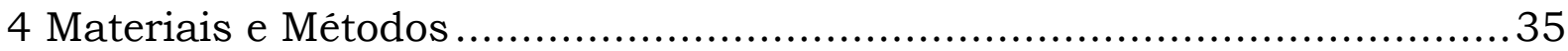

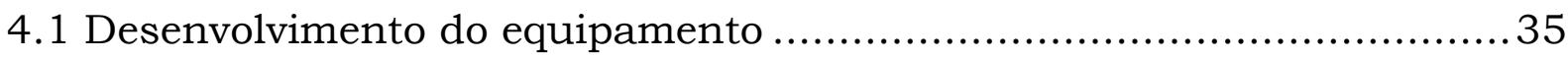

4.1.1 Gerador de Alta tensão em alta frequência ...........................35

4.1.2 Aparato para coletar a imagem da descarga ........................37

4.1.3 Software de aquisição e controle ...................................4 41

4.1.4 Aquisição das imagens com filme fotográfico ......................43 
4.2 Testes com o aparelho

4.3.1 Simulação da distribuição do potencial utilizando o método dos elementos finitos 45

4.3.2 Simulação da distribuição do potencial utilizando algoritmo genético 45

5 Resultados e Discussão 48

5.1 Equipamento de efeito corona ......................................... 48

5.2 Captação do efeito corona ................................................. 51

5.2.1 Imagens com câmera digital............................................. 51

5.2.2 Visualização de alterações no fruto ...................................... 55

5.2.3 Captação do efeito corona com filme tradicional .........................59

5.3 Simulações ............................................................... 62

5.3.1 Simulação com elementos finitos .................................... 62

5.3.2 Simulação com Algoritmo Genético ..................................... 63

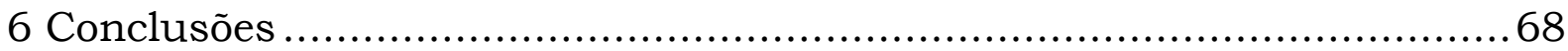

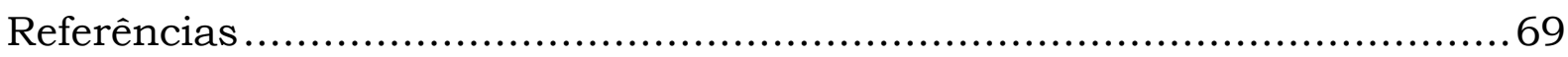

APÊNDICE A - Programa para o Microcontrolador PIC 16f628A ................76

APÊNDICE B - Programa e GUI em MATLAB® responsável pela ativação do

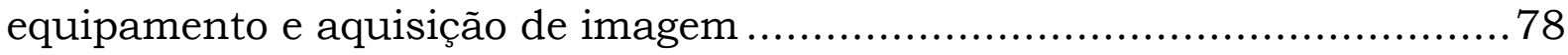

APÊNDICE C - Programa em MATLAB ${ }^{\circledR}$ responsável pela simulação do potencial elétrico utilizando algoritmo genético ................................. 84

APÊNDICE D - Programa para o Microcontrolador Atmega - placa ............92 


\section{Introdução}

No que se diz respeito a alimentos, existe um problema desafiador pertinente aos setores industriais alimentícios, que é a qualidade dos produtos e controle de segurança de sua produção. Este desafio remete ao objetivo de destinar esforços a fim de obter adequação e conformidade com as normas de boas práticas, garantindo tanto a qualidade do produto como a segurança e satisfação do consumidor (VARNAMKHASTI; MOHTASEBI; SIADAT, 2010).

No entanto, o conceito de qualidade de alimentos é complexo e difere entre os setores industriais relacionados. Para o mercado implica em apelo de vendas e economia para o consumidor. No setor de nutrição está relacionado à boa saúde. Já para estudos toxicológicos qualidade quer dizer segurança, uma vez que estes alimentos devem ser inofensivos e sanitariamente adequados, não colocando em risco a saúde do consumidor (CRUZ; SCHNEIDER, 2010).

Em decorrência da inadequação das normas tanto de produção, manipulação e armazenamento, os alimentos podem ter efeito maléfico a saúde das pessoas. Portanto, é de extrema importância o controle de qualidade dos produtos alimentícios antes de serem consumidos, para a proteção da saúde pública, já que o número de severidade de casos de enfermidades relacionados a alimentos aumentaram muito na última década.

Segundo cientistas americanos cerca de trinta e três milhões de casos de infecção e intoxicação relacionados a alimentos ocorrem anualmente nos Estados Unidos, além de inúmeros casos de doenças crônicas como neoplasias e alergias. No entanto, dados deste tipo não foram coletados no Brasil (FILHO; SANTOS, 2010).

Visto a necessidade de controle e importância da qualidade dos alimentos, as empresas estão desenvolvendo novas ferramentas ou aperfeiçoando as existentes, com o objetivo de implantá-las nas indústrias 
alimentícias, da mesma forma que as técnicas destinadas a manipulação e armazenamento dos produtos, que tem a premissa de garantir a segurança do consumidor e a inocuidade do alimento. Dentre as ações tecnológicas que estão sendo desenvolvidas, destacam-se a Análise de Perigos e Pontos Críticos de Controle (APPCC), Boas práticas de fabricação (BPF) e Procedimento Padrão de Higiene Operacional (PPHO).

O APPCC é considerado o mais importante sistema de Controle e Garantia de Qualidade. Este sistema está fundamentado em conceitos de prevenção, no qual as etapas envolvidas no preparo do alimento como recepção de matéria-prima, ambiente, pessoas, processamento, estocagem e distribuição devem estar sob controle rigoroso, caracterizando assim o cuidado e a segurança que está sendo empregada no ramo alimentício (CERF; DONNAT, 2011).

No entanto, a eficácia desta ferramenta está relacionada com a implantação prévia tanto de BPF quanto PPHO. De acordo com a resolução RDC 275, (BRASIL, 2002), Boas Práticas de Fabricação abrangem medidas e comportamentos que devem ser adotadas tanto pelas indústrias de alimentos quanto por seus manipuladores para garantir a qualidade sanitária e a conformidade dos alimentos com os regulamentos técnicos.

Por meio da aplicação dessas ferramentas, visa-se minimizar os riscos de contaminação durante as etapas do processo de produção. Para tanto, é necessário monitorar diversas variáveis do processo, assim como os manipuladores envolvidos em todo o processamento e isto implica em capacitação e comprometimento.

Tendo isto em vista, vários métodos são utilizados para caracterizar a deterioração de alimentos, tais como luminescência, espectroscopia e o método do cultivo para contagem. Métodos tradicionais, como a luminescência e a espectroscopia possuem grande precisão, mas tem como desvantagem serem aparelhos complexos e caros, ocupando muito espaço e inviabilizando a montagem em locais de produção ou linhas móveis.

Desenvolver novos métodos de caracterização dos processos envolvidos na produção e na deterioração de alimentos é muito importante e pode levar 
a um maior entendimento dos processos bioquímicos, além de novas aplicações tecnológicas na indústria alimentícia.

Estudos recentes mostram que a captação do Efeito Corona pode ser utilizada como uma forma alternativa de se obter informações a respeito da impedância de um material, (YOUNG, 2004). Isto torna a captação do efeito corona um método alternativo de se identificar propriedades dos alimentos através das imagens geradas pela descarga elétrica, uma vez que uma série de propriedades dos alimentos já foi relacionada a alterações na sua impedância, conforme Bhatt e Nagaraju (2009), Maindonald e Harker (1994), Arnold, Harker e Bauchot (2000), Ogawa e Tagawa (2008), Marchello, Slangere e Carsol (1999), Lepetit e colaboradores (2007) entredd outros.

A vantagem da utilização do efeito corona em relação a técnicas de impedância é devido ao baixo custo do equipamento e versatilidade, já que é um equipamento pequeno e não requer um laboratório para se realizar as medidas. Neste contexto situa-se o presente trabalho, que teve como objetivo o desenvolvimento de um equipamento para captar o efeito corona em alimentos de forma automatizada. 


\section{Revisão bibliográfica}

\subsection{A qualidade dos Alimentos}

As doenças de origem alimentar são consideradas um dos maiores perigos à saúde pública. Sendo de grande relevância, o controle do ambiente de processamento do alimento, bem como a temperatura, a umidade e o armazenamento são essenciais para minimizar o risco de disseminação desses patógenos, que crescem continuamente (FREITAS; LEMOS; MARIN, 2006).

É nesse contexto que são inseridas técnicas de detecção e monitoramento de microrganismos e toxinas a fim de diminuir, significativamente, os casos de infecção e intoxicação veiculada por alimentos industrializados fora das conformidades.

Em recentes pesquisas laboratoriais foi encontrada uma excelente alternativa para os atuais métodos de diagnósticos microbiológicos: a reação em cadeia da polimerase (Polymerase Chain Reaction - PCR) (FREITAS; LEMOS; MARIN, 2006). Utilizando esta técnica como meio de diagnóstico de detecção de Staphylococcus aureus e determinação de diferentes enterotoxinas relacionadas a casos de intoxicação. Zocche e colaboradores, (2009), mostraram como duas PCRs podem detectar os genes de enterotoxinas isolados em leite in natura e em outros alimentos de origem animal.

Técnicas simples e convencionais também são aplicadas, como por exemplo, o método de Coloração Gram, que é amplamente empregado devido a seu largo espectro de coloração, no qual as bactérias são divididas em dois grupos: gram-positivas e gram-negativas. Este espectro inclui praticamente todas as bactérias, muitos parasitas, fungos e protozoários (MARTINEZ; TADEI, 2005). Em análises de frutas, Pinheiro e colaboradores (2005) utilizaram a técnica de coloração para confirmação de colônias encontradas nas amostras analisadas. 
Outro método de detecção por cor rápido e simples, aplicado para detecção de Salmonella, ocorre por meio de coloração de anticorpo fluorescente. Segundo Ibrahim e Fleet (1985), este consiste na aplicação direta de anticorpo tratado com corante fluorescente e após preparação prévia, a amostra é examinada com um microscópio fluorescente. Esta técnica foi aplicada em alimentos secos e congelados, como leite em pó seco.

Para determinação da população de coliformes totais, coliformes fecais, E. Coli e S. Aureus, a técnica denominada Número Mais Provável (NMP) é utilizada. Esta técnica baseia-se na observação da produção de gás em tubos com amostras inoculadas e incubadas. Diferente das demais análises, esta técnica não fornece uma análise quantitativa da população, e os resultados são visualizados por meio de tabelas, como por exemplo as tabelas fornecidas pela Associação Brasileira de Normas Técnicas (SILVA, 2002).

Técnicas mais avançadas como cromatografia e espectrofotometria também são utilizadas para este tipo de análise. Eyles e Adams (1986) utilizaram a cromatografia gasosa para analisar alimentos enlatados deteriorados por microrganismos. Estes são capazes de gerar metabólitos diferentes, portanto esta técnica também é capaz de indicar a identidade dos microrganismos de destruição, sendo ácidos e álcoois os metabólitos mais úteis para este fim.

Zöllner e Mayer-Helm (2006) avaliaram a associação de cromatografia líquida e espectrofotometria de massa para análise de micotoxinas em queijos. Sua presença em alimentos e as graves propriedades tóxicas, estrogênicas e cancerígenas associadas a sua produção têm sido reconhecidas como ameaça potencial para a saúde pública.

A espectroscopia também é utilizada para monitoração da qualidade de alimentos em geral. Dado o perigo da bactéria patógena Bacillus-cereus na indústria de alimentos em produtos como leites e derivados, peru, carne, arroz e batata, Velusamy e colaboradores (2012) obtiveram uma técnica para verificar esta contaminação em tempo real, o que é vital para a inocuidade dos alimentos.

As micotoxinas também podem ser analisadas por meio de espectroscopia de impedância. Por meio desta técnica Bilyy e colaboradores 
(2012) analisaram micotoxinas presentes em alimentos e rações animais. Este método baseia-se no registro ótico de mudança de comportamento de agentes bacterianos em solução sob ação de um campo elétrico, onde o resultado final é obtido por análise fotométrica. 


\subsection{Espectroscopia de Impedância Complexa}

A Espectroscopia de Impedância Complexa (EIS) é uma forma de se determinar propriedades elétricas de materiais através da medida da impedância em função da frequência aplicada. Com a variação da frequência, têm-se informações sobre a composição do material uma vez que os elementos microscópicos deste podem ser entendidos como contendo componentes resistivas, capacitivas e indutivas, sendo que todas tem comportamento diferente em função da frequência, assim como mostrado nas equações 1,2 e 3.

$$
\begin{aligned}
& Z_{R}(w)=R \\
& Z_{C}(w)=-\frac{i}{w * C} \\
& Z_{L}(w)=w * L
\end{aligned}
$$

Onde $R$ é a resistência, $C$ a capacitância, $L$ a indutância, $i=\sqrt{-1}, Z$ a impedância e $w$ a frequência angular.

Na Física Aplicada, a EIS é amplamente utilizada para caracterizar materiais sólidos segundo Prabakar e Mallikarjun Rao (2007), uma vez que comparado com outras técnicas, sua aplicação é de fácil execução (WU; OGAWA; TAGAWA, 2007).

$\mathrm{Na}$ área médica, a EIS é utilizada para diferenciar tecido maligno e benigno em câncer de próstata (HALTER et al., 2007). Outra aplicação na área da saúde, é na determinação da massa magra do corpo dos pacientes de forma não invasiva, rápida e simples, (LORENZO, BOSAEUS E KYLE, 2004).

O uso da EIS na área de alimentos ainda é restrito à área de pesquisa, mas é um assunto amplamente pesquisado para diferentes tipos de alimentos. A razão deste estudo é que as propriedades físico-químicas dos alimentos alteram diretamente as medidas na capacitância e resistência do mesmo (BHATT e NAGARAJU, 2009). 
O estudo das propriedades elétricas das carnes data de 1936, quando Callow (1936) determinou as propriedades elétricas da carne. Depois disto, estudos de Ducrot e colaboradores (1970) relacionaram a variação nas propriedades elétricas em função do tipo do tecido, além de propor um modelo matemático para as propriedades de vários tecidos biológicos (LEPETIT et al. 2007). Depois disso, a aplicação da EIS em carnes tem tido sucesso para a determinação da quantidade de gordura e composição corporal em carcaças bovinas (MARCHELLO, SLANGER E CARLSOL, 1999), porcos e peixes.

Em vegetais, experimentos realizados com berinjelas mostraram que pode-se utilizar a EIS para determinar quantidade de água em secagens e para o efeito do congelamento e descongelamento do alimento (WU; OGAWA; TAGAWA, 2008). Artigos mostraram também a relação entre o amadurecimento de frutas e as medidas de impedância, como por exemplo Arnold, Harker e Bauchot (2000) com o estudo do amadurecimento do kiwi e Maindonald e Harker (1994), com o estudo da nectarina.

Com o desenvolvimento de um modelo matemático adequado, é possível estudar uma série de tecidos biológicos e investigar propriedades intrínsecas de nível celular. Para isto, modelos devem ser criados, com elementos resistivos, capacitivos e indutivos, simulando os elementos biológicos em nivel celular. Com isto, pode-se comparar as medidas de EIS com tais modelos e obter mais informações importantes dos dados coletados na espectroscopia. A figura 1 ilustra um desses modelos para células, por Arnold, Harker e Bauchot (2000). 


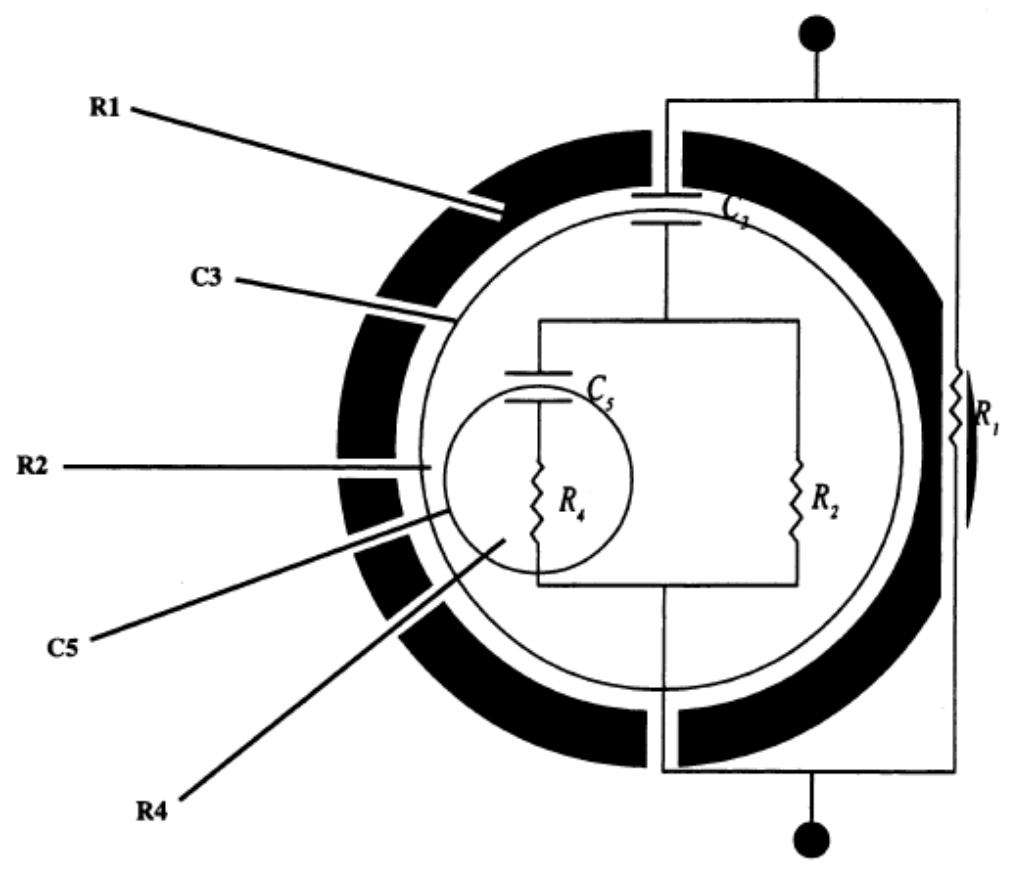

Figura 1 - circuito elétrico equivalente a uma célula, com a parede celular (R1), membrana plasmática (C3), citoplasma (R2), tonoplasma (C5) e vacúolo (R4). Adaptado de Arnold, Harker e Bauchot (2000). 


\subsection{O efeito Corona}

Quando um material isolante é colocado em uma região com campo elétrico, este material, por não ter cargas livres, não permite a passagem de corrente elétrica. No entanto, este campo elétrico modifica as propriedades microscópicas do material, pois apesar de não ter cargas livres, este campo rearranja as moléculas do material criando uma polarização. Esta terá como efeito a alteração do valor do campo elétrico, (REITZ, 1982), que com a presença de um dielétrico é dada por:

$$
D=\varepsilon E
$$

O Efeito Corona é observado quando a tensão aplicada a um condutor é suficientemente alta para que ocorra a quebra da rigidez dielétrica do meio a sua volta, causando um arco elétrico. Para que isto ocorra, o campo elétrico aplicado tem que ser tal que os átomos do meio se polarizem e os elétrons ligados sejam removidos, (REITZ, 1982). Quando isto ocorre, o meio deixa de possuir apenas cargas ligadas e gera elétrons livres, deixando então de ser um meio dielétrico ideal, já que por definição um dielétrico ideal não possui cargas livres. Estas cargas livres mudam completamente as propriedades elétricas, fazendo com que este meio deixe de ser um isolante e passa a conduzir eletricidade.

O valor de campo elétrico aplicado para que isto ocorra depende do meio, pois para cada molécula a energia de ionização é uma. O principal meio em que o efeito corona ocorre é o ar, tendo como exemplo os raios e as descargas na rede de distribuição elétrica. O valor médio da rigidez dielétrica do ar é de $3,2 * 10^{6} \frac{\mathrm{V}}{\mathrm{m}}$ nas condições normais de temperatura e pressão. Este valor depende de algumas variáveis como umidade e pressão, sendo que a 10 ATM, o valor aumenta para $22,6 * 10^{6} \frac{\mathrm{V}}{\mathrm{m}}$, e no limite de saturação de umidade a rigidez dielétrica cai para $3 * 10^{6} \frac{\mathrm{V}}{\mathrm{m}}$ 


\subsubsection{Visualização da descarga elétrica}

$\mathrm{O}$ ar é o caso mais comum de dielétrico já que ele banha tudo na superficie terrestre. Para que ocorra o processo de descarga do efeito corona no ar, é necessário um gatilho ou iniciador do processo, que irá gerar o primeiro íon e elétron livre (FEYNMAN; LEIGHTON; SANDS, 2008).

Existem 3 tipos de iniciadores, capazes de ionizar uma molécula do ar, são eles: Radiação $\beta$, efeito fotoelétrico, raios cósmicos.

Até o início do século XX, pensava-se que as ionizações na atmosfera eram geradas principalmente devido à radiação. Como esta é maior na superficie da terra e cai com a altitude, pensava-se que existiriam menos partículas ionizadas na estratosfera do que na superficie, fato que entrou em desacordo com experimentos meteorológicos que mostraram que a quantidade de íons aumenta com a altitude. Estes experimentos vieram a revelar então, a existência dos raios cósmicos, elemento fundamental no estudo da astronomia (FEYNMAN; LEIGHTON; SANDS, 2008), uma vez que a energia da onda eletromagnética necessária para tal reação, transformando $3 \mathrm{O}_{2}$ em $2 \mathrm{O}_{3}$ necessita de comprimento de onda de $\lambda>320 \mathrm{~nm}$.

No entanto, sem a presença de um campo elétrico, estes íons e elétrons livres gerados logo se recombinam e nenhum efeito é observado. Para que ocorra a quebra da rigidez dielétrica, é necessário a existência de um campo elétrico para acelerar o elétron de forma que ele ganhe energia suficiente no seu caminho livre médio de forma a retirar um elétron no próximo átomo que ele se chocar. Depois disso, ocorre um efeito em cadeia, já que o elétron é acelerado pelo campo elétrico e se choca com outra partícula, gerando outro íon e elétron e assim por diante, (DALLAROSA, 2005).

Com isto, é criada a chamada "avalanche de elétrons", que faz com que exista uma quantidade significativa de cargas livres no dielétrico e este, que antes era um isolante, passe a conduzir eletricidade.

Para o ar, as partículas ionizadas são, em sua maioria, moléculas de $\mathrm{O}_{2}$ transformadas em $\mathrm{O}_{3}$ e também ocorre a ionização de moléculas de água 
dispersas no ar. Quando estas moléculas ionizadas se recombinam formando novamente $\mathrm{O}_{2}$ e $\mathrm{H}_{2} \mathrm{O}$ elas emitem energia em forma de onda eletromagnética de acordo com a equação de Planck:

$$
E=h * v
$$

Onde $h$ é a constante de Planck, $E$ é a energia da Ionização e $v$ é a frequência da onda eletromagnética emitida.

\subsubsection{A fotografia Kirlian}

Historicamente, a aquisição de imagens da descarga elétrica data de 1777, quando G. C. Lihtenberg utilizou a descarga elétrica em torno de partículas para impressionar um filme dielétrico (KONENKO, 2001). Depois disso, outros pesquisadores também investigaram o efeito, como por exemplo, o cientista e inventor Nicola Tesla (1856 - 1943).

No entanto, deve-se ao técnico em eletrônica, Semyon Davidovich Kirlian, o desenvolvimento de um sistema que utilizava um filme fotográfico que era capaz de captar as imagens das descargas corona em objetos. Não se sabe exatamente quando o primeiro aparato foi montado, mas em 1949 a fama de suas fotografias já havia se espalhado pela região. Kirlian fez experiências com vários objetos como minerais, folhas e principalmente com a ponta dos dedos. Ele estava convencido de que as imagens que ele tirava com seu aparelho eram a "aura" dos objetos. Neste mesmo ano Kirlian patenteou sua descoberta e passou as próximas duas décadas realizando testes e aprimoramentos em sua invenção.

Como não era do meio acadêmico, as descobertas de Kirlian demoraram a ser investigadas propriamente em pesquisas científicas com a utilização de uma metodologia científica adequada. Com isto, foi apenas no final da década de 60 que a fotografia kirlian chamou a atenção do meio científico. 
No início da década de 70, a fotografia kirlian já tinha sido difundida e muitos entusiastas em todo o mundo replicavam os experimentos, (JERMAN; BERDEN; SKARJA, 1999). Além disso, uma série de artigos foi publicada em revistas científicas de respeito, relatando as imagens principalmente de fotos de dedos e vegetais, (FAUST; KYLER; PEHEK, 1976). Os resultados publicados nas pesquisas iniciais foram de dificil reprodução e vários pesquisadores chegaram a conclusões diferentes, principalmente nas pesquisas com organismos vivos, (JERMAN; BERDEN; SKARJA, 1999).

Devido à baixa reprodutibilidade e característica estocástica dos experimentos, variando de acordo com a pressão do objeto, umidade, temperatura, geometria, atividade iônica e outros parâmetros, a opinião geral no meio científico era a de que as imagens, principalmente as realizadas em humanos nas pontas dos dedos, não continham informações relevantes e que os efeitos vistos eram apenas flutuações estatísticas (KONENKO, 2001). A técnica caiu em desuso e ficou "mal vista" dentro do circulo dos pesquisadores.

Com o desenvolvimento da tecnologia, principalmente o poder computacional e da digitalização das imagens, novos experimentos surgiram com alta reprodutibilidade e a técnica voltou novamente em uso.

As novas pesquisas mostraram que de fato, em seres humanos utilizando as fotos dos dedos, pode-se correlacionar a imagem do efeito corona com uma série de doenças manifestadas em outros locais teoricamente sem nenhuma relação com os dedos utilizados para a captação das imagens, como observou Young (2004). Além disso, as variações dos estados psicológicos também estão diretamente correlacionadas com alterações nas imagens. Ainda não existe um modelo satisfatório explicando porque a foto kirlian apresenta resultados em várias situações, no entanto, a quantidade de pesquisadores e locais que se dedicam a tal pesquisa é extremamente limitada se comparado com o seu potencial e o paradigma científico que ela representa. A impressão deste autor é que há um preconceito em relação a pesquisas nesta área e o meio científico também apresenta seus dogmas de difícil remoção. 
Apesar destas dificuldades, assim como a acupuntura, que mesmo sem um entendimento da ciência ocidental conquistou seu espaço devido aos seus inegáveis resultados, a fotografia kirlian é hoje aceita na Rússia como uma forma alternativa de diagnóstico.

\subsubsection{Aplicações em geral}

Apesar do alvoroço que causou no meio científico na década de 70 , investigações posteriores mostraram que as imagens captadas através deste método são dependentes de uma série de fatores, que estão ligados ao objeto, como temperatura, umidade, resistividade e concentração iônica, portanto muitos dos resultados poderiam ser explicados por variações nestes parâmetros, (McGINTY; POMERANZ; ROUSSER, 1975). "Devido ao grande número de parâmetros que influenciam a foto Kirlian, existia sempre um elemento de variação estocástica, o que levou ao desuso da técnica até que a tecnologia moderna possibilitou uma nova técnica com maior reprodutibilidade" (KONONENKO, 1998). Esta nova técnica surgiu em 1995, quando uma câmera de vídeo $\mathrm{CCD}$ substituiu o filme fotográfico, possibilitando experimentos com maior reprodutibilidade e menos flutuação estatística (KOROTKOV; WILLIANS; WISNESKI, 2001). Com estas alterações, o processo ficou conhecido como GDV (Gas Discharge Visualization) e o processo foi patenteado na Rússia (2234854 PФ, A 61 B 5/05, 2003) e nos Estados Unidos (Patente US 7.869.636, 2011). Isto, aliado com o processamento e tratamento dos dados com métodos computacionais, possibilitaram resultados muito promissores para a técnica GDV (SHADURI, 2005).

Com estas melhorias, uma série de experimentos foi realizada com esta nova técnica, a maioria envolvendo organismos vivos, segundo Korotkov, Williams e Wisneski (2001), sendo que minerais (VAINSHELBOIM; $\mathrm{MOMOH}, 2005)$ e líquidos, com Skarja (1998), também foram alvo de 
estudos. "As pesquisas em seres humanos visavam principalmente investigar a influência de variações físicas e psicológicas nos padrões de descarga corona ao redor dos dedos" (SKARJA, 1998).

Os experimentos com minerais mostraram que é possivel obter uma perspectiva da organização dos cristais com a caracterização das imagens, podendo não só diferenciar o tipo de mineral, mas também diferenciar um mesmo mineral em função das jazidas, (VAINSHELBOIM e MOMOH, 2005).

Experimentos com líquidos revelaram que a GDV pode detectar alterações na concentração iônica bem como diferenciar diferentes solutos em água, (SKARJA, 1998). A pesquisa com diferentes solventes e solutos ainda não foi feita, o que mostra que esta é uma área em aberto, com potencial futuro para a utilização do efeito corona.

A maior parte dos estudos é concentrada em experimentos com seres vivos, sendo os efeitos em humanos os mais estudados e, em geral, são captadas imagens das pontas dos dedos das mãos. As pontas dos dedos são utilizadas devido à facilidade experimental de sua colocação na placa para visualização da descarga, porém, existem experimentos com outras partes do corpo como pés, queixo e nariz, (SHADURI, 2005).

Uma série de autores encontrou relações entre alterações físicas e emocionais nas imagens do efeito corona nos dedos, (SKARJA, 1998) e (KONONENKO, 1998).

Unestahs, Kortov, e Pavel (2002), por exemplo, realizaram experimentos com técnicas de relaxamento e concentração, com 117 voluntários (56 no grupo de controle e 61 realizando o treinamento). As alterações devidas às técnicas de relaxamento foram monitoradas pela análise do EEG (eletroencefalograma) e as alterações nas imagens do efeito corona foram as mesmas obtidas pele EEG, com significância estatística de 99,9\%.

Korotkov, Williams e Wisneski (2001), Konenko (2000) e Shaduri (2005), fizeram uma série de experimentos utilizando um grupo de controle e um grupo com alguma doença física específica, como por exemplo doença cardíaca, (KONONENKO et al., 1999) e a conclusão geral é a de que as alterações em órgãos do corpo resultam em alterações específicas em locais 
dos dedos especificados pelo mapa de meridianos da medicina chinesa (KONONENKO et al., 1999), (SHADURI, 2005).

No entanto, falta ainda uma explicação física e biológica adequada para os resultados. A medicina tradicional, baseada no conhecimento científico que se tem até o momento, ainda não conseguiu explicar satisfatoriamente os mecanismos de ação da acupuntura, que também segue os mapas de meridianos da medicina chinesa. Um esboço de modelo foi feito por Young (2004), relacionando o mapa dos meridianos com canais de transmissão de ondas eletromagnéticas, e os pontos de acupuntura com nós de ondas estacionárias. Para que estes processos sejam realmente entendidos e aceitos pela medicina tradicional, é necessário que se entenda física e biologicamente o que está ocorrendo durante a captação do efeito corona e qual a sua relação com o mapa de meridianos.

\subsubsection{Aplicações em alimentos}

A aplicação na área de alimentos é recente. Pesquisas foram feitas com maçãs por Weibel, Konomenko e Sadikov (2004), mostrando que se pode identificar os tipos de maçãs, e idade pré-colheita através das imagens do efeito corona observado no fruto. Neste caso, as imagens não eram visivelmente diferenciáveis, mas quando inseridas em um sistema utilizando aprendizado de máquina, o sistema foi capaz de separar as imagens automaticamente.

Em outro estudo, realizado com uvas, mostrando que a imagem GDV de uma uva é influenciada por doenças na planta, mesmo que esta não tenha ainda se manifestado fisicamente no fruto (KONONENKO et al., 1999).

Nota-se então que a pesquisa das imagens corona em frutas e vegetais é uma área promissora e que a padronização de um sistema voltado para captação das imagens em frutas e vegetais seria de grande valia na indústria alimentícia, visto que os aparelhos GDV são portáteis e com custo de fabricação relativamente baixo, o que viabiliza a utilização deste método 
como um caracterizador do estado do produto, indicando o grau de deterioração, quantidade microbiana e outras características. 


\subsection{Modelagem e Simulação na engenharia de alimentos}

O desenvolvimento e aprimoramento de equipamentos na área da engenharia de alimentos possibilitou um enorme incremento na qualidade dos produtos bem como no aprimoramento dos processos de produção. A utilização de simulações através de modelos matemáticos produz uma ferramenta muito importante neste processo e sua utilização vem crescendo muito com os recentes desenvolvimentos na área da computação.

Simulações para identificar probabilidade de contaminação e estimar a quantidade de bactérias ou outro agente patógeno em alimentos têm sido muito utilizadas e é o exemplo mais comum na área de alimentos, (SILÓNIZ; HERVÁS-MARTINEZ E GARCIA-GIMENO, 2002).

O sucesso das simulações nestes casos se da devido à natureza estocástica e do grande número de variáveis envolvidas nos processos patológicos e de contaminação, que podem ser tratados estatisticamente quando se conhece a distribuição de probabilidade de cada elemento. Nestes casos, modelos de cálculo de risco, baseados no método de monte-carlo são os mais utilizados e fornecem informações sobre a distribuição final (risco) e quais as etapas mais e menos significativas no processo (VOSE, 1996).

Além das simulações relacionadas a riscos de contaminação e segurança alimentar, simulações numéricas são utilizadas para investigar e melhorar os processos de produção. Esta abordagem é extremamente importante em casos em que os experimentos reais são dificeis, custosos ou demorados de se realizar. As simulações podem ser utilizadas em parte do processo para se estudar partes cruciais isoladamente e entender o seu mecanismo encontrando parâmetros para otimização. Além disso, simulações podem ser utilizadas para checar resultados e validar novos aparatos.

O tipo de metodologia a ser utilizada na simulação depende do sistema, número de variáveis, tipo de relação entre estas variáveis, e principalmente da fisica envolvida no problema. Para os processos de aquecimento, são utilizados modelos baseados nas equações de difusão e 
mecânica de fluidos, através do método dos elementos finitos, diferenças finitas e volumes finitos.

O sistema de tratamento de alimentos via campo elétrico pulsado, PEF (Pulsed Electric Field), teve seu desenvolvimento auxiliado por simulações que puderam indicar melhorias no sistema e otimizar o procedimento ao se simular como a descarga elétrica era conduzida através do alimento .

Para simulações de sistemas complexos, onde a quantidade de variáveis e o número de grandezas físicas atuando no sistema é muito grande, os métodos citados anteriormente sofrem da dificuldade de se encontrar equações que descrevam o sistema como um todo. Nestes casos, os sistemas baseados em Inteligência Artificial tem se mostrado como a melhor opção. Dentre as várias linhas de Inteligência Artificial, as Redes Neurais Artificiais e o Algoritmo Genético são técnicas que já possuem aplicações na Engenharia de alimentos (SILÓNIZ; HERVÁS-MARTINEZ E GARCIA-GIMENO, 2002).

\subsubsection{Algoritmo Genético}

Algoritmo Genético, (GA - Genetic Algorithm) é o nome dado a rotinas de programação utilizadas em sistemas de busca e otimização que tem o seu funcionamento inspirado no mecanismo da natureza de melhorar uma espécie ao longo das gerações (Russell; Norving, 2001). Os GA fazem parte de uma área da computação chamada computação evolutiva, introduzida em 1960 por I. Rechenberg e são de grande utilidade em problemas NPCompleto, que em geral são de natureza simples, mas demandam tempo computacional muito grande para se encontrar a melhor solução em um mecanismo de busca tradicional.

Por serem baseados no melhoramento genético biológico, os GA utilizam o conceito da teoria da evolução, desenvolvida por Charles Darwin e e James Baldwin, onde o melhoramento de uma espécie ocorre devido a 
mutações e cruzamentos, sendo que os mais aptos tem maior chance de transmitir sua informação genética e os menos aptos não a transmitem.

O GA pode ser considerado uma variante do mecanismo de busca em feixe estocástica, porém os conceitos de crossover e mutação encontrados na natureza são imitados no Algoritmo Genético. Nele, cada indivíduo representa uma solução específica e o conjunto de indivíduos forma uma população. Cada indivíduo possui uma série de informações sequenciais que leva a solução (não otimizada) do problema.

Os indivíduos são gerados aleatoriamente no início do programa, formando a população inicial e as regras da evolução são aplicadas a esta população, excluindo os piores indivíduos e premiando os melhores, que passarão seus cromossomos para a próxima geração. Os cromossomos representam parte da informação de um indivíduo e os melhores indivíduos (pais) são escolhidos para passar essa informação (cromossomos) para a próxima geração. Assim como na natureza, são inseridas mutações para evitar a estagnação do algoritmo, ou seja, evitar que ele fique "preso" em um mínimo local.

Algoritmos Genéticos devem ser utilizados em problemas de aprendizagem assistida, uma vez que em cada geração deve-se avaliar os indivíduos. Essa avaliação é em função do parâmetro que se deseja otimizar, chamado de função fitness.

Uma das aplicações onde o GA é mais bem sucedido são os problemas correlatos ao Problema do Caixeiro Viajante (PCV). Nele, deseja-se saber qual a melhor rota que um vendedor deve tomar para passar por $\mathrm{n}$ cidades, apenas uma vez em cada uma e retornar a sua cidade. Tal problema é utilizado obviamente por empresas de logística mas suas aplicações vão muito além disto, como por exemplo na fabricação de circuitos integrados, onde o roteamento das milhares de trilhas condutoras deve ser escolhido de forma a minimizar o custo de produção. 


\section{Objetivos}

Este trabalho teve o seguinte objetivo:

"Desenvolver um equipamento automatizado para captação do efeito corona em alimentos".

Para atingir tal objetivo, o seguinte conjunto de ações foi seguido:

1- Desenvolvimento de um equipamento gerador de alta tensão em alta frequência.

2- Desenvolvimento um sistema de captação digital do efeito corona.

3- Desenvolvimento de um software de aquisição e tratamento das imagens.

4- Comparar as imagens digitais obtidas pelo sistema desenvolvido com imagens kirlians tradicionais.

5- Simular o efeito corona em diferentes situações a fim de validar das imagens captadas. 


\section{Materiais e Métodos}

Os experimentos foram realizados na Faculdade de Zootecnia e Engenharia de Alimentos da Universidade de São Paulo na cidade de

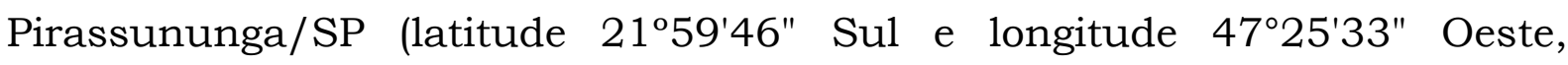
altitude de 627 metros) no período de 01/08/2010 à 10/09/2012.

\subsection{Desenvolvimento do equipamento}

\subsubsection{Gerador de Alta tensão em alta frequência}

Como ilustra a figura 2, o gerador de alta tensão foi desenvolvido com um circuito eletrônico microcontrolado, montado em uma placa de cobre/fenolite (a), ligado a um flyback (b), sendo o sistema todo montado em uma caixa de acrílico e alimentado por uma tensão de $110 \mathrm{~V}$ AC, que é transformada em $12 \mathrm{~V}$ DC por um transformador retificador (c), acoplado a uma ponte de diodos retificadora.

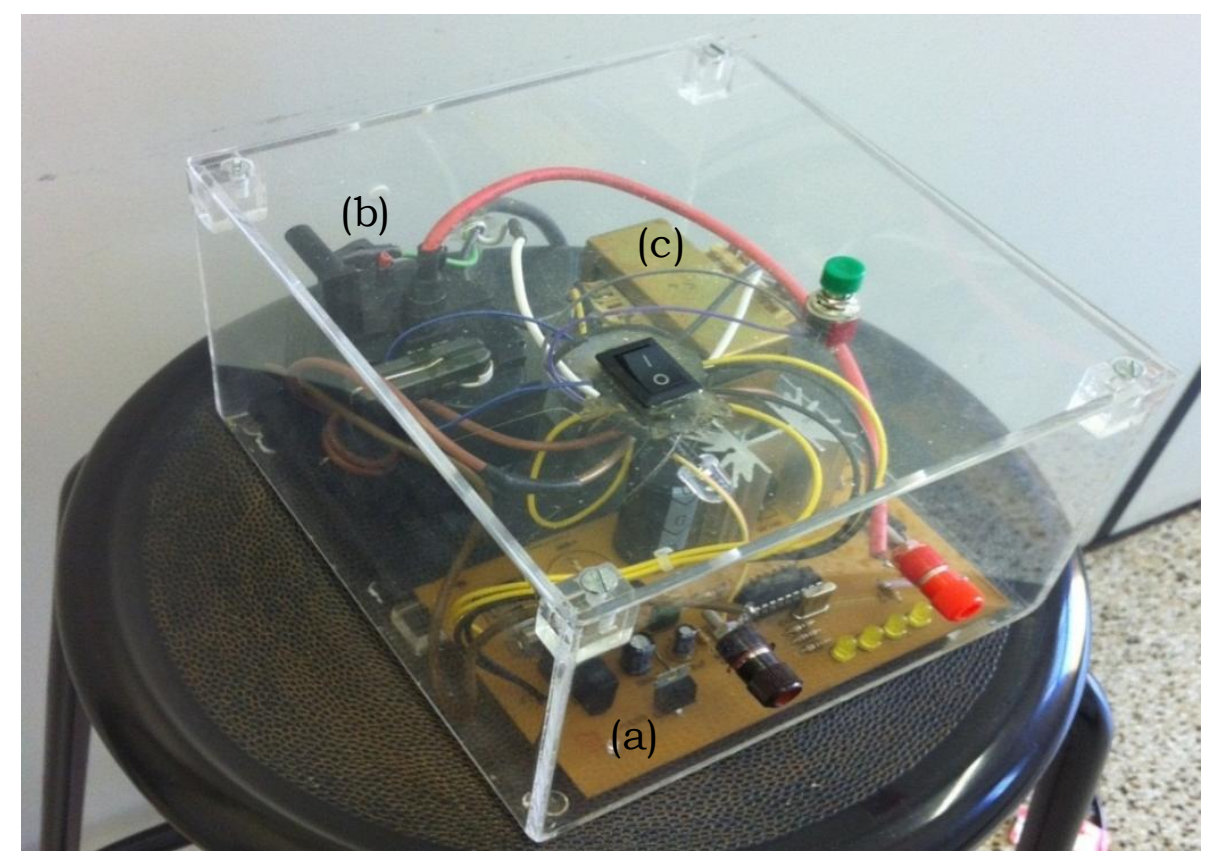

Figura 2 - Gerador de alta tensão. (a) placa de fenolite. (b) flyback. (c) transformador retificador. 
O circuito desenvolvido utiliza um microcontrolador PIC16F628A, da Microchip ${ }^{\circledR}$, que gera pulsos de $240 \mathrm{kHz}$ e tensão de $5 \mathrm{~V}$. O programa gravado no microcontrolador foi desenvolvido na linguagem $\mathrm{C}$, no compilador C da CCS ${ }$ e gravado através do software MPlab e do gravador mosaico ICD2 ${ }^{\text {BR }}$ (os códigos encontram-se no Apêndice A).

Para isolar o microcontrolador do sistema de alta corrente no circuito, foi utilizado um transistor BC337, que transfere o pulso para o gate de um transistor de efeito de campo tipo $\mathrm{N}$ modelo IRF740, de modo que após a saída no transistor, o pulso gerado é de $12 \mathrm{~V}$ com possibilidade de suprir até 5 Amperes de corrente.

O circuito eletrônico foi projetado no Software NI Multisim ${ }^{\circledR}$, como apresentado na figura 3 , e manufaturado pelo método da corrosão da placa de cobre por percloreto de ferro, sendo que o layout da placa de circuito foi desenvolvida no software PCAD ${ }^{\circledR}$ e é apresentada na figura 4.

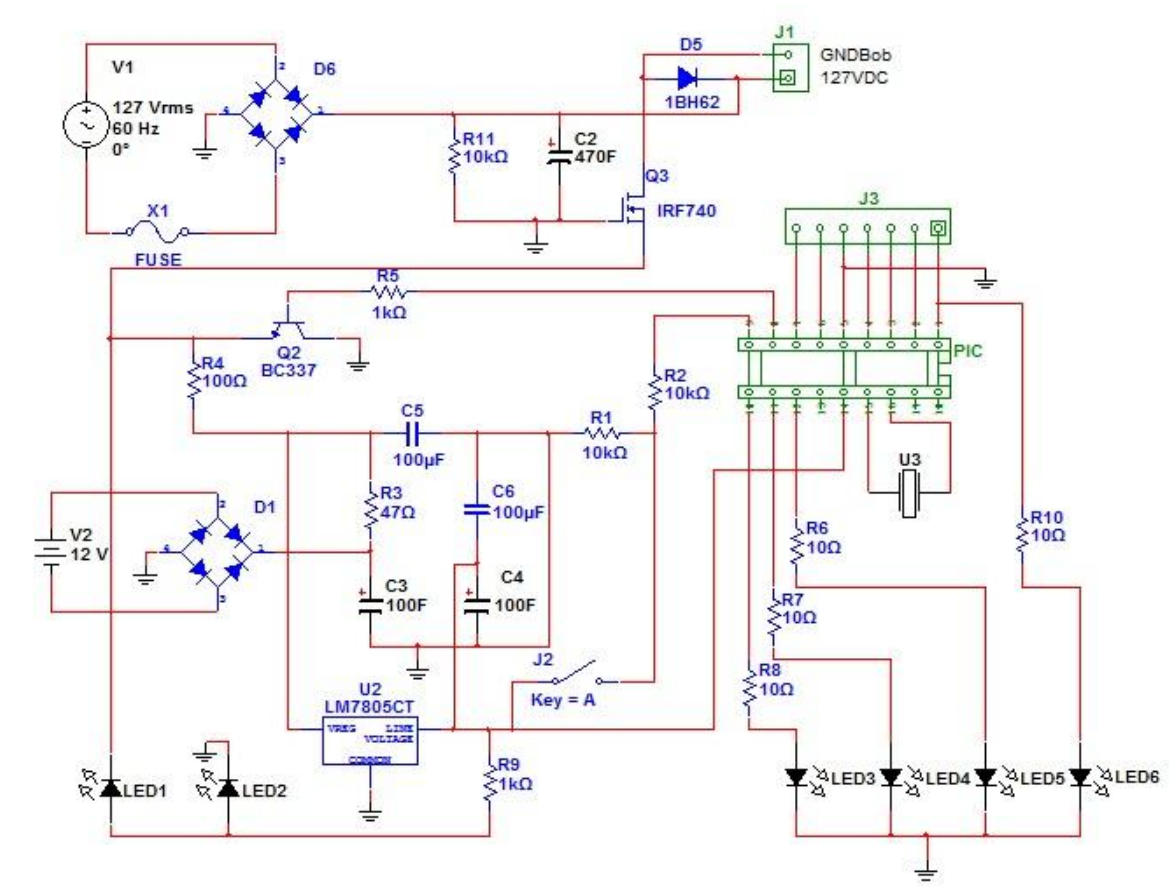

Figura 3 - Esquema elétrico do circuito gerador dos pulsos de alta frequência 

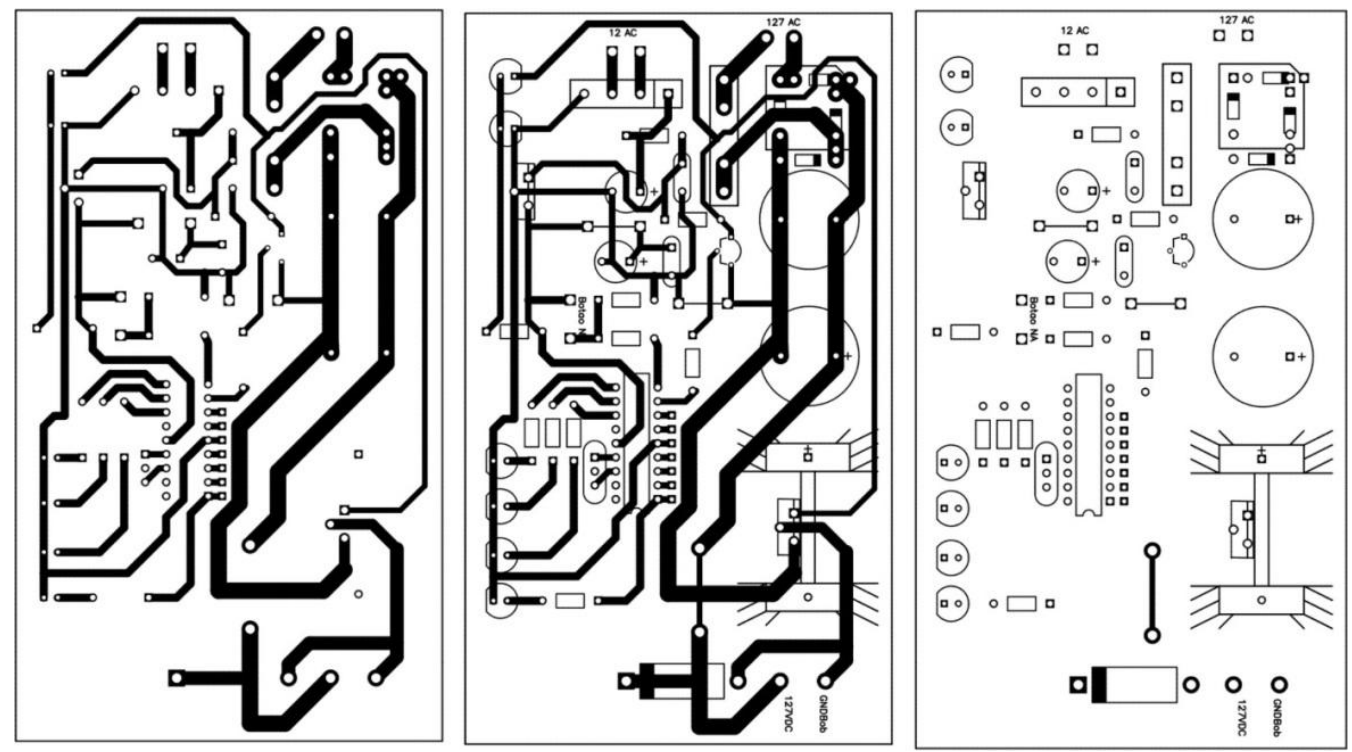

Figura 4 - Circuito para impressão e confecção na placa de fenolite e cobre.

A saída deste circuito foi conectada a um flyback retirado de um monitor de tubo, de forma a elevar a tensão do pulso para até $43,78 \mathrm{kV}$. Para o pulso de entrada, foram testadas várias frequências, porém devido ao casamento de impedância entre o flyback e o circuito, existe uma frequência específica em que a elevação de tensão é máxima, que para o caso deste aparelho é de $240 \mathrm{kHz}$.

\subsubsection{Aparato para coletar a imagem da descarga}

O aparato da coleta foi desenvolvido de forma que a visualização do efeito corona no alimento pudesse ser feita por uma câmera digital e transmitida em tempo real para um sistema de aquisição (computador), como ilustra a figura 5 . 


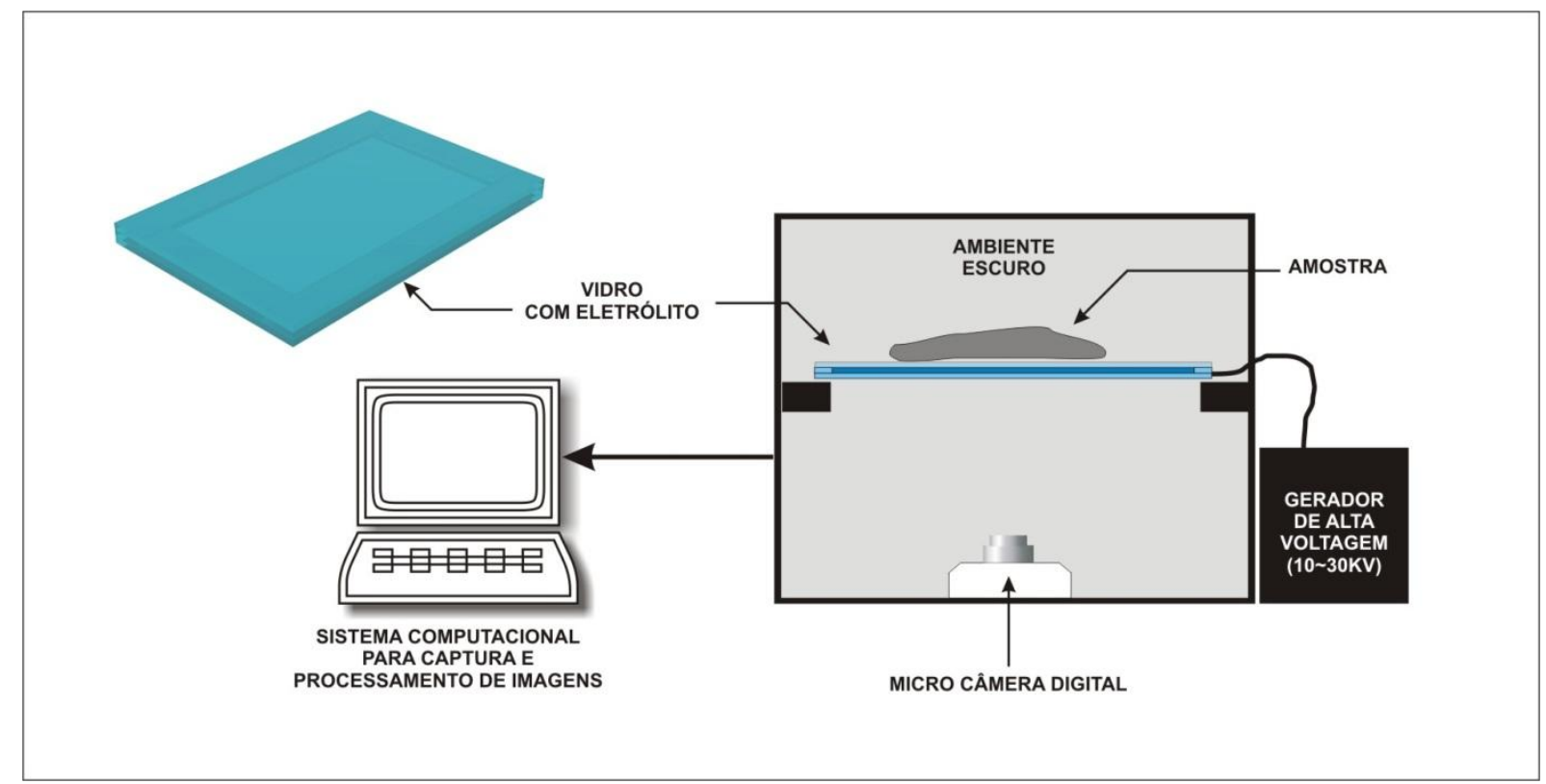

Figura 5 - Sistema de aquisição, com gerador de alta voltagem, Sistema de captação da imagem contendo ambiente escuro, vídeo com eletrólito, amostra e micro câmera digital e sistema computacional.

Para que a imagem possa ser captada pela câmera digital, o eletrodo, que se situa entre a amostra e a câmera deve ser transparente. Foram feitos testes com vários materiais candidatos a eletrodo e o que apresentou melhor relação custo/benefício foi uma solução de Água + Sal de cozinha $(\mathrm{NaCl})$ em um recipiente de vidro, Figura 6.

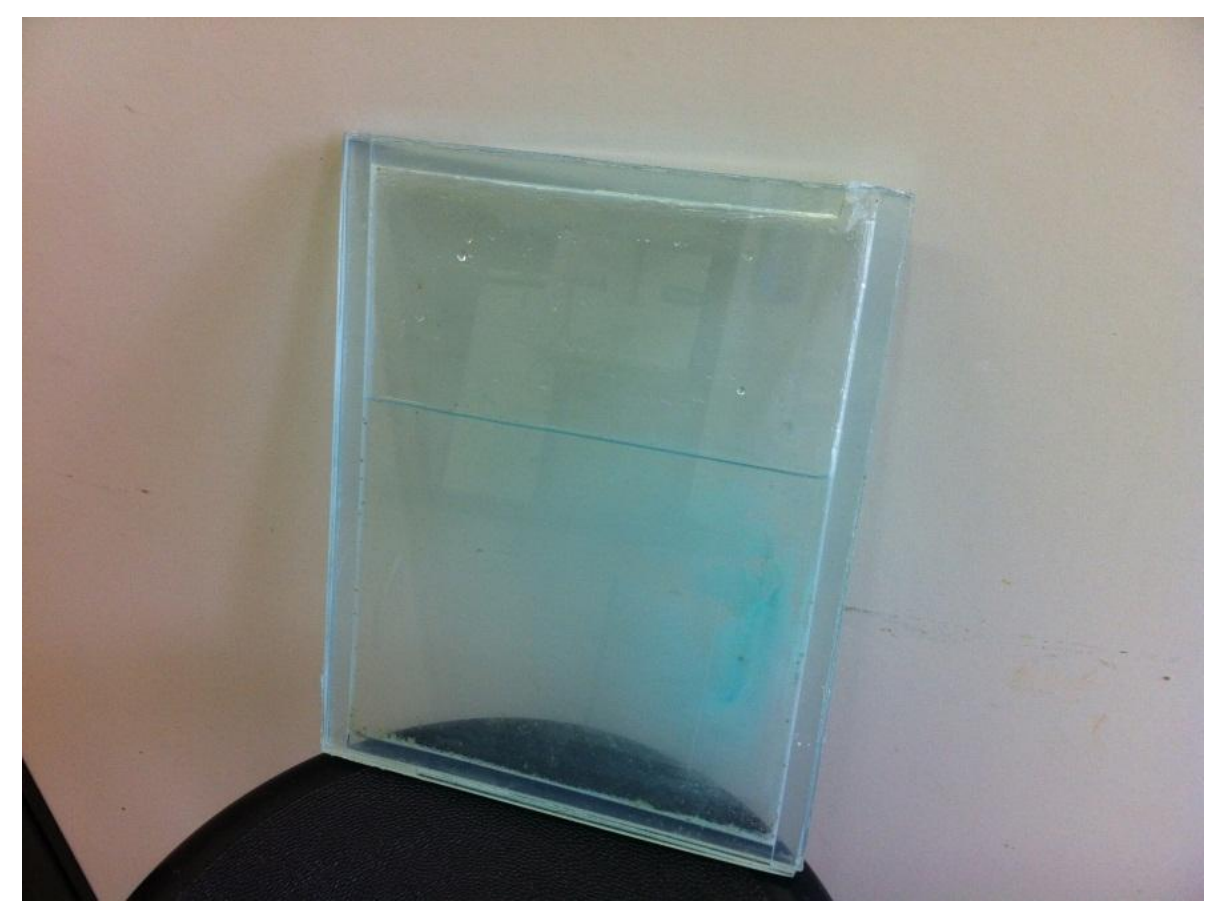

Figura 6 - Eletrodo com placas de vidro e solução Sal + Água. 
$\mathrm{Na}$ confecção do eletrodo foram utilizadas duas placas de vidro com $2 \mathrm{~mm}$ de espessura e $15 \times 20 \mathrm{~cm}$ de largura e profundidade. Na lateral das placas foram colocadas tiras de vidro, deixando apenas um orificio para a entrada do eletrólito (água + sal) e então foi aplicado silicone para fixação e vedação do eletrodo. A figura 6 mostra o eletrodo montado.

O aparato onde são colocados o eletrodo, a amostra e a câmera, foi montado com retalhos de MDF (Medium density fiberboard), utilizado em marcenaria, com dimensões de 20,24, $42 \mathrm{~cm}$, como pode ser visto na figura 7. O sistema possui uma abertura na parte superior (a) para a troca da amostra e uma inferior (b) para o posicionamento da câmera digital. Todo o aparato é vedado para que não haja iluminação no seu interior, facilitando a captação da imagem que possui baixa luminosidade.

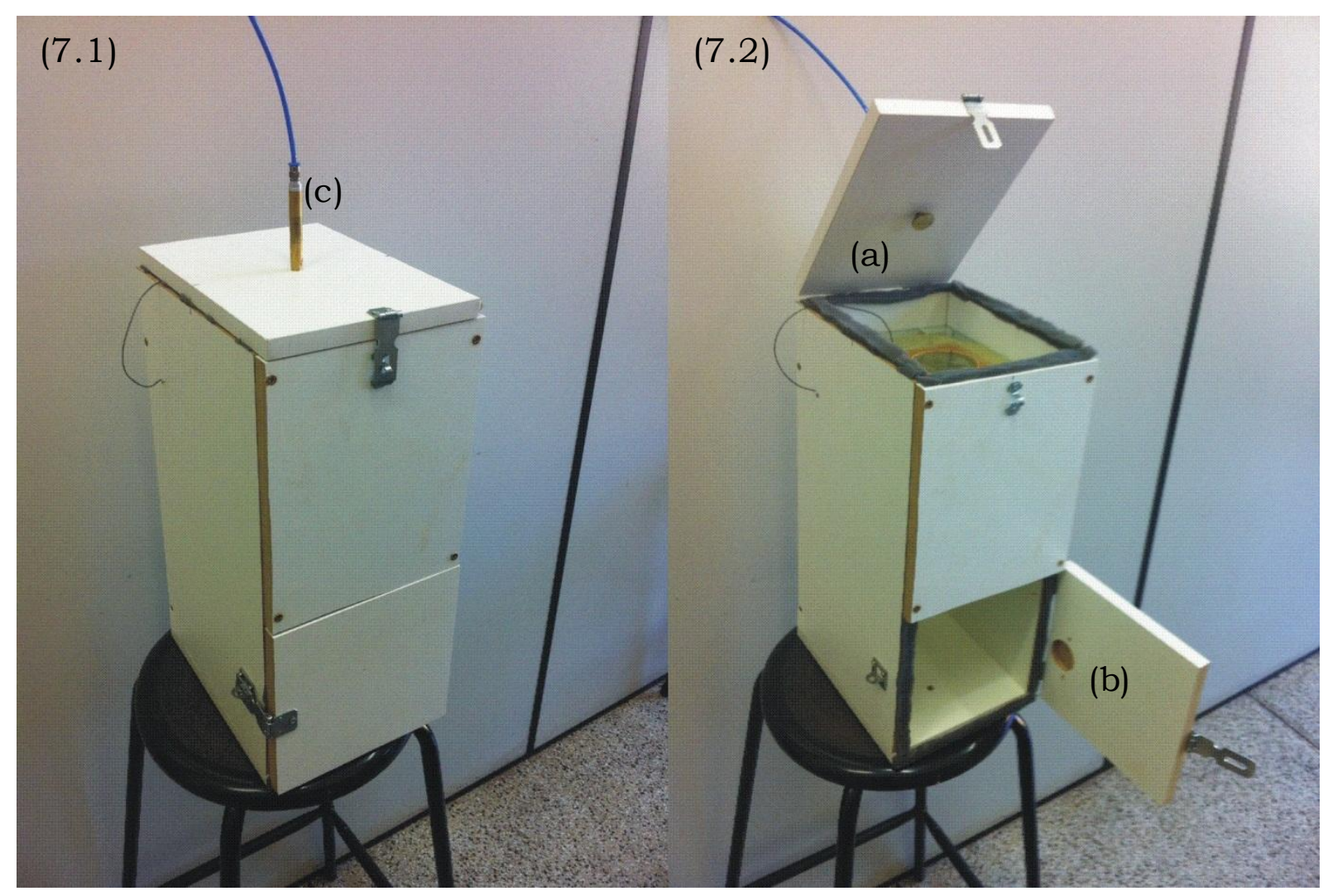

Figura 7 - Equipamento em MDF fechado (7.1) e aberto (7.2). (a) Abertura para colocar a amostra. (b) local para entrada da câmera. (c) Pistão para acionamento e aplicação da tensão.

$\mathrm{Na}$ parte superior do aparato foi colocado o eletrodo que faz contato com a amostra e é responsável pela aplicação do potencial elétrico. Para 
evitar problemas com diferença nas imagens devido a diferentes pressões da amostra no eletrodo, este faz contato com a amostra por meio de um pistão (c), que quando acionado desce até a amostra. Desta forma, existe uma garantia de que todas as amostras entrem em contato com o eletrodo sempre com a mesma pressão. A pressão é regulada por um sistema pneumático Festo ${ }^{\circledR}$ e o pistão utilizado foi o Festo ESN-9-50-P, de ação simples com $50 \mathrm{~cm}$ de curso e retorno por mola, como mostrado pela figura 8 .

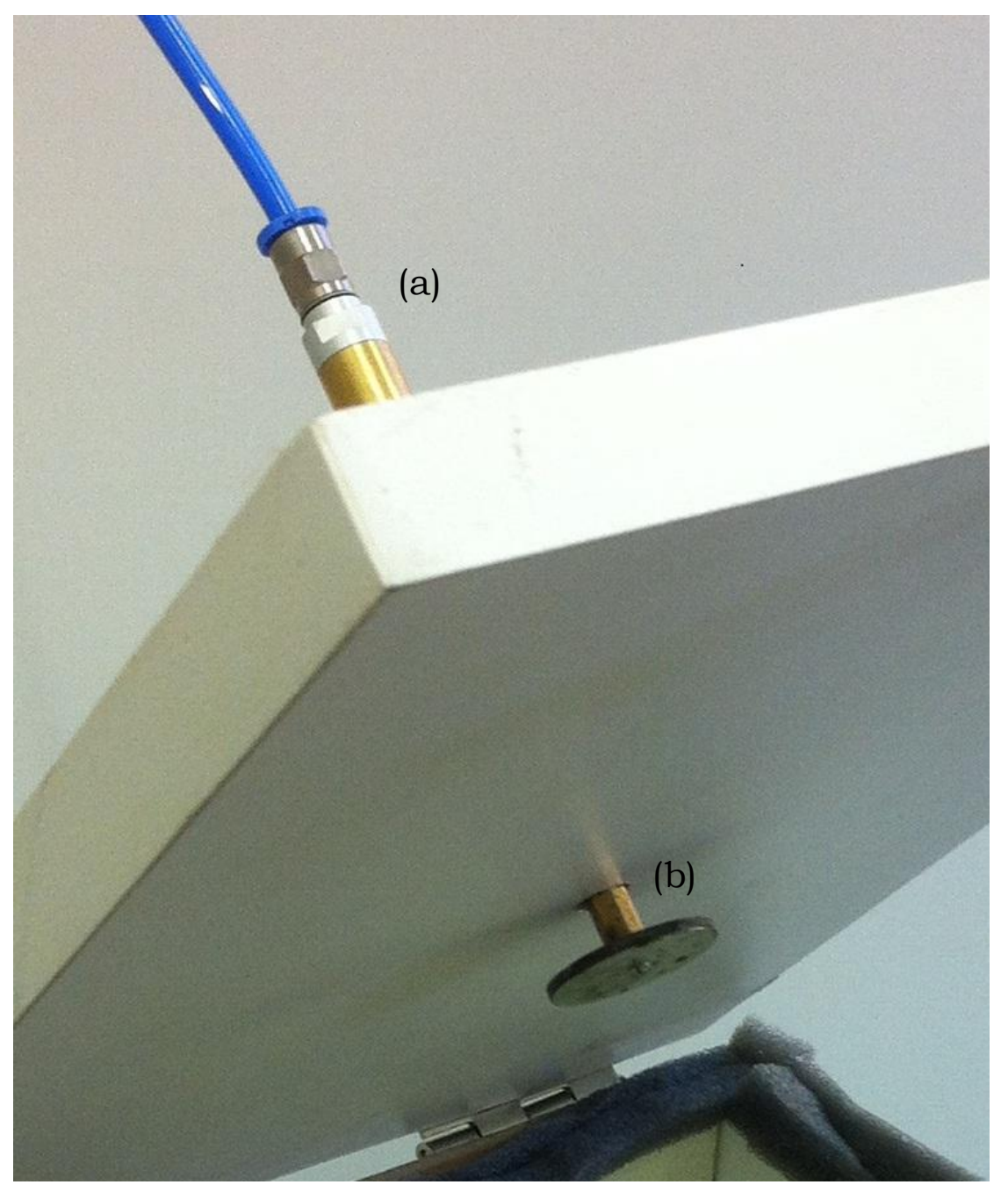

Figura 8 - Pistão que aplica a alta tensão na amostra. (a) Lado externo do pistão. (b) Lado interno do pistão com placa para contato com amostra.

Como o pistão é feito de metal, que é condutor elétrico, o fio proveniente do gerador de alta tensão entra em contado direto com o pistão (a) na parte de fora do sistema e este, por sua vez, transmite a tensão aplicada a uma placa de cobre que é colocada na ponta do pistão e faz contato com a amostra (b). 


\subsubsection{Software de aquisição e controle}

O software de controle tem a tarefa de acionar o gerador de alta tensão, receber as informações captadas pela câmera e trata-las.

As imagens foram captadas através de uma câmera de um celular Iphone4, da marca apple ${ }^{\circledR}$, com 5.0 MP (megapixels) e enviadas para um computador em tempo real via Wi-Fi pelo mesmo celular. Foi desenvolvido um software para capturar e tratar estas imagens no programa Matlab ${ }^{\circledR}$, além de ativar o gerador de alta tensão. O código fonte está disponível no apêndice B.

Para que o celular transmitisse as informações em tempo real para o computador, foi utilizado o software livre Epocam wireless HD, da empresa kinoni ${ }^{\circledR}$, que quando instalado no sistema do celular e do computador, transforma a câmera em uma webcam, desde que o computador de controle esteja conectado na mesma rede que o celular.

As imagens da câmera que são capturadas no computador podem ser processadas no Matlab ${ }^{\circledR}$ com a ajuda do Toolbox de aquisição de imagens Imaqtool, recebendo os dados de uma câmera conectada ao computador e salva em um objeto do Matlab®.

O acionamento via software é feito como uma alternativa ao acionamento manual do equipamento de alta tensão. Para isto, foi utilizado uma placa Arduino $\mathrm{UNO}{ }^{\circledR}$, com o controlador Atmega328, da empresa atmel $\AA$ e uma placa bluetooth JY-MCU, que recebem as informações do software de controle e acionam o botão remotamente. Para que a informação "ligar o equipamento" seja enviada via software, foi utilizada a biblioteca Arduino-Matlab, e o programa gravado no microcontrolador Atmega está no apêndice D. 
O software de controle foi desenvolvido no Matlab através do ambiente de desenvolvimento GUI (Grafical User Interface), de forma que um usuário do software possa utiliza-lo sem a necessidade de conhecimentos de algoritmos e programação.

Como é ilustrado na figura 9, a interface permite ao usuário, a visualizacão do que está sendo captado pela câmera em tempo real através do botão "Liga Camera" (a) e fazer uma gravação do video através do botão "Grava Imagem" (d) em um banco de videos, com a opção de escolher o período de gravação, o nome do arquivo e diterório onde o video será armazenado. Existe também a opção de congelar a imagem através do botão "Preview" (b) e então salvá-la em diversos formatos utilizando o botão "salva imagem" (c).

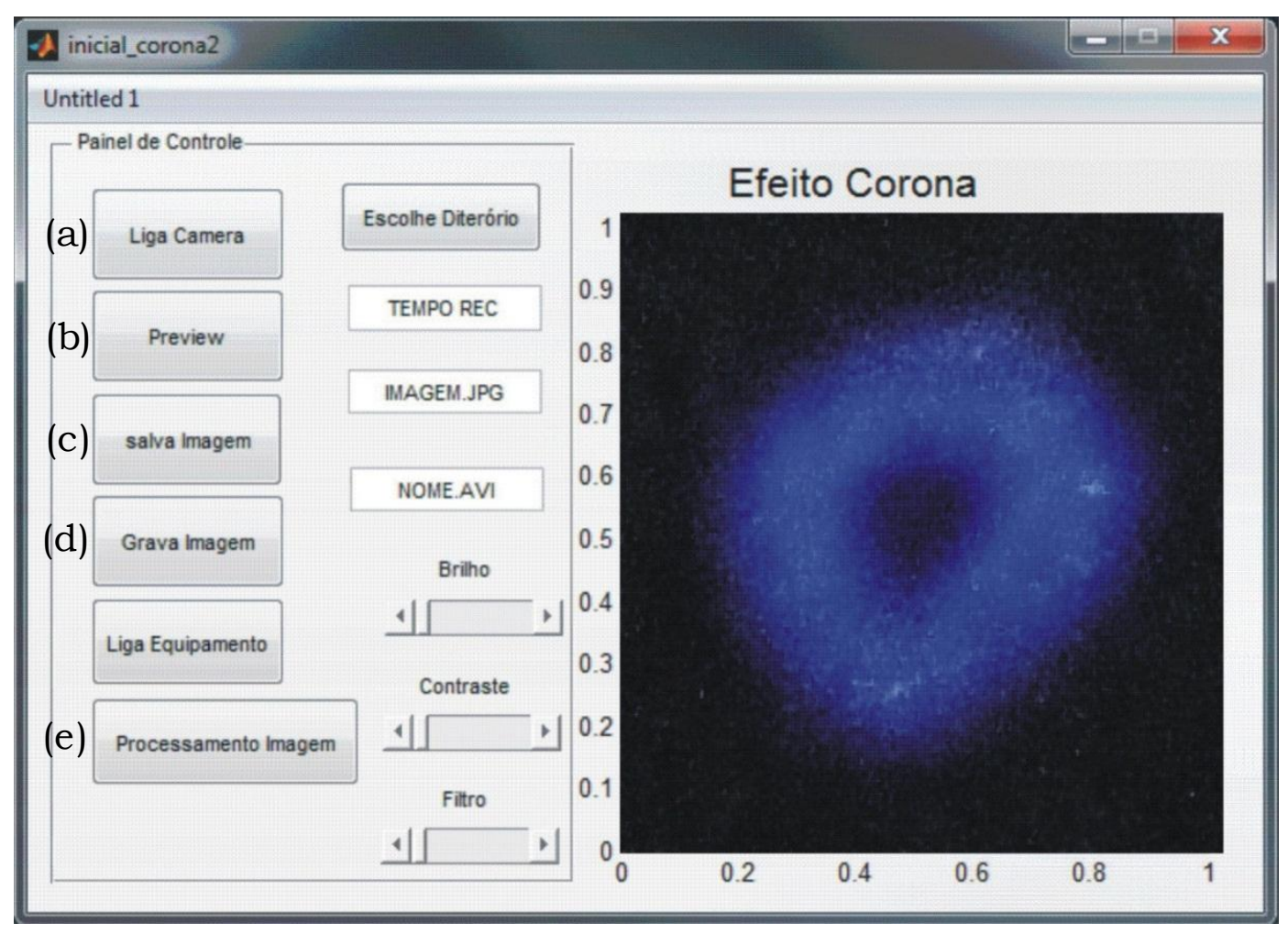

Figura 9 - Interface do software de controle.

Ao clicar no botão "Processamento de imagem" (e), ou nos sliders de "brilho", "contraste" e "filtro", são executados altoritmos de processamento de imagem com os parâmetros configurados pelo usuário, de forma a facilitar a visualização do efeito corona. 


\subsubsection{Aquisição das imagens com filme fotográfico}

Para efeito de comparação, foram tiradas fotos do efeito corona em alimentos pelo método kirlian convencional.

O gerador de alta tensão utilizado foi o mesmo, no entanto, não foi utilizado o software de controle uma vez que a captação da imagem é feita de maneira manual e analógica. Também não foi utilizado o sistema de aquisição (caixa e eletrodo), pois o método convencional envolve um mecanismo diferente. A figura 10 abaixo mostra o sistema convencional utilizado.
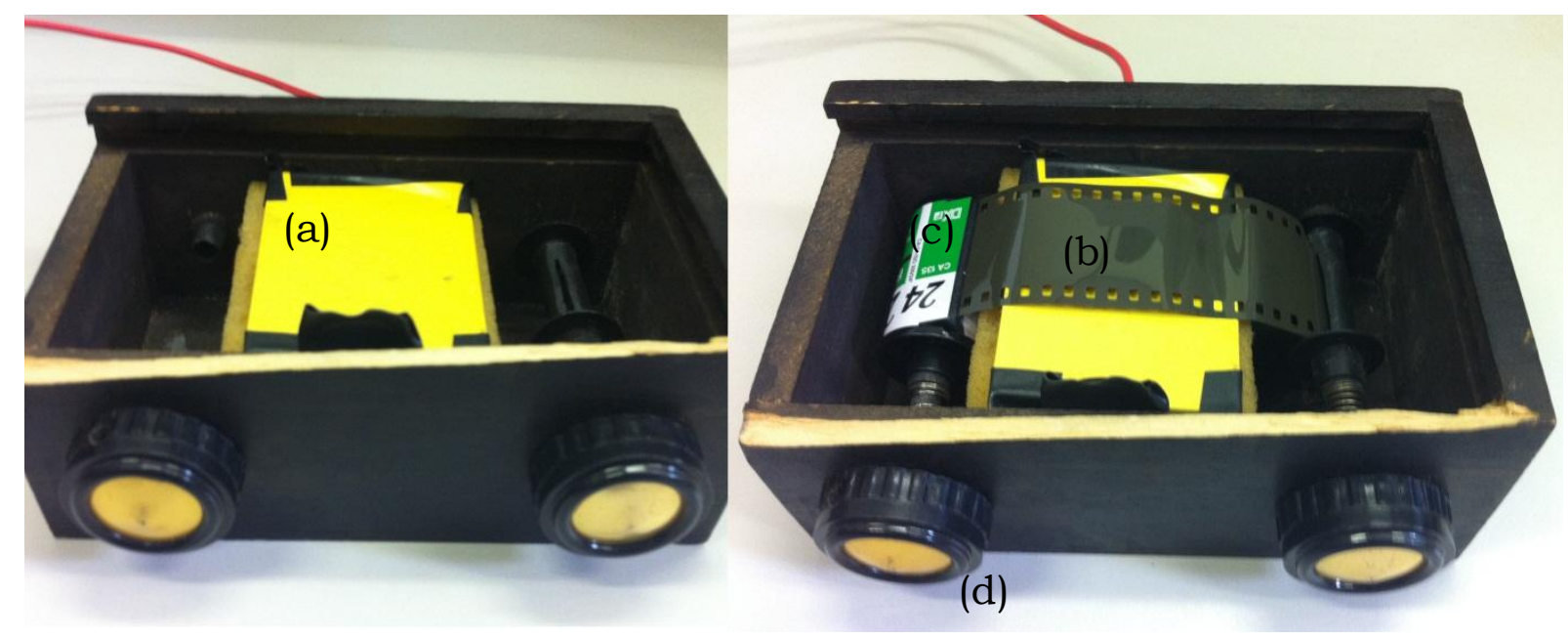

Figura 10 - Sistema Kirlian

Nesta figura, vemos que o eletrodo (a) não é transparente, uma vez que não existe uma câmera do outro lado captando a imagem. O filme fotográfico utilizado foi o Filme isso 200 Superia ${ }^{\circledR} 24$ poses. Ele é posicionado entre o eletrodo e a amostra (b). O rolo do filme é colocado no suporte (c) e a cada descarga e imagem captada, o filme é puxado pelo cilindro (d) e após todas as imagens serem captadas o rolo é puxado de volta.

Como o filme reage à luz, todo o procedimento para a captação da imagem deve ser feito em total escuridão uma vez que o filme não pode ser exposto à luz ambiente, e apenas a luz do efeito corona deve impressioná-lo. O tempo de exposição utilizado foi de 5 segundos. 


\subsection{Testes com o aparelho}

Para os testes do aparelho com captação da imagem pela câmera digital e com o método tradicional, foram utilizadas as seguintes frutas: Maçã Gala, Pera Willians, Ameixa Preta Nacional, Uva Thompson, e Limão Taiti. Todas as frutas foram compradas em um supermercado no dia do experimento e estavam dentro do tempo de prateleira adequado para o consumo.

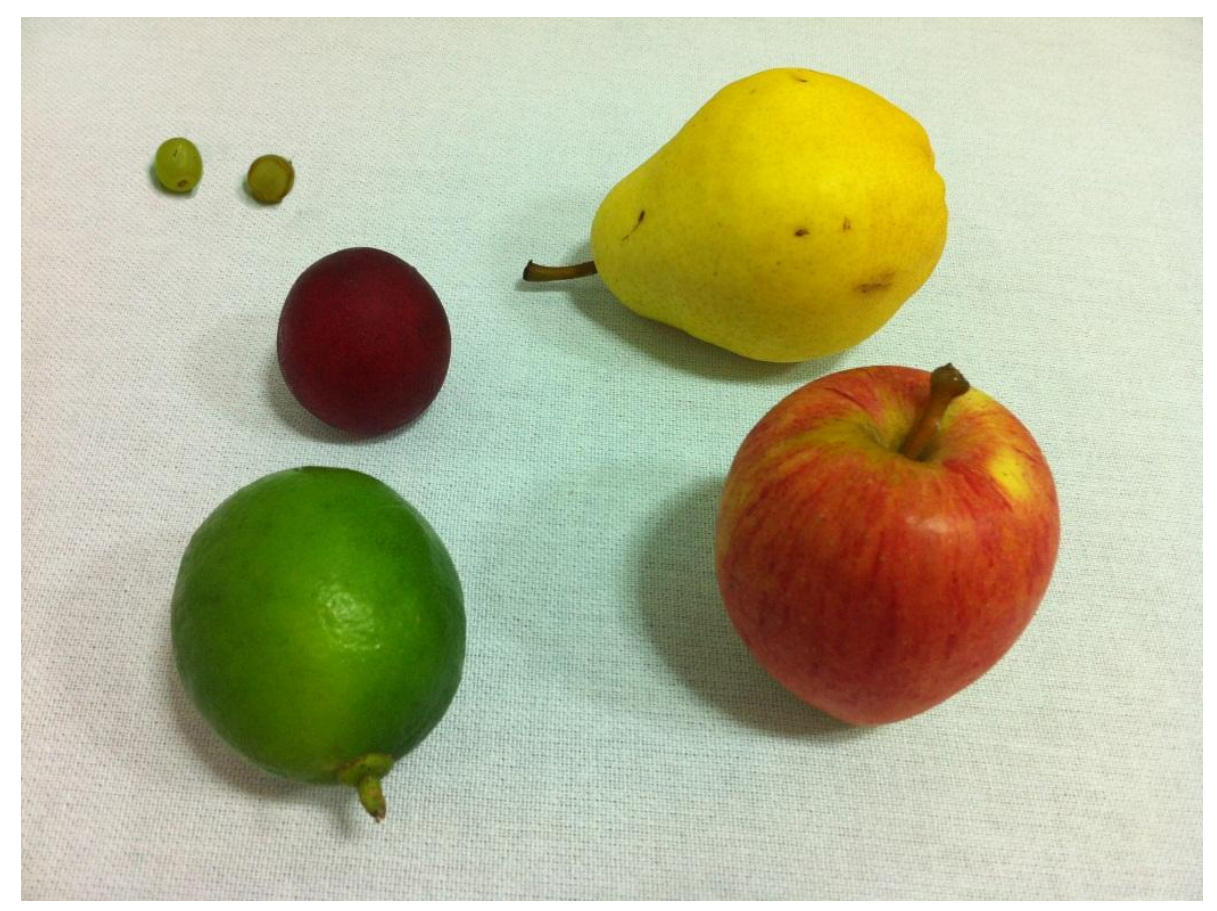

Figura 11 - Frutas utilizadas no teste do aparelho (Maçã Gala, Pera Willians, Ameixa Preta Nacional, Uva Thompson, e Limão Taiti).

A maçã, o limão e a ameixa foram testados sem nenhum corte, com a parte lateral externa em contato com o eletrodo. A uva também foi testada desta forma e um teste adicional nesta fruta foi feito com um corte transversal, colocando a parte cortada em contato com o eletrodo.

A pera foi cortada em um formato retangular de $2 \times 3 \mathrm{~cm}$, deixando a polpa em contado com o eletrodo.

Foram utilizadas 3 frutas de cada tipo e foram coletadas 5 imagens de cada fruta. 


\subsection{Simulação do efeito corona}

Com o intuito de comparar as imagens captadas com os valores teóricos de uma descarga elétrica em um objeto em função da geometria e da condutividade do material, foram realizadas simulações através do método dos elementos finitos e com algoritmo genético.

Todas as simulações foras realizadas em um computador com processador AMD Phenom II x4 945 Quadcore, com 4 Gb de memória RAM, utilizando o sistema operacional Linux Ubuntu 12.04 .

\subsubsection{Simulação da distribuição do potencial utilizando o método dos elementos finitos}

Foram realizadas simulações da distribuição das cargas elétricas nas amostras de em geometrias, circular e esférica.

A simulação foi obtida utilizando o software Matlab ${ }^{\circledR}$ e um script desenvolvido nesta plataforma pela NEVA Electromangetics ${ }^{\circledR}$, o EP22.m, que utiliza o método de elementos finitos para calcular a distribuição de cargas quando um potencial é aplicado em um material condutor

\subsubsection{Simulação da distribuição do potencial utilizando algoritmo genético}

Como uma forma alternativa de simulação, foi desenvolvido um programa em Matlab ${ }^{\circledR}$ para calcular a distribuição das cargas em amostras de geometria quadrada com diferentes condutividades e o código fonte se apresenta no apêndice $\mathrm{C}$. 
O algoritmo genético foi utilizado a fim de se encontrar a distribuição de cargas que apresentasse a menor energia eletrostática final. Isto porque a movimentação das cargas na amostra se dará segundo a força eletrostática,

$$
\vec{F}_{12}(r)=\frac{1}{4 \pi \varepsilon_{0}} \frac{q_{1} * q_{2}}{r^{2}} \hat{r}
$$

O valor da energia eletrostática pode ser obtido integrando-se o a força

$$
U_{i j}=-\int_{\infty}^{r_{i}} F_{i j} * d r=\frac{1}{4 \pi \varepsilon} \frac{q_{i} q_{j}}{r_{i j}}
$$

Considerando um conjunto de $n$ cargas, a energia total da distribuição poderá ser calculada segundo o princípio da superposição (FEYNMAN; LEIGHTON; SANDS, 2008), e então a o valor da energia total será dado por

$$
U_{\text {total }}=\sum_{i=1}^{n} \sum_{j=1}^{n} U_{i j}
$$

Segundo o principio de Hamilton, também conhecido como o princípio da mínima ação (9), as equações do eletromagnetismo (6), (7) e (8) levam sempre a uma distribuição com a menor energia possível.

$$
A=\int_{a}^{b}(T-V) * d t
$$

Onde T é a energia cinética e $\mathrm{V}$ a potencial. Portanto, dentre todas as distribuições de cargas na amostra, a distribuição real é a que apresenta a menor energia. Em vista disto, o algoritmo genético foi desenvolvido para se encontrar tal distribuição.

Neste programa, cada indivíduo representava uma distribuição de cargas dentro da amostra e cada cromossomo a posição de uma carga desta amostra.

O programa foi desenvolvido de forma a ser flexível, sendo que o número de cargas (que é o número de cromossomos) e o número de indivíduos (população) podem ser escolhidos pelo usuário ao executar o programa.

Ao ser executado, o programa gera uma população de indivíduos aleatória, verifica quais os indivíduos são os melhores (os que apresentam menor energia total). Depois disso, é feito um mecanismo de seleção, guardando sempre os 4 melhores indivíduos e excluindo os 4 piores.

A mutação é uma função que quando aplicada, substitui de forma randômica uma sequencia de cromossomos em um indivíduo por outra sequencia gerada aleatoriamente. A função CrossOver cruza os indivíduos 
mais bem sucedidos gerando novos individuos com os cromossomos dos dois individuos mais bem sucedidos (pais).

Esta rotina é repetida por um número fixo de iterações escolhidas pelo usuário ou até que a menor energia seja encontrada. A figura 12 representa o fluxograma do programa.

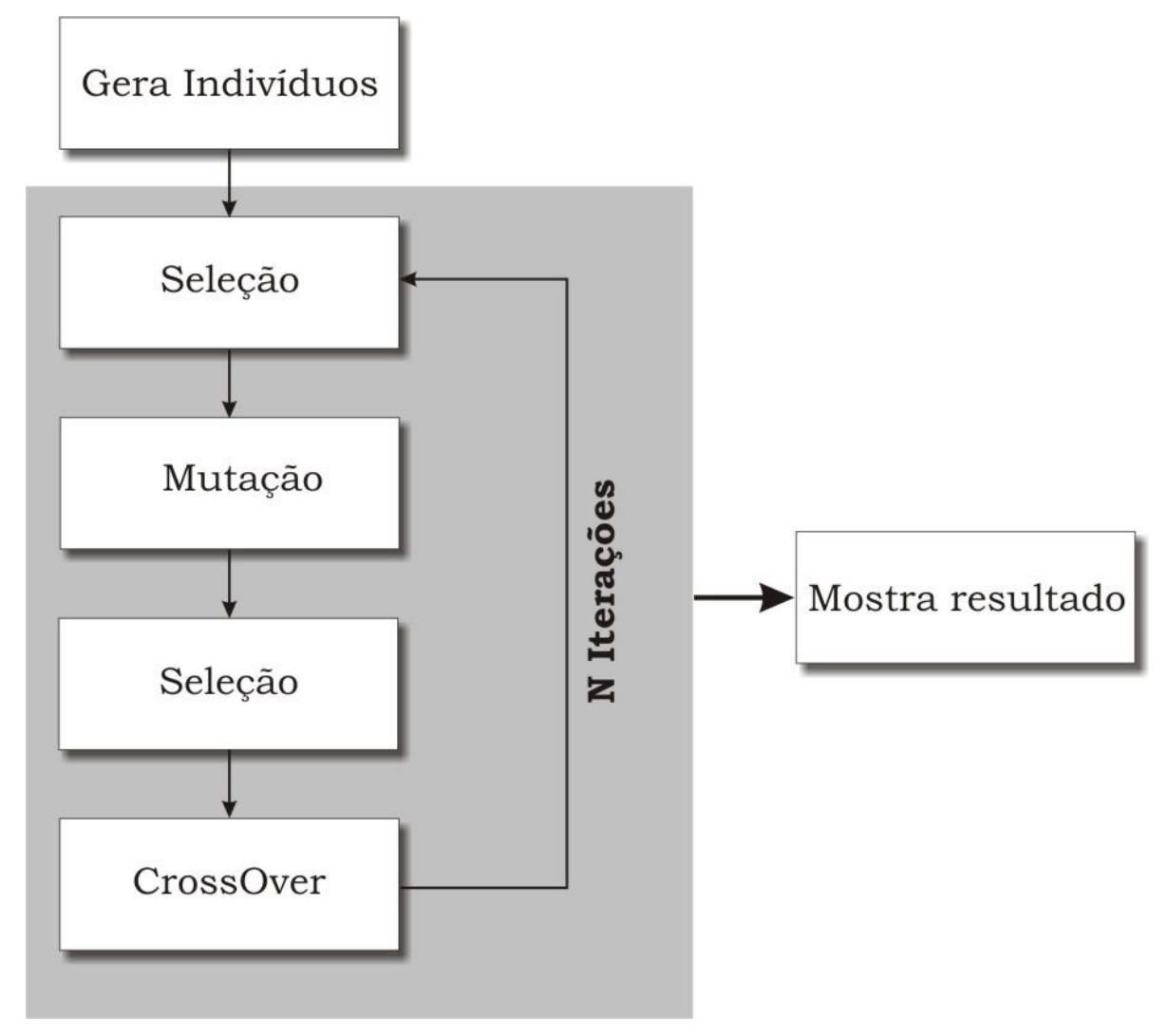

Figura 12 - Fluxograma do algoritmo

Em todas as simulações foi considerada apenas a analise dimensional adequada para cada unidade utilizada e não os valores em algum sistema de unidade, uma vez que se pretendeu encontrar a proporção da distribuição de cargas e não propriamente o valor numérico do potencial e do campo elétrico.

Outra simulação foi feita utilizando duas regiões, uma com permissividade elétrica 1 e outra com permissividade elétrica 2. Ambos os valores adimensionais, seguindo o mesmo procedimento das simulações anteriores. A amostra foi separada em 4 setores quadrados iguais, de $0.5 \mathrm{x}$ 0.5 u.d.a., sendo que o ultimo setor, com $x>0.5$ e y $>0.5$ foi escolhido para o valor de constante dielétrica igual a 2 e os outros 1. 


\section{Resultados e Discussão}

\subsection{Equipamento de efeito corona}

A figura 13 apresenta o equipamento montado. Devido à alta corrente que é necessária para alimentar o Flyback, o microcontrolador (a) foi programado para deixar o sistema funcionando por 5 segundos quando ativado. Outra medida adotada para se evitar o superaquecimento dos equipamentos foi a instalação de um dissipador de calor (b) no transistor de efeito de campo (IRF740), pois este componente é o que recebe mais corrente no equipamento.

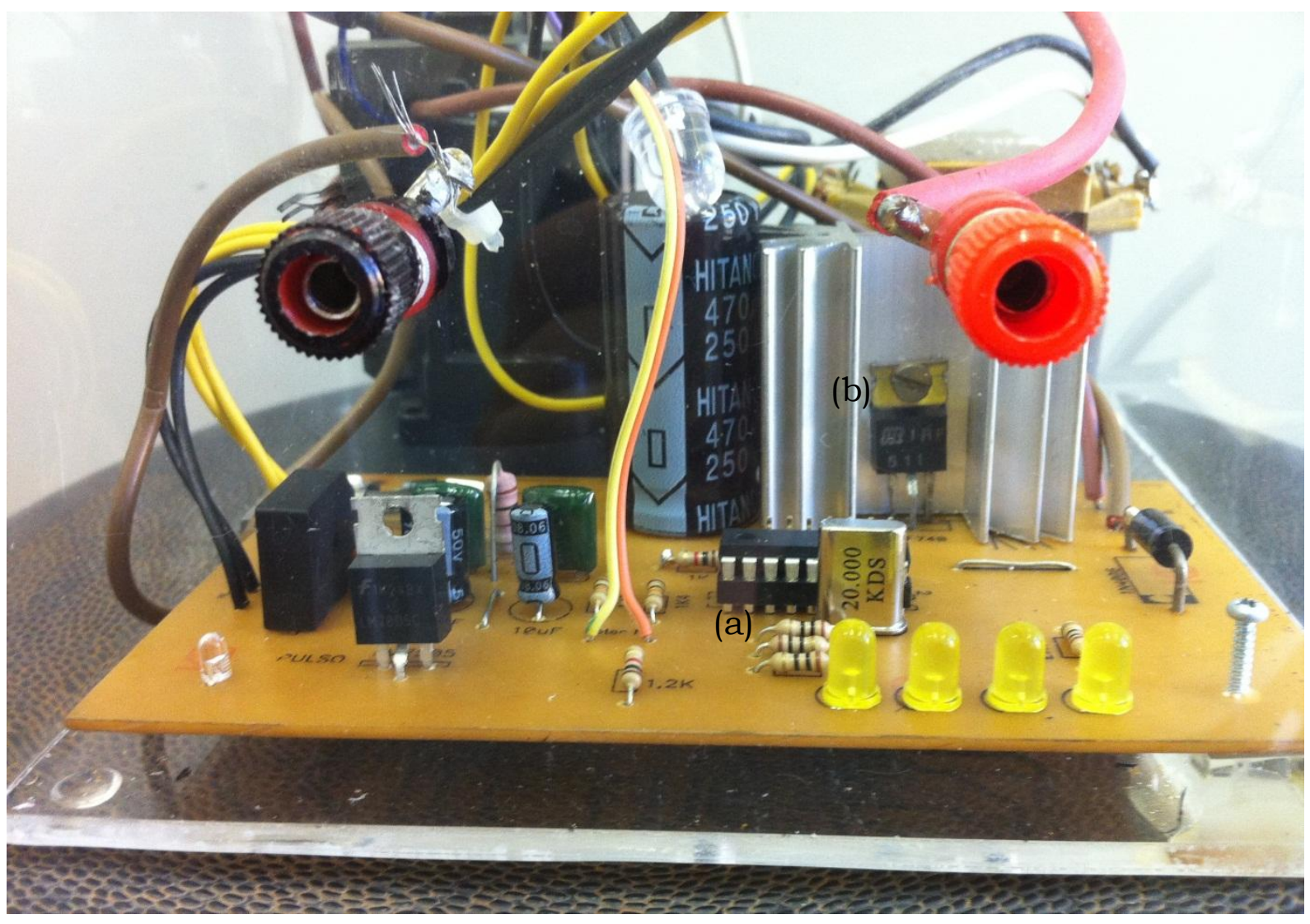

Figura 13 - Equipamento gerador de alta tensão

A caixa foi construída em acrílico para possibilitar a visualização dos componentes e também por questões de segurança, isolando o usuário da alta tensão dentro do equipamento. 
A tensão e frequência de saída na placa foi medida em um Osciloscópio, para se garantir que o flyback recebesse o sinal de entrada desejado. A figura 14 apresenta a tensão lida no osciloscópio em função do tempo, obtida entre o coletor do transistor BC337 e o terra.

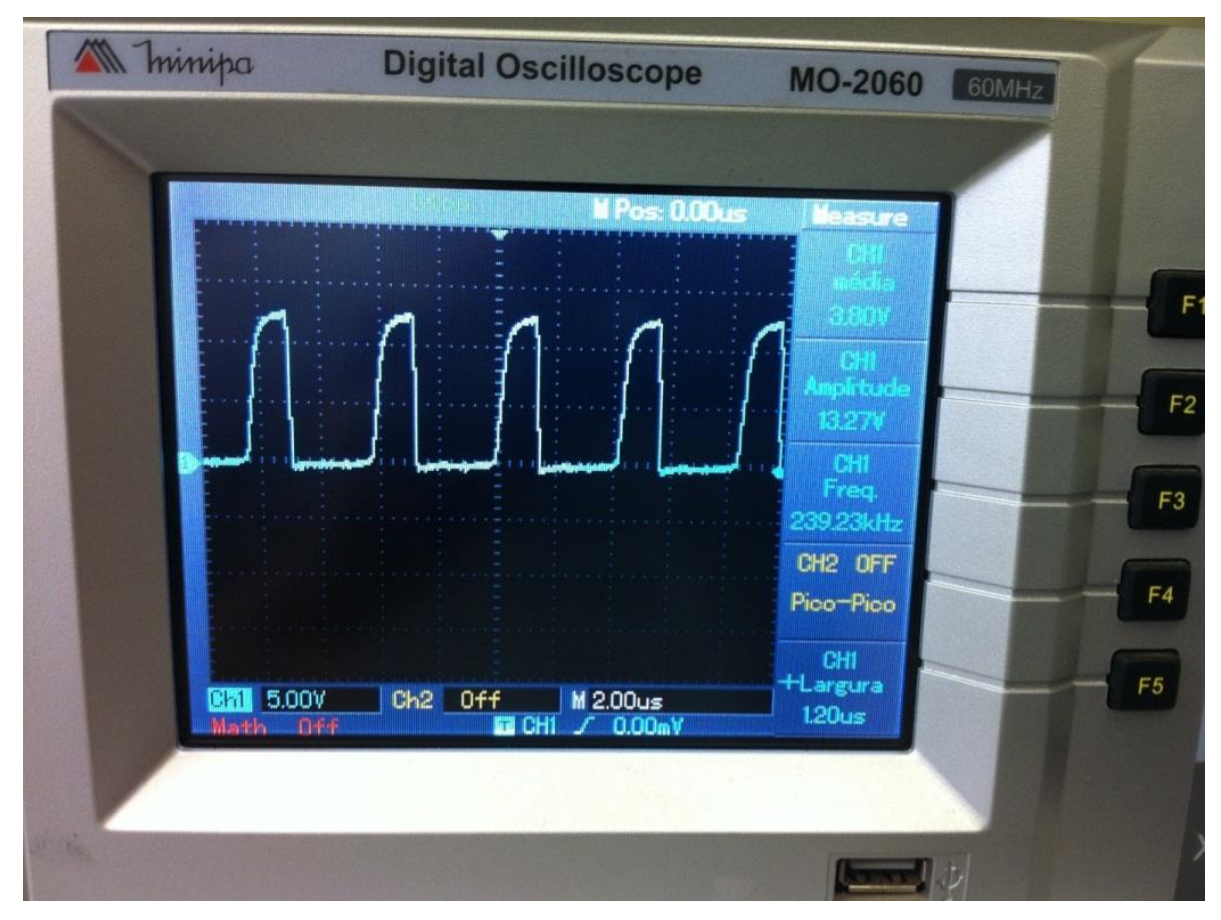

Figura 14 - Tensão Lida no Osciloscópio.

Como o valor da tensão na saída do flyback é muito elevado, não pôde ser medido em um equipamento comum. A forma mais simples de se obter a tensão de saída para este caso foi medir o comprimento máximo do arco elétrico para então calcular a tensão de saída indiretamente utilizando o valor da constante dielétrica do ar. Na figura 15, tem-se a imagem da descarga com uma régua de fundo para se medir o comprimento desta descarga. 


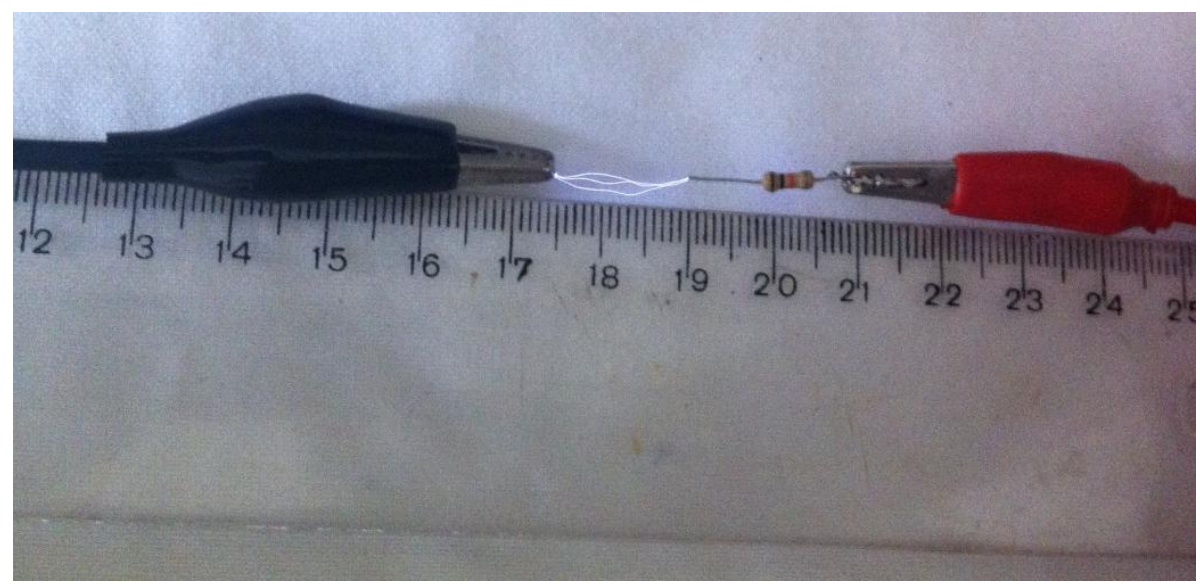

Figura 15 - Descarga elétrica entre os polos dos eletrodos, com a máxima distância obtida para a descarga.

Como pode ser observado na figura 15, o valor máximo de distância entre os eletrodos para que houvesse a descarga foi de $1,5 \mathrm{~cm}$.

O valor teórico para a rigidez dielétrica do ar é de $30 \mathrm{kV} / \mathrm{cm}$ nas condições normais de temperatura e pressão. A Umidade do ar quando este teste foi realizado era de $21 \%$ e a temperatura era $28,1^{\circ} \mathrm{C}$. Com estes parâmetros, pode ser calculado o valor corrigido para a tensão de saída levando em conta estes dois parâmetros através da lei de Paschen, equação (10).

$$
V=d *\left(24,22+\frac{6,08}{\sqrt{d}}\right)
$$

Temos que a tensão de saída é de $\mathrm{V}=43,78 \mathrm{kV}$ 


\subsection{Captação do efeito corona}

\subsubsection{Imagens com câmera digital}

A figura 16 apresenta a imagem captada pelo software de controle após o tratamento digital, com aumento de brilho e contraste, em uma uva inteira.

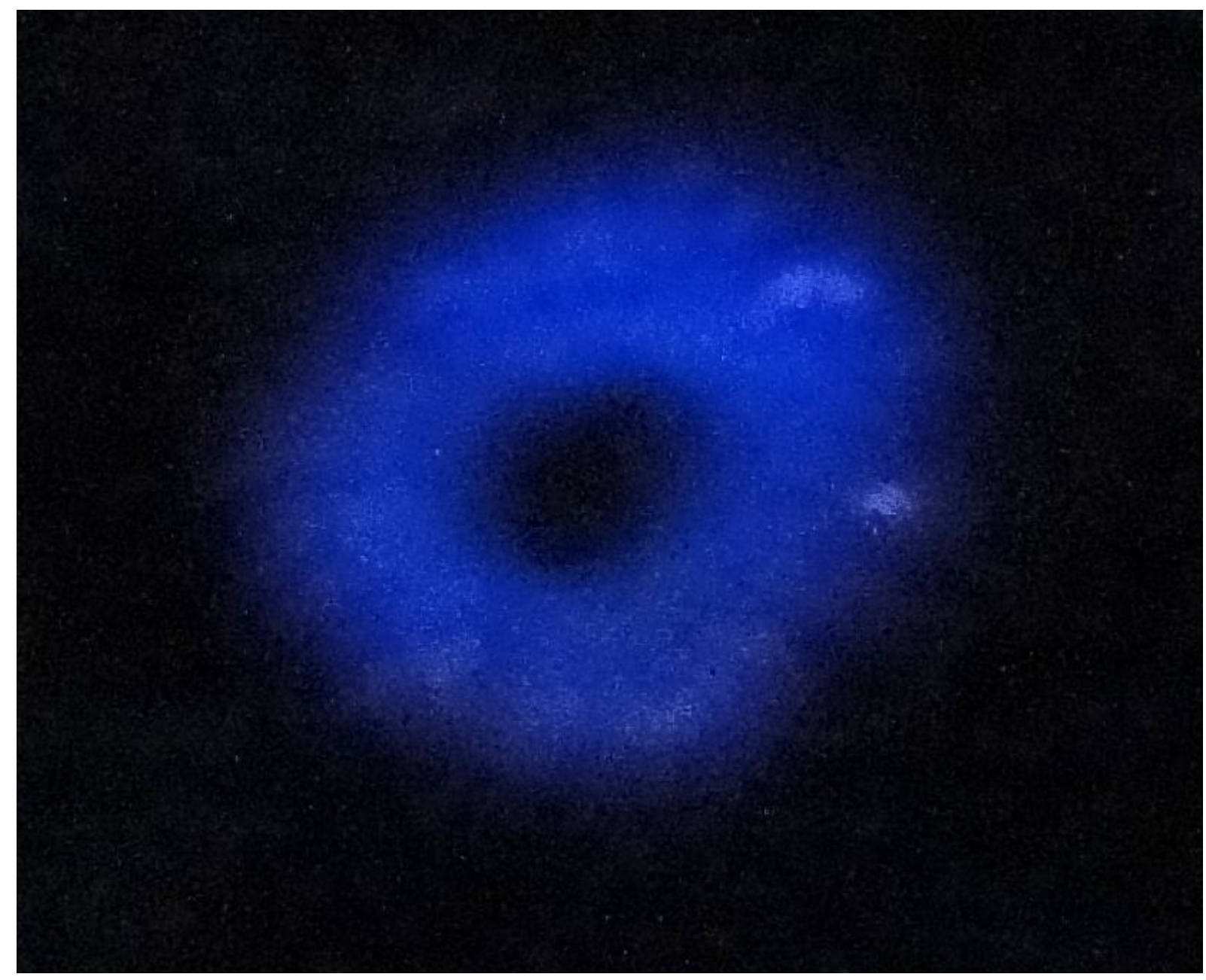

Figura 16- Uva Inteira

Todas as imagens sofreram o mesmo tratamento, com aumento de $50 \%$ no brilho e 30\% no contraste. Este tratamento foi necessário devido à câmera utilizada não ser própria para captura de imagens em baixa luminosidade. O tipo de tratamento pode alterar dependendo da câmera 
utilizada, sendo que com uma câmera profissional com foco e tempo de exposição regulado manualmente, poderia evitar a necessidade deste tratamento e obter uma imagem de melhor qualidade.

Pode-se observar a diferença visual da aplicação do tratamento da imagem na figura 17, que apresenta a mesma imagem, uma uva cortada, depois e antes do processamento.

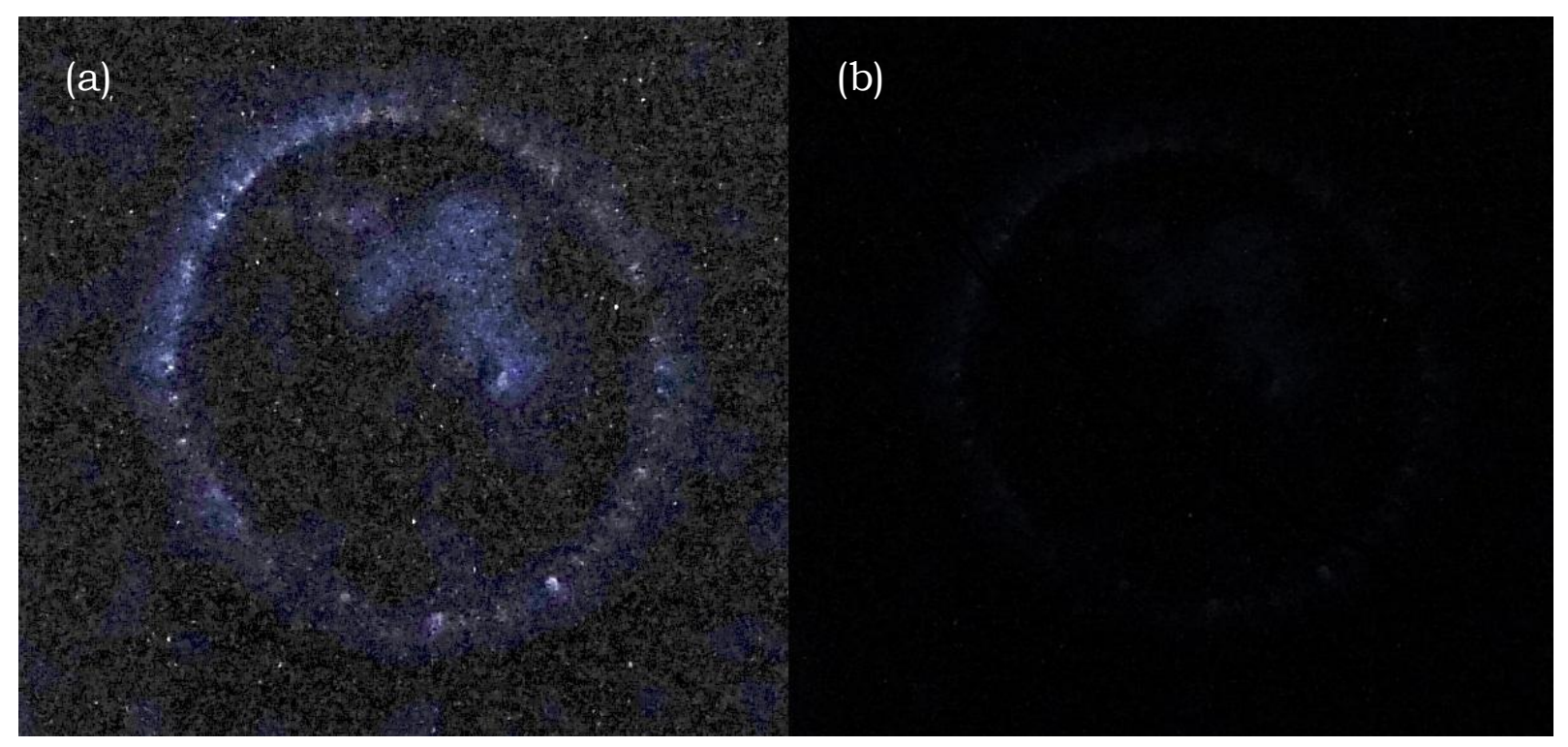

Figura 17- Uva Cortada. (a) imagem processada. (b) imagem não processada.

As figuras 18, 19, 20 e 21 ilustram o resultado para maçã inteira, limão inteiro, ameixa inteira e pera (polpa cortada de forma retangular), respectivamente. 


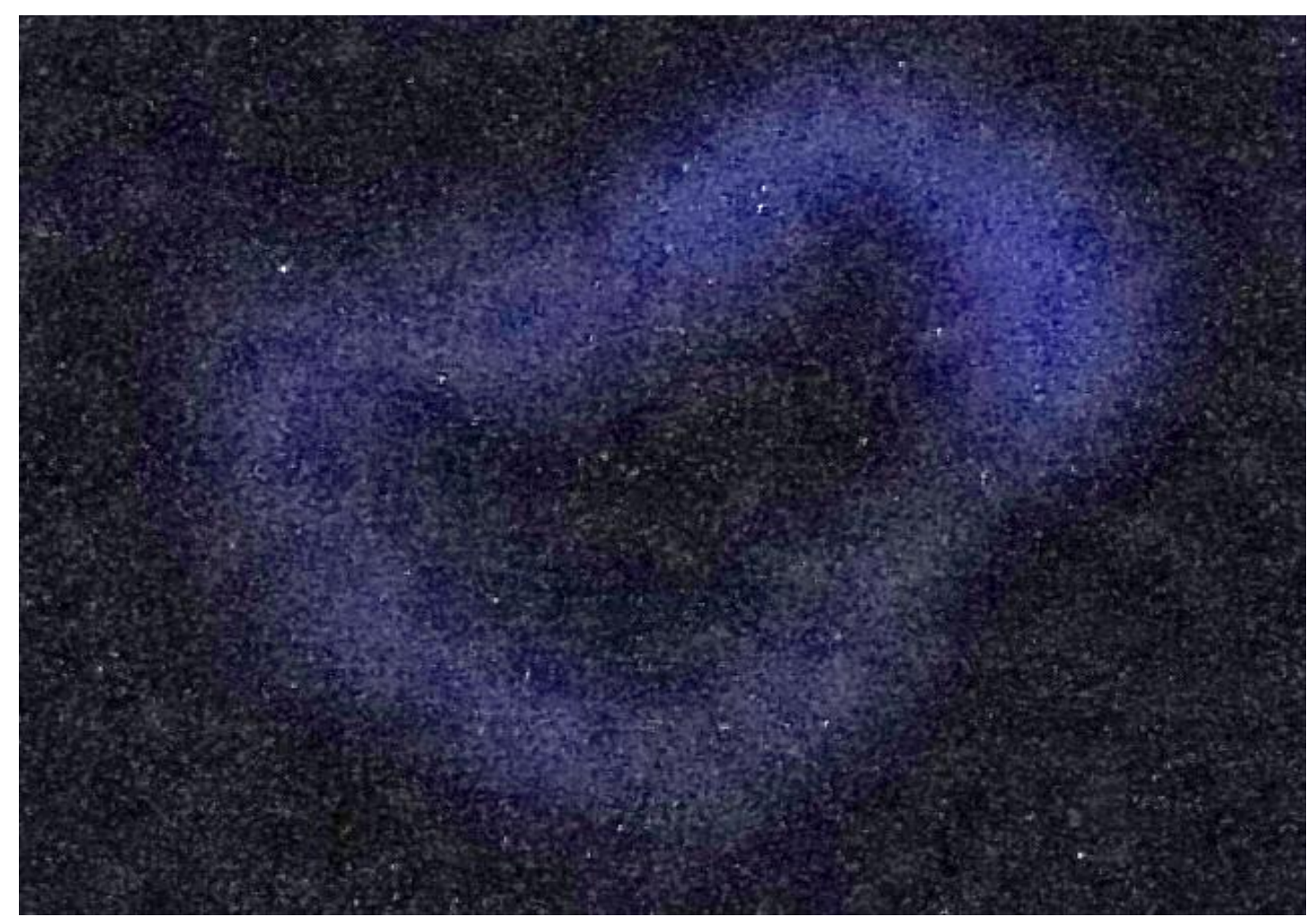

Figura 18 - Maçã.

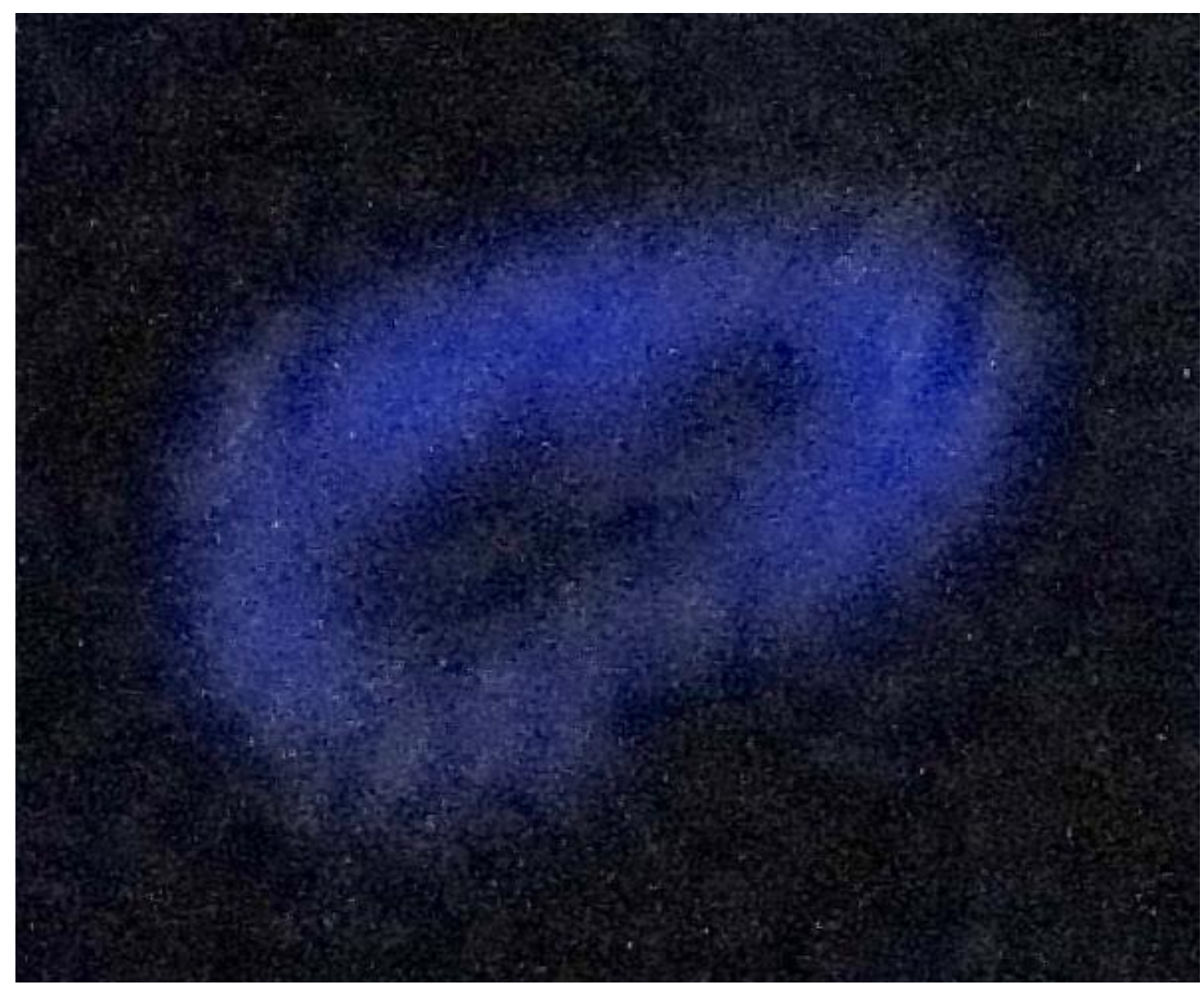

Figura 19 - Limão 


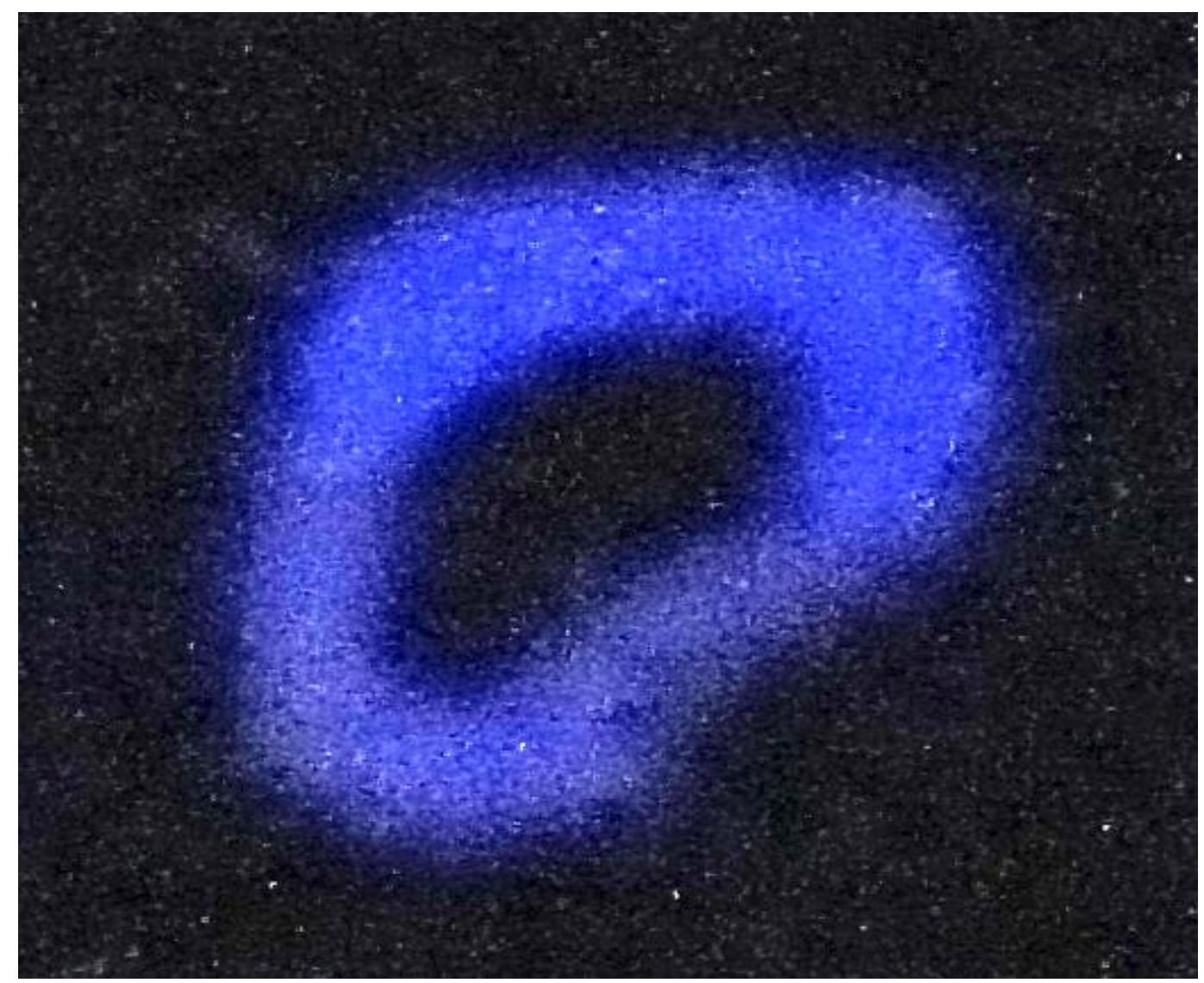

Figura 20 - Ameixa

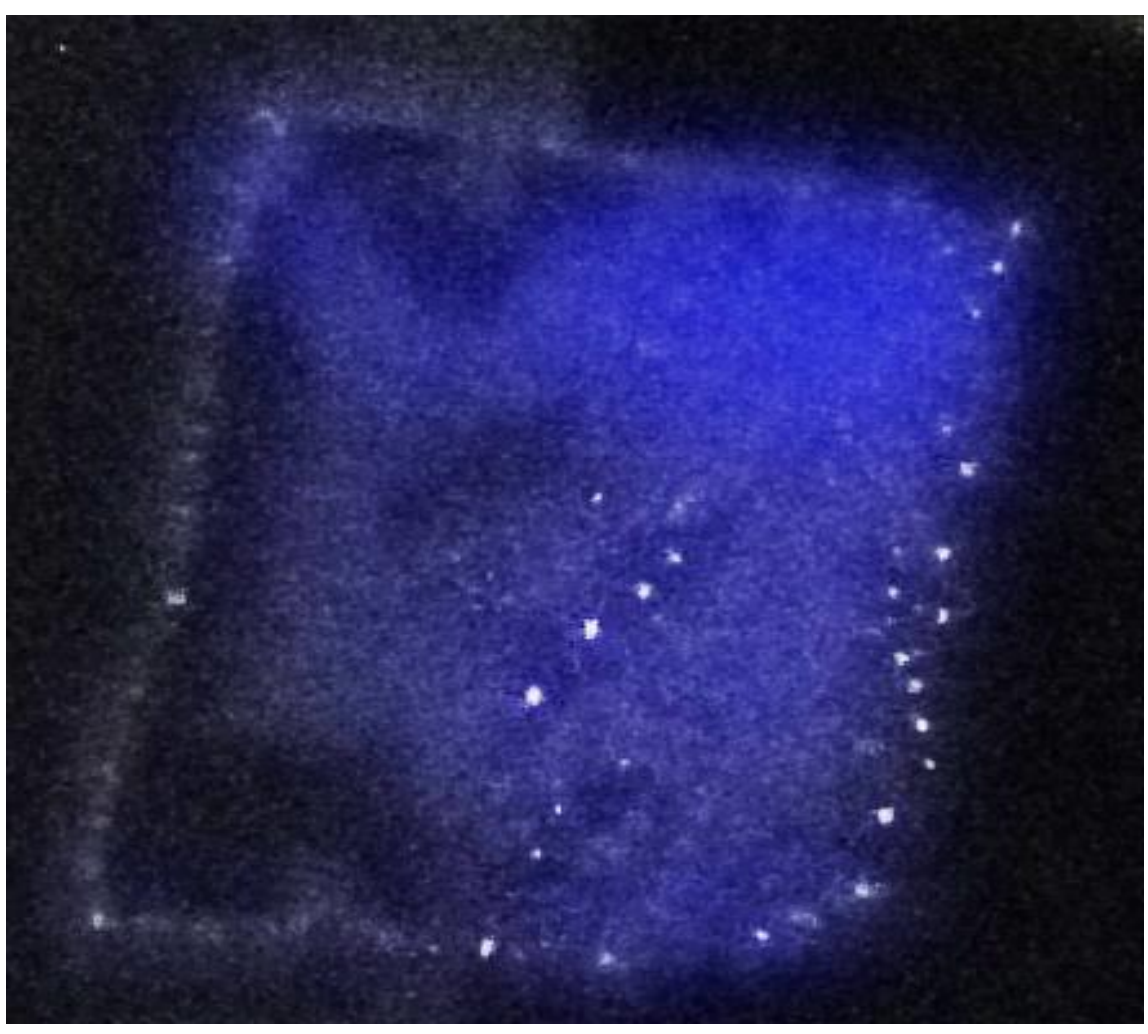

Figura 21 - Pera 
A pera apresentou maior número de pontos de saturação na imagem, possivelmente devido ao contato de líquido com o eletrodo, já que ela foi cortada e teve sua polpa exposta.

As imagens apresentaram diferentes padrões em função do tipo de fruta utilizada e do estado da fruta, no entanto quando comparamos várias imagens do mesmo tipo de fruta, notam-se similaridades entre elas (Figura 22).

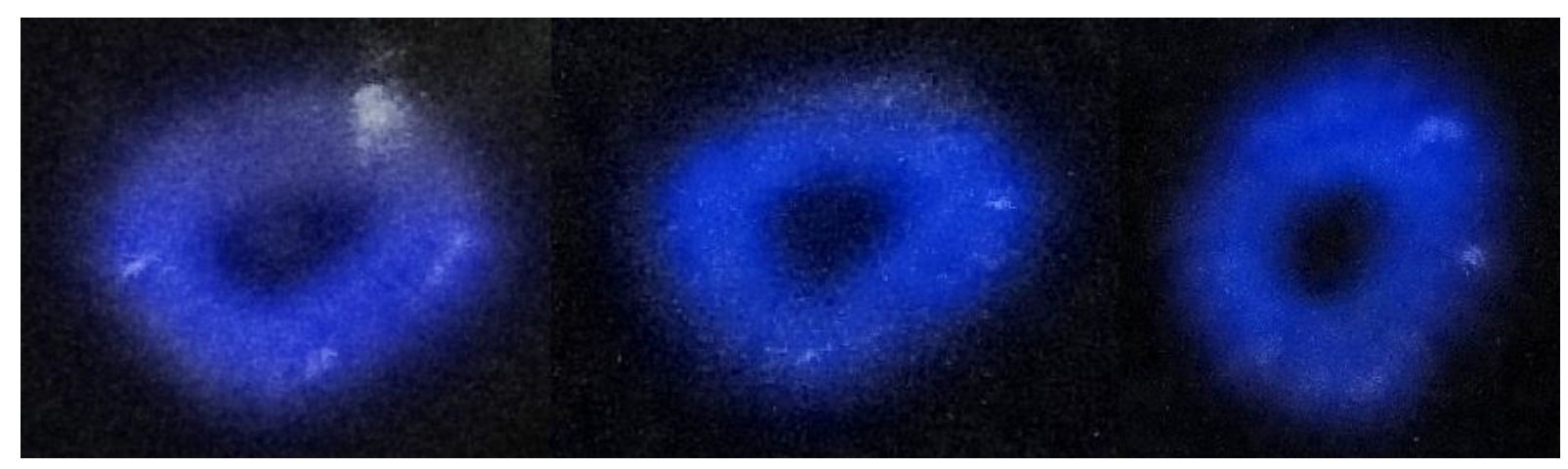

Figura 22 - Imagens captadas separadamente de 3 uvas inteiras.

A visivel semelhança entre imagens do mesmo tipo de fruta $\mathrm{e}$ diferenças entre tipos diferentes de frutas indica que este tipo de imagem pode conter informações relevantes a respeito das características físicoquímicas da fruta. Para que isto possa ser afirmado, mais experimentos com uma quantidade estatisticamente significativa de cada tipo de fruta, devem ser feitos, com a utilização de técnicas de reconhecimento de padrões e extração de características.

\subsubsection{Visualização de alterações no fruto}

As imagens de frutas com e sem alguma alteração aparente foram colocadas em uma mesma figura para facilitar a comparação. Na figura 23 tem-se a imagem do efeito corona em duas maçãs, uma com uma marca na casca (a) e a outra sem nenhum problema aparente (b). 


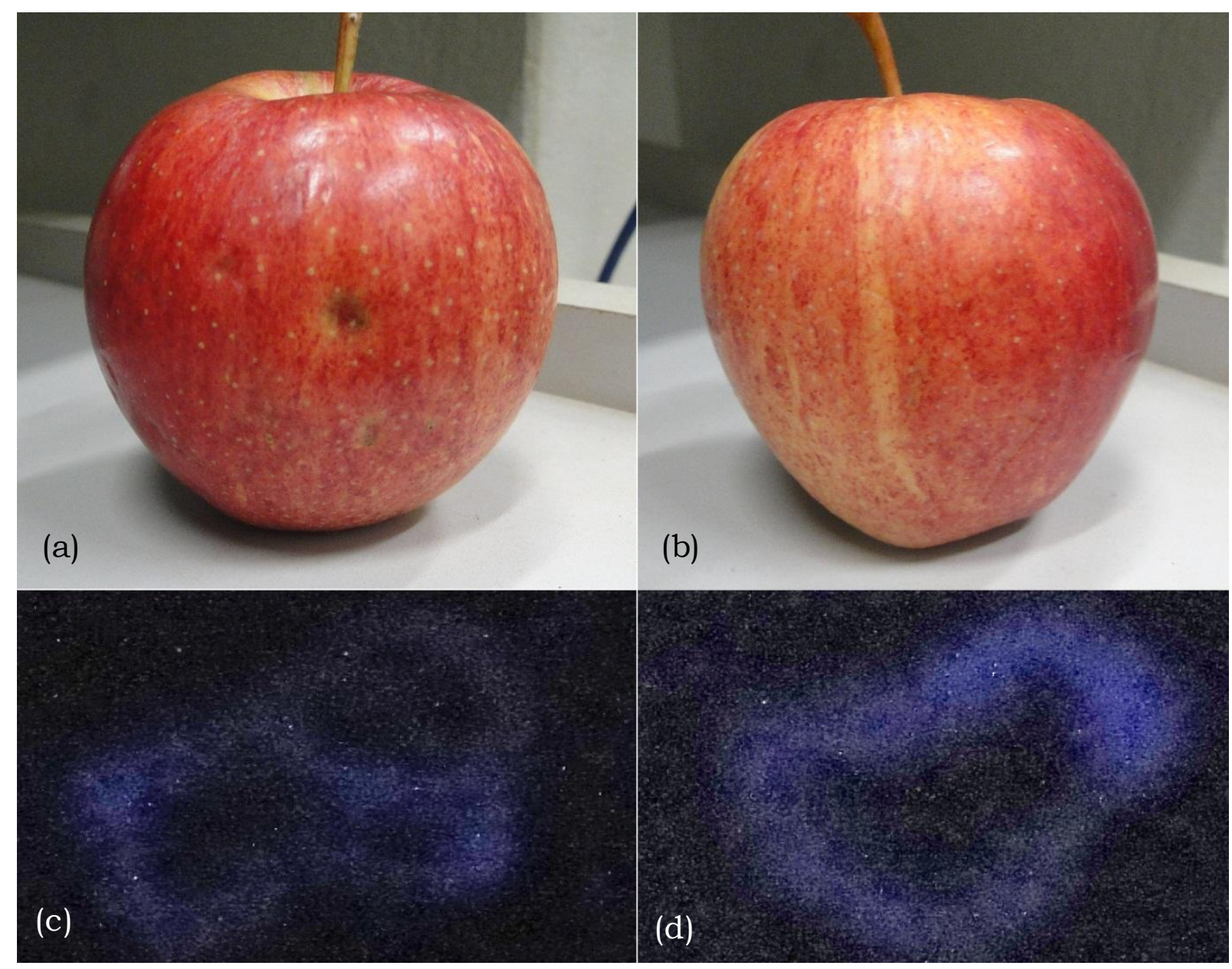

Figura 23 - maçã. (a) imagem da maçã com marca. (b) imagem da maçã sem problema aparente. (c) Efeito corona na maçã com marca. (d) Efeito corona na maçã sem problema aparente.

Pode-se ver uma diferença no padrão do efeito corona, dependendo da condição da fruta utilizada. Estes resultados estão em acordo com Weibel, Konomenko e Sadikov (2004), que também observaram alterações no efeito corona em função de problemas no fruto.

O mesmo procedimento foi feito para o limão e para a ameixa, que são apresentados nas figuras 24 e 25 . 


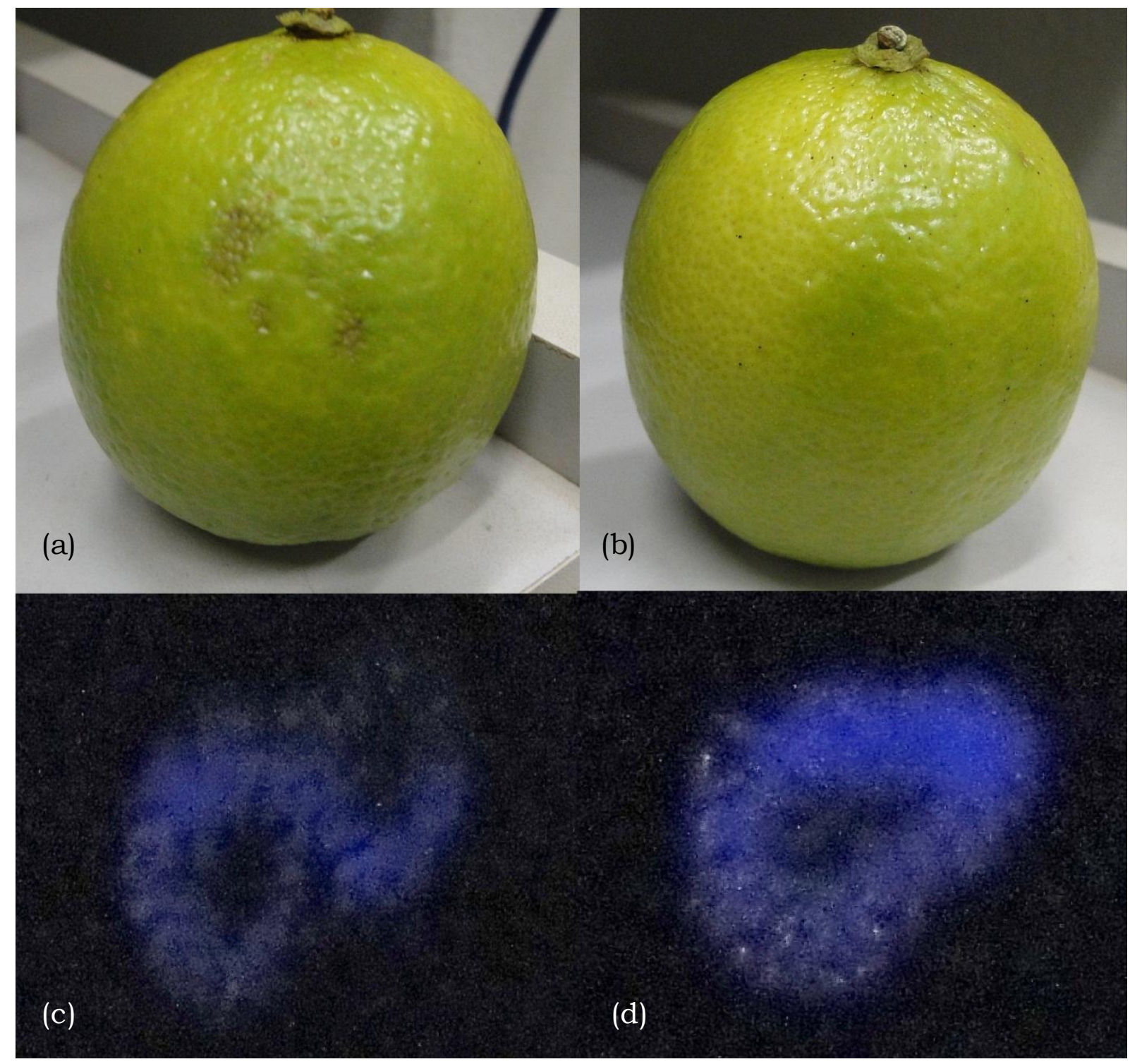

Figura 24 - limão. (a) imagem do limão com marca. (b) imagem do limão sem problema aparente. (c) Efeito corona no limão com marca. (d) Efeito corona no limão sem problema aparente. 


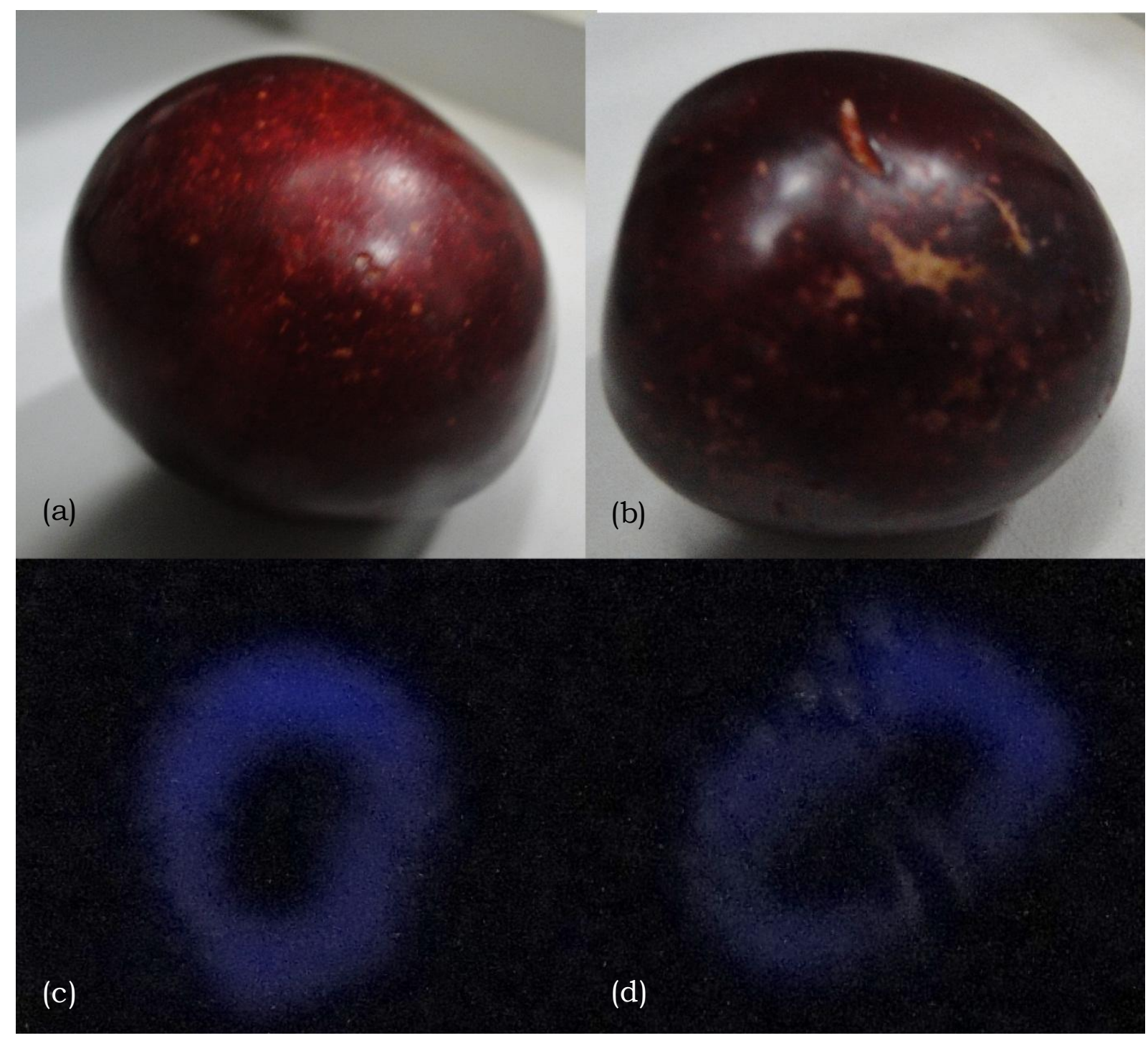

Figura 25 - Ameixa. (a) imagem da ameixa com marca. (b) imagem da ameixa sem problema aparente. (c) Efeito corona na ameixa com marca. (d) Efeito corona na ameixa sem problema aparente.

Em ambas as frutas podem-se ver alterações na imagem devido a problemas no fruto. O equipamento desenvolvido apresenta uma possibilidade para futuras pesquisas, que poderão mostrar quais fatores influenciam para a alteração da imagem e de que forma. Isto poderia levar a utilização do efeito corona em alimentos para aplicações industriais, como por exemplo, detectar a presença de agrotóxicos em um alimento ou alguma contaminação. 
5.2.3 Captação do efeito corona com filme tradicional

As figuras 26 à 30 apresentam as imagens captadas da forma tradicional, com a revelação do filme fotográfico.

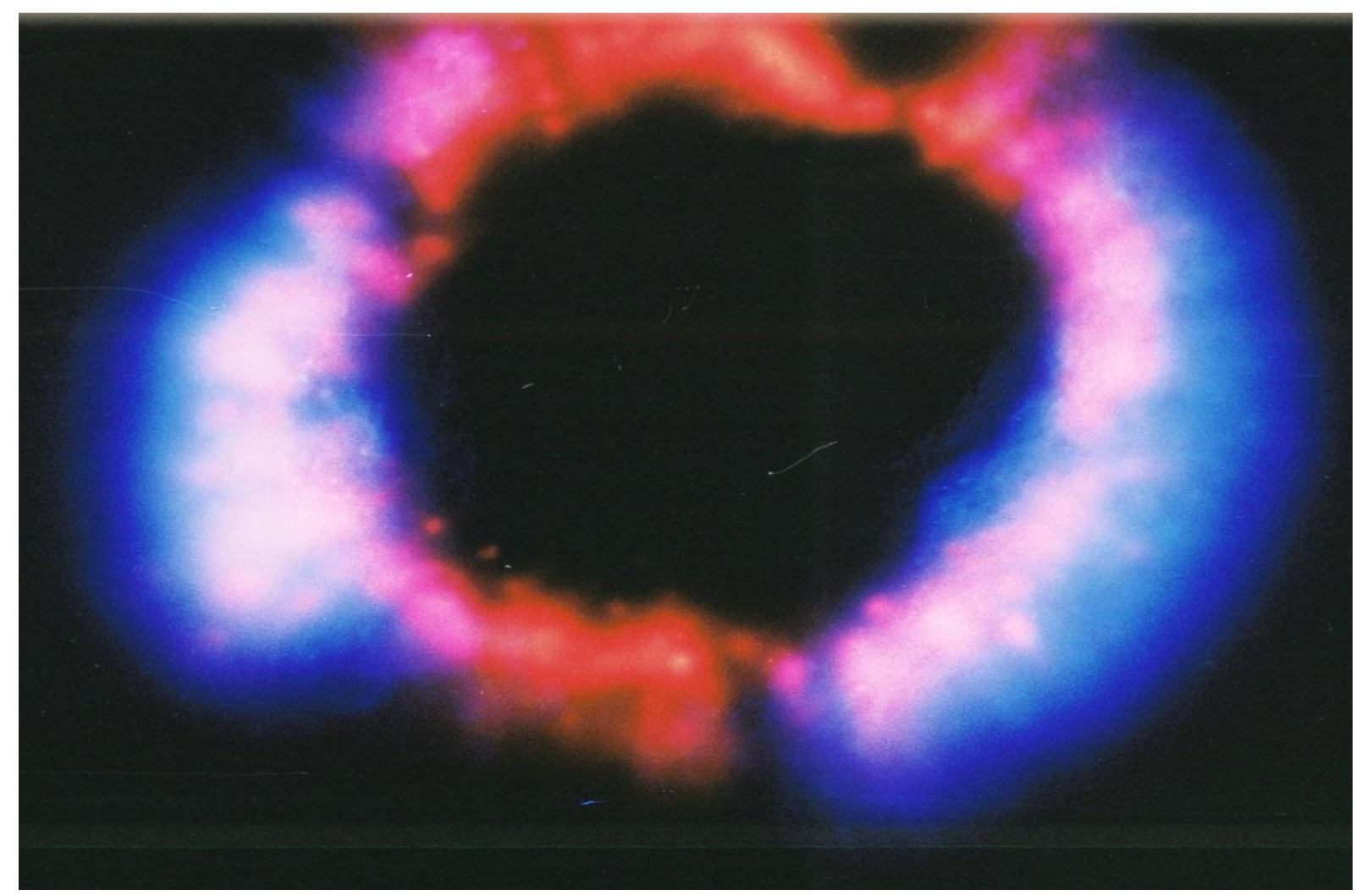

Figura 26 - Ameixa.

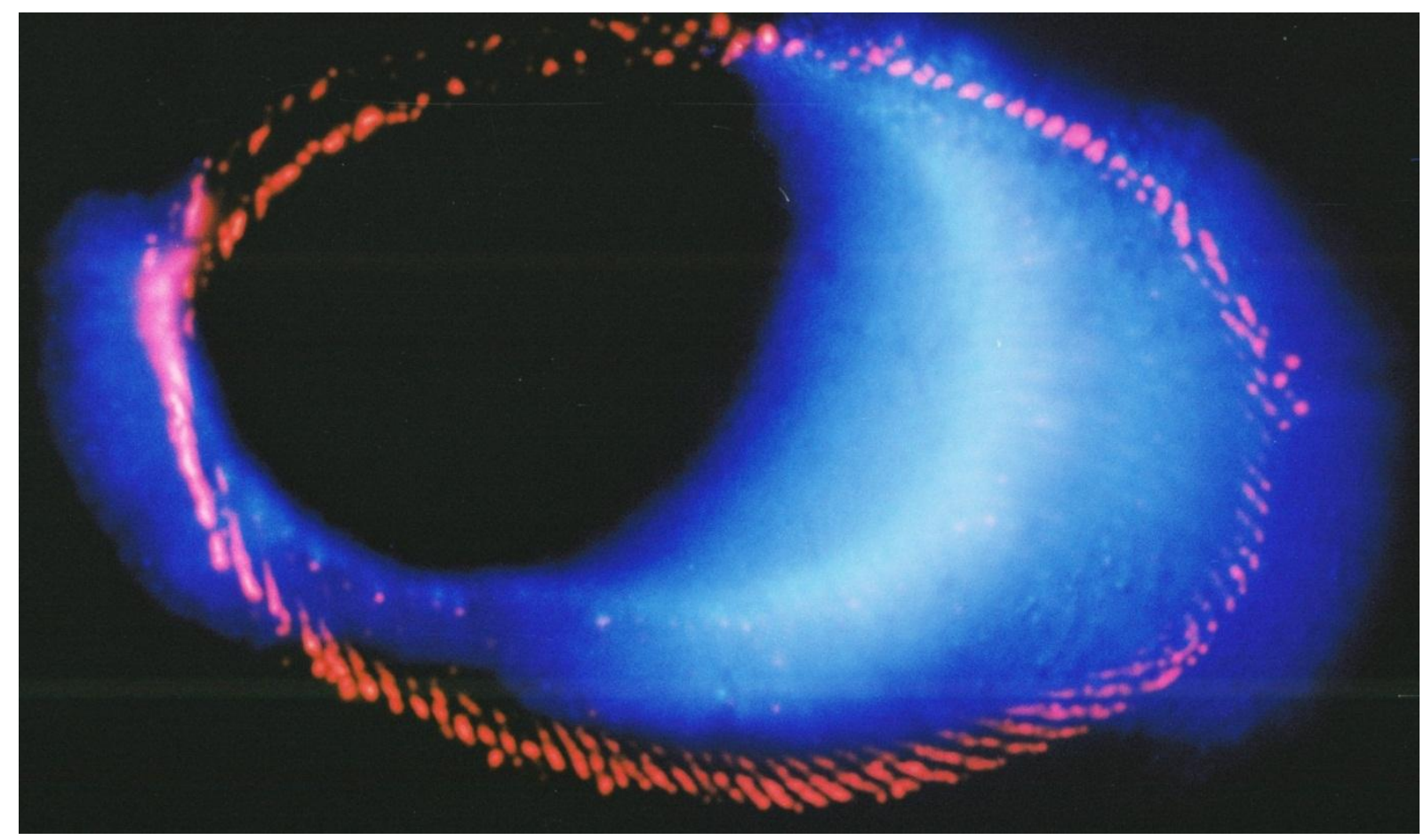

Figura 27 - Limão. 


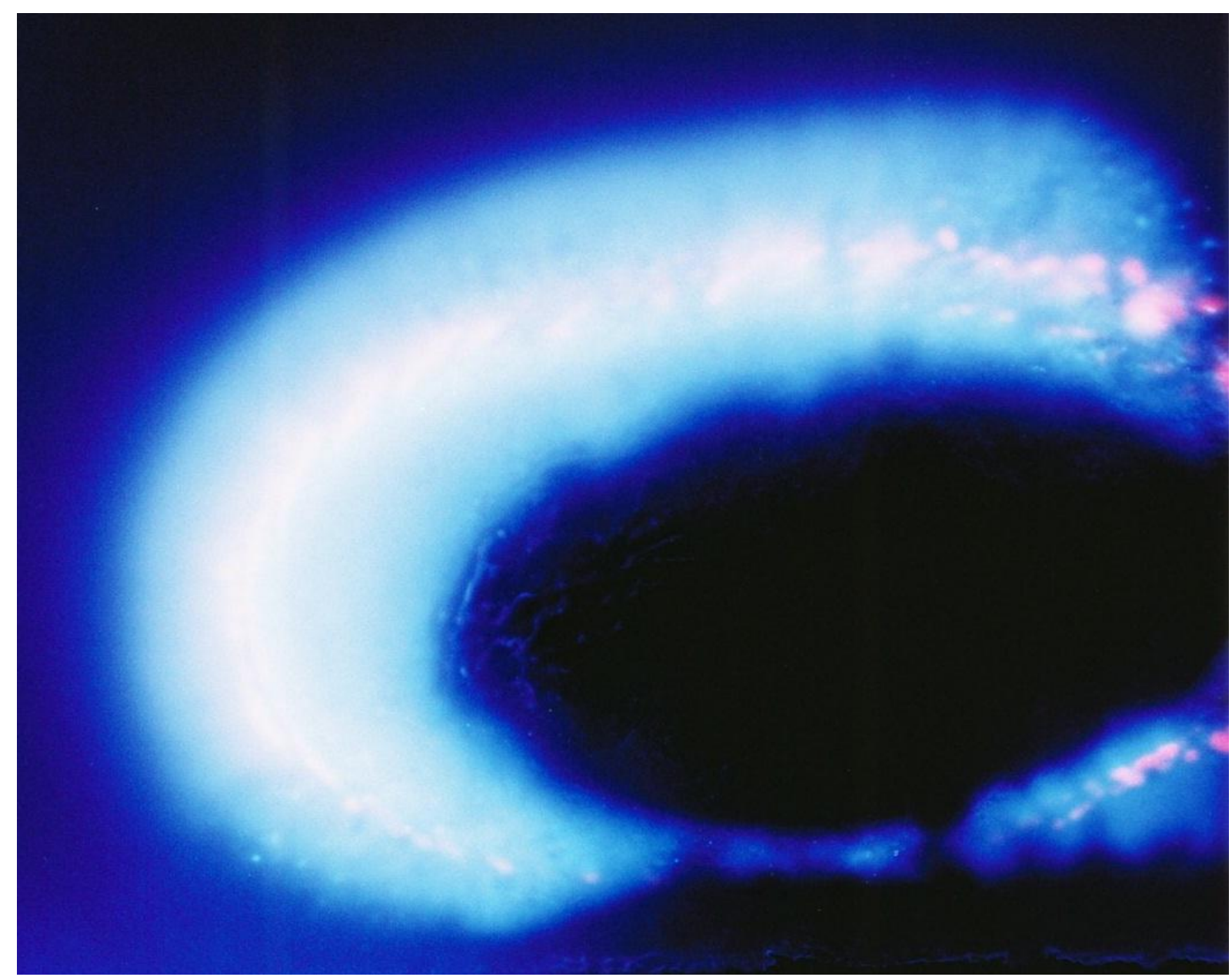

Figura 28- Maçã.

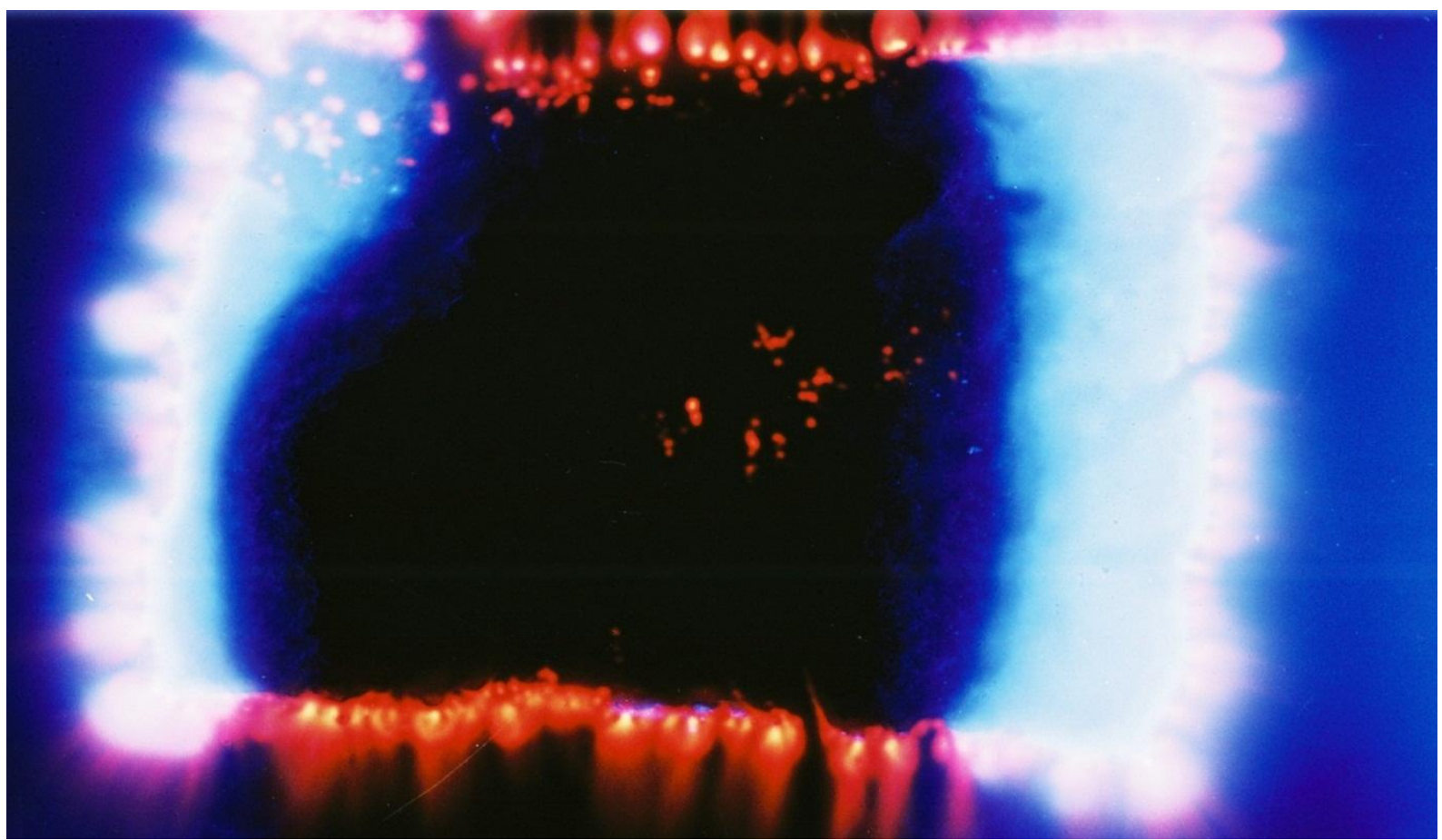

Figura 29 - Pera cortada. 


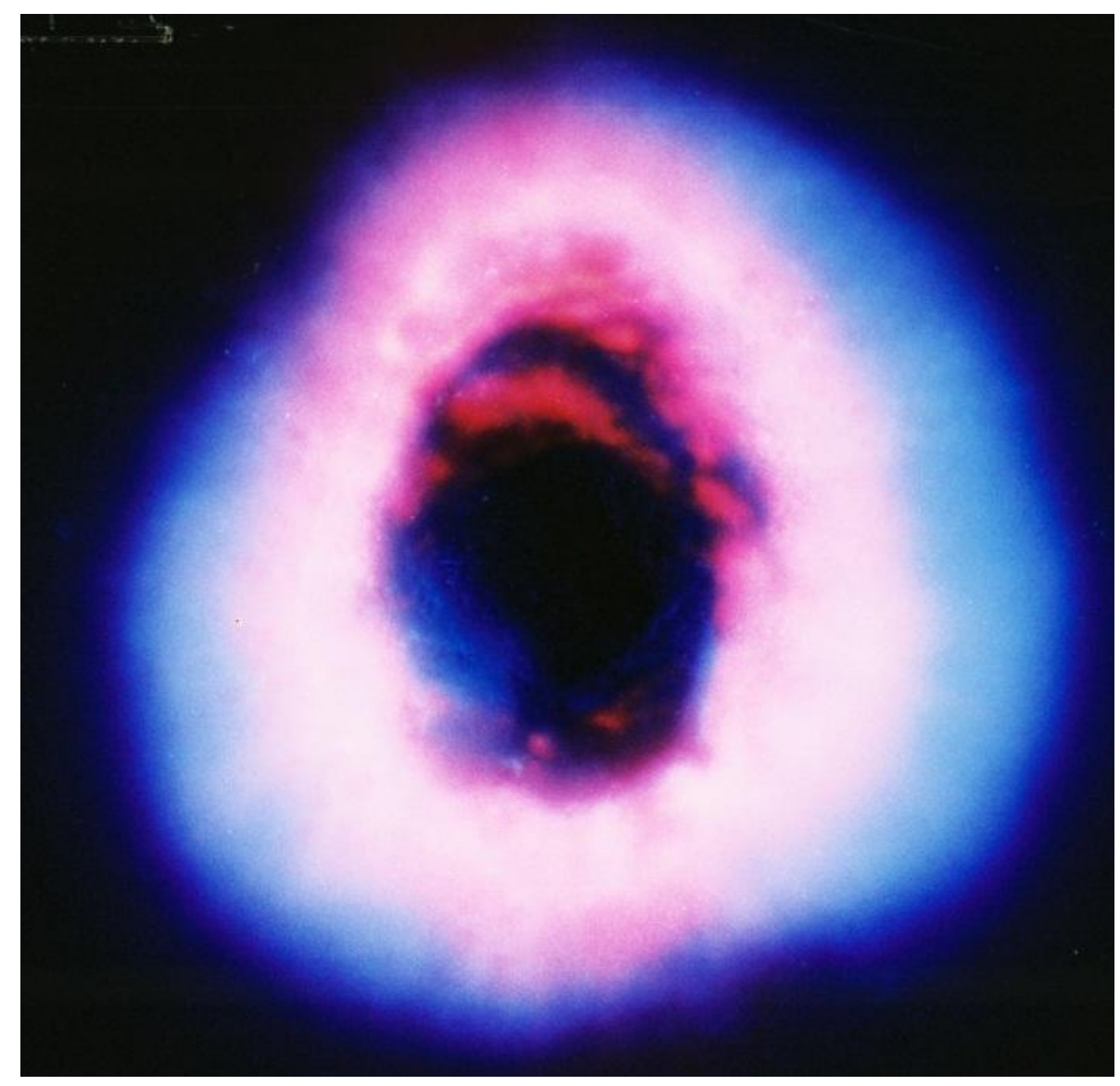

Figura 30 - Uva inteira.

Para obter melhores imagens, deve-se adequar o tempo de exposição ao efeito corona para cada tipo de amostra. O melhor tempo para cada amostra deve ser encontrado experimentalmente, de forma que o máximo de informação possa ser extraída da imagem. 


\subsection{Simulações}

\subsubsection{Simulação com elementos finitos}

Foram feitas simulações da densidade de carga em uma amostra com dois tipos de geometria diferentes, circular e quadrada. Os resultados estão apresentados na figura 31 e 32 .

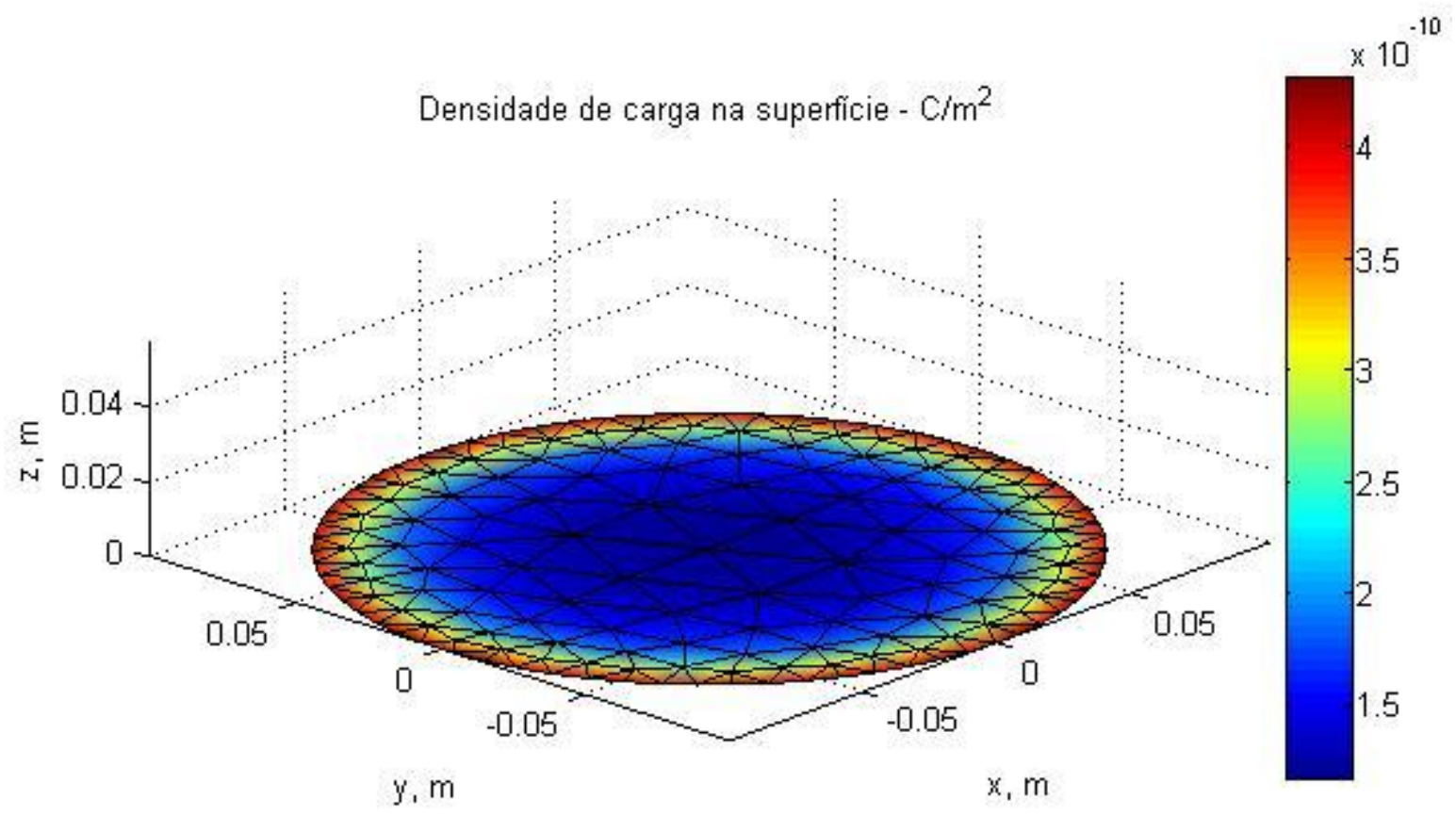

Figura 31 - Densidade de cargas em superficie circular. Eixo x e y em metros, densidade de carga em $\mathrm{C} / \mathrm{m}^{2}$. Escala: Vermelho: 4,5 x $10^{-10} \mathrm{C} / \mathrm{m}^{2}-$ Azul escuro: $4,5 \times 10^{-10} \mathrm{C} / \mathrm{m}^{2}$. 


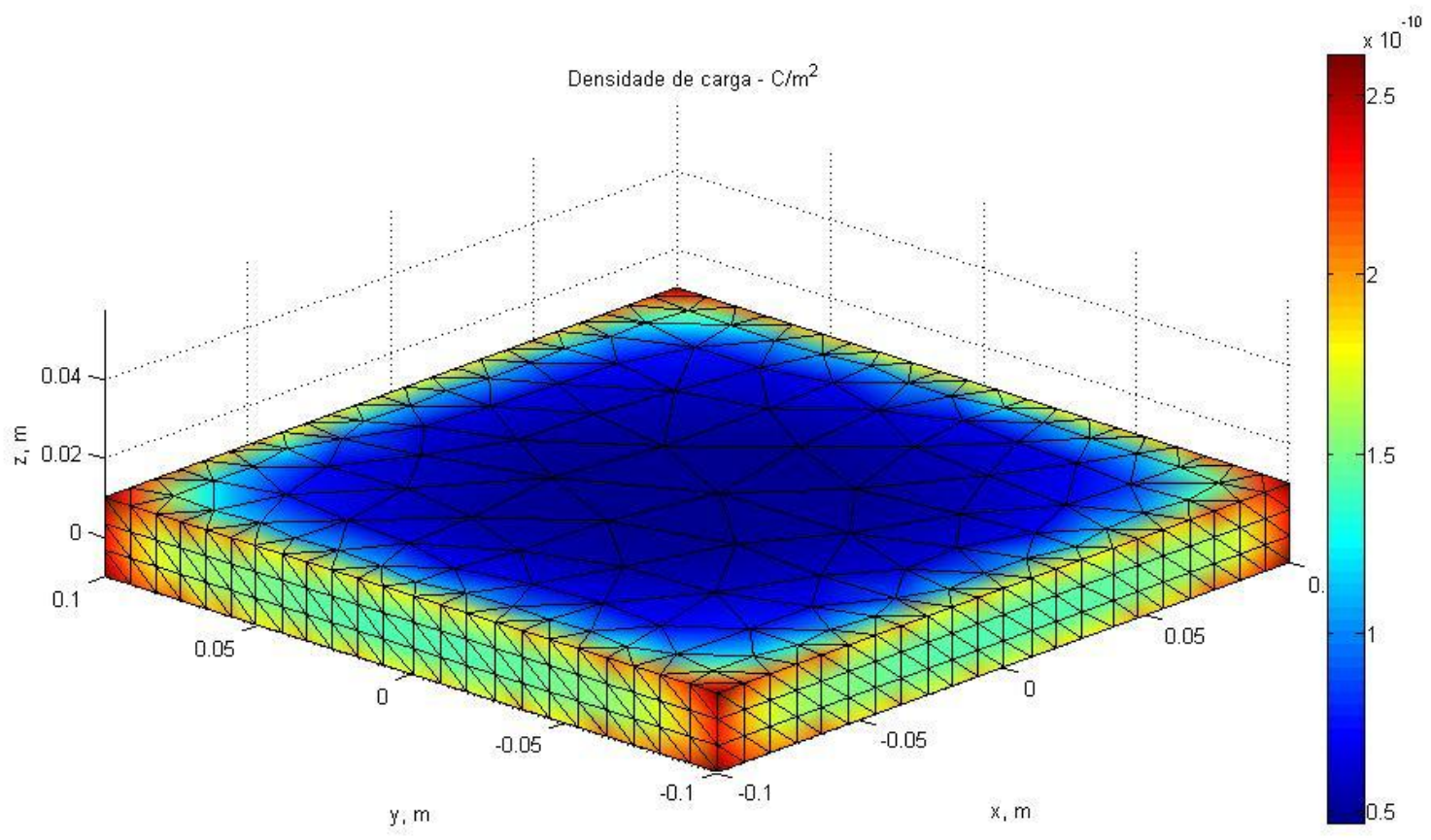

Figura 32 - Densidade de cargas em superficie quadrada. Eixo x e y em metros, densidade de carga em C/m2. Escala: Vermelho: 4,5 x 10-10C/m2 Azul escuro: $4,5 \times 10-10 \mathrm{C} / \mathrm{m} 2$.

Pelas imagens pode-se verificar que o efeito de borda ocorre, sendo que as laterais apresentam maior concentração do que o centro. Além disso, a mudança na geometria altera a distribuição, já que para a amostra circular, não existe diferenciação entre nenhum local na borda e na amostra quadrada existem 4 cantos que estão com maior carga.

\subsubsection{Simulação com Algoritmo Genético}

Foram feitas várias simulações utilizando o software desenvolvido (apêndice C), alterando o número de cargas, indivíduos e iterações. A figura 33 mostra o teste inicial do software, com apenas 4 cargas, distribuição em que a menor energia é facilmente calculada, e é a que cada carga está em 
um canto da amostra. Foram utilizados 30 indivíduos e 300 iterações. O tempo de processamento foi de aproximadamente 1 segundo.

(a)

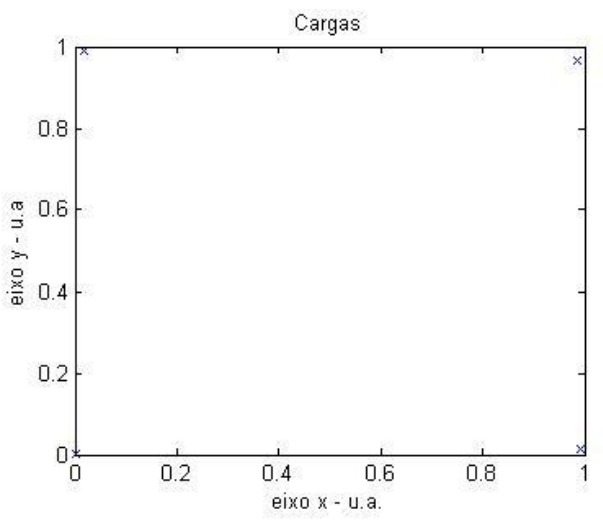

(c)

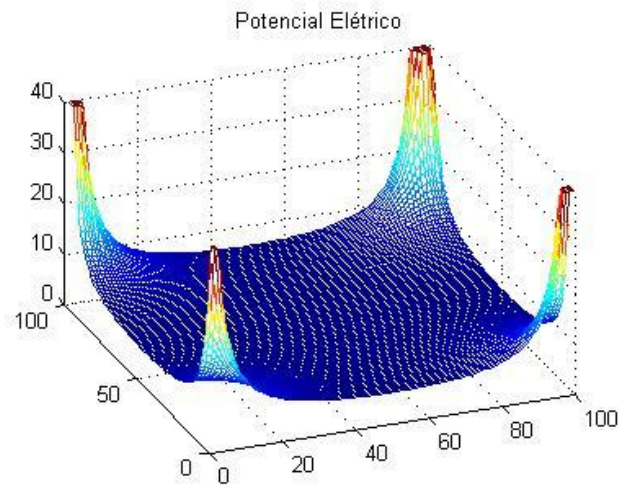

(b)

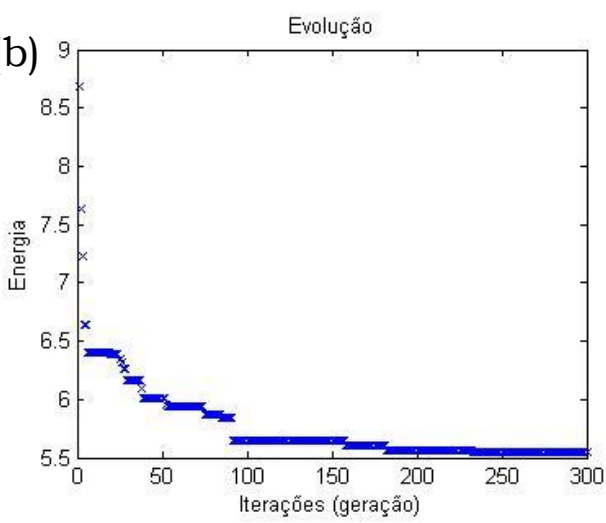

(d)

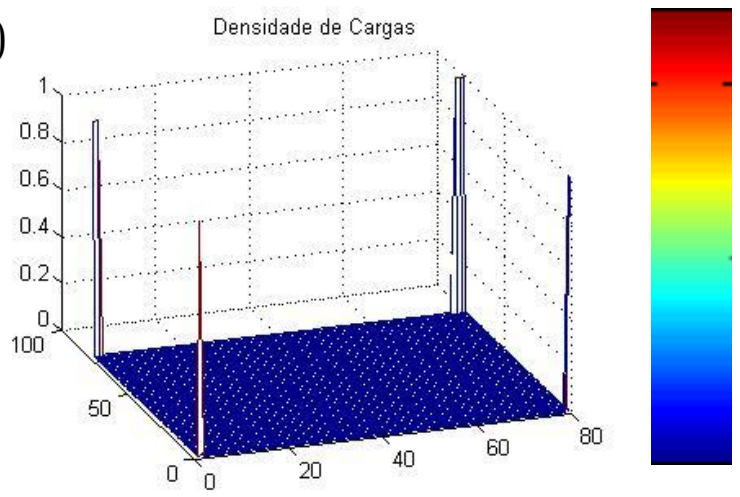

Figura 33 - Teste do algoritmo com 4 cargas. (a) Cargas na amostra. (b) Energia total do sistema em função do número de iterações. (c) Potencial elétrico na amostra. (d) Densidade de cargas na amostra.

Pela figura 34, pode-se ver que a simulação realmente encontrou a menor distribuição com a menor energia, com uma carga em cada ponta da amostra.

Para todas as simulações foi considerada uma placa com dimensão $1 \mathrm{x}$ 1 u.d.a. (unidade de distância adimensional) e o valor da carga elétrica em cada carga também é adimensional. Desta forma, os valores de energia encontrados em na figura 34 (b) também são adimensionais, fato que não interfere no objetivo da simulação uma vez que se pretendeu encontrar a evolução 'temporal' da energia com o número de iterações e não um valor numérico para ela. 
De forma análoga, os gráficos da figura 34 (c) e (d) possuem natureza adimensional. Para os eixos x e y destes gráficos, foi feita uma partição da u.d.a. em 100 pontos (c) e 80 pontos (d) para facilitar a execução do programa.

O segundo teste foi realizado com 50 indivíduos, 500 cargas e 5000 iterações. O tempo de processamento foi de 10.820,248 segundos (aproximadamente 3 horas) e os resultados estão expressos na figura 34 .

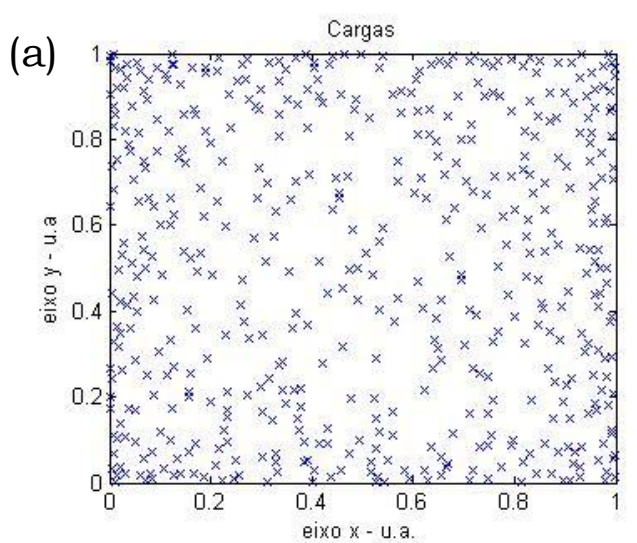

(c)

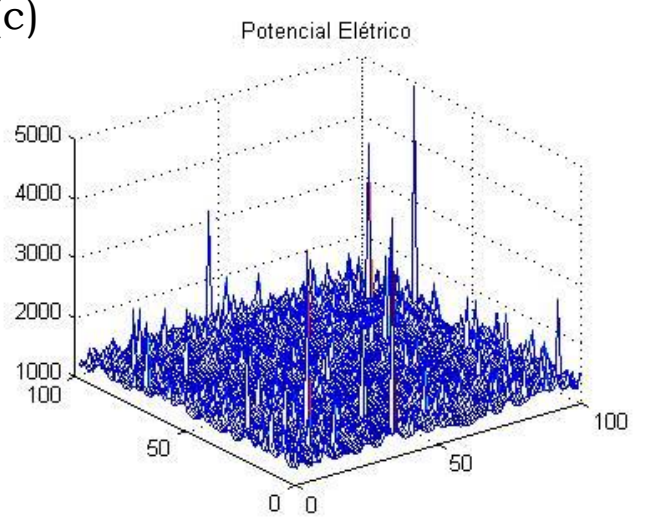

(b)

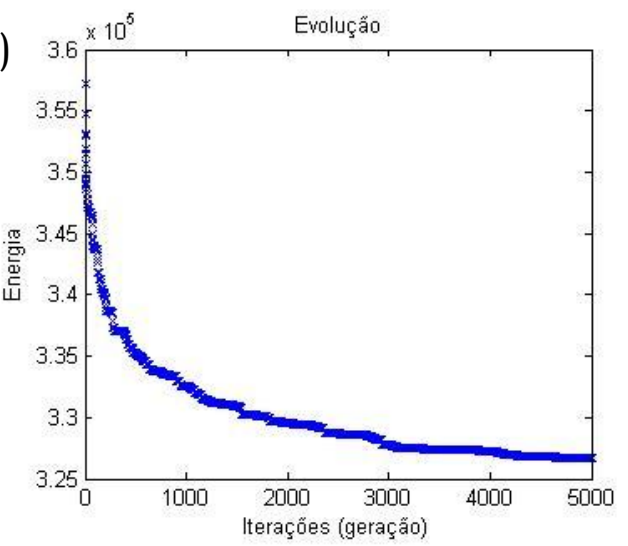

(d)

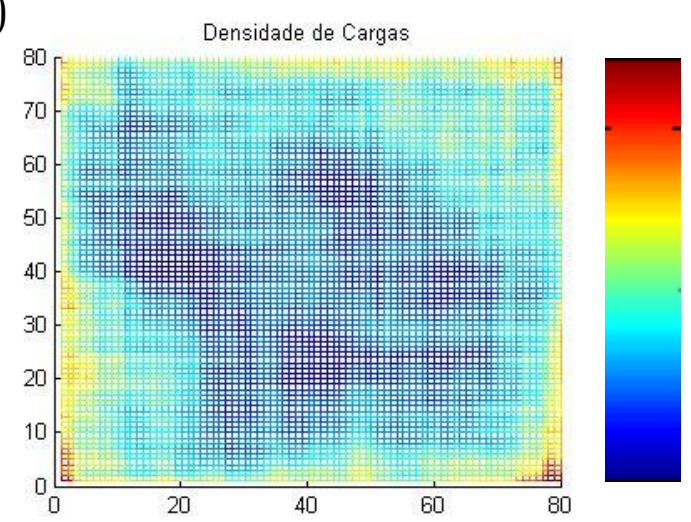

Figura 34 - 50 indivíduos, 500 cargas, 5000 iterações. (a) Cargas na amostra. (b) Energia total do sistema em função do número de iterações. (c) Potencial elétrico na amostra. (d) Densidade de cargas na amostra.

Pela figura 35 (d) observa-se o efeito de bordas, com toda a lateral contendo mais cargas que o centro e os 4 cantos possuindo a maior concentração de cargas, assim como na simulação com elementos finitos. No gráfico do potencial (c), o mesmo efeito pode ser visualizado, porém com picos distribuídos ao longo de toda a amostra. 
Estes picos no potencial devem-se ao fato de que o potencial entre duas cargas é proporcional a $1 / \mathrm{r}$. Portanto, mesmo em uma região com baixa densidade de carga, picos de potencial podem ocorrer, explicando o porque observam-se descargas em regiões que não estão na borda, apesar destas descargas serem menos frequentes.

A próxima simulação realizada contou com áreas da amostra com diferentes constantes dielétricas, para verificar as alterações na concentração das cargas e no potencial elétrico.

Nesta simulação foi utilizado o mesmo algoritmo (apêndice $\mathrm{C}$ ) porém a função DistQ, que calcula a energia de todos os indivíduos foi alterada para computar a diferença com as duas constantes dielétricas. A nova função utilizada foi a "DistQ \% diferentes constantes dielétricas", que também está contida no apêndice $\mathrm{C}$.
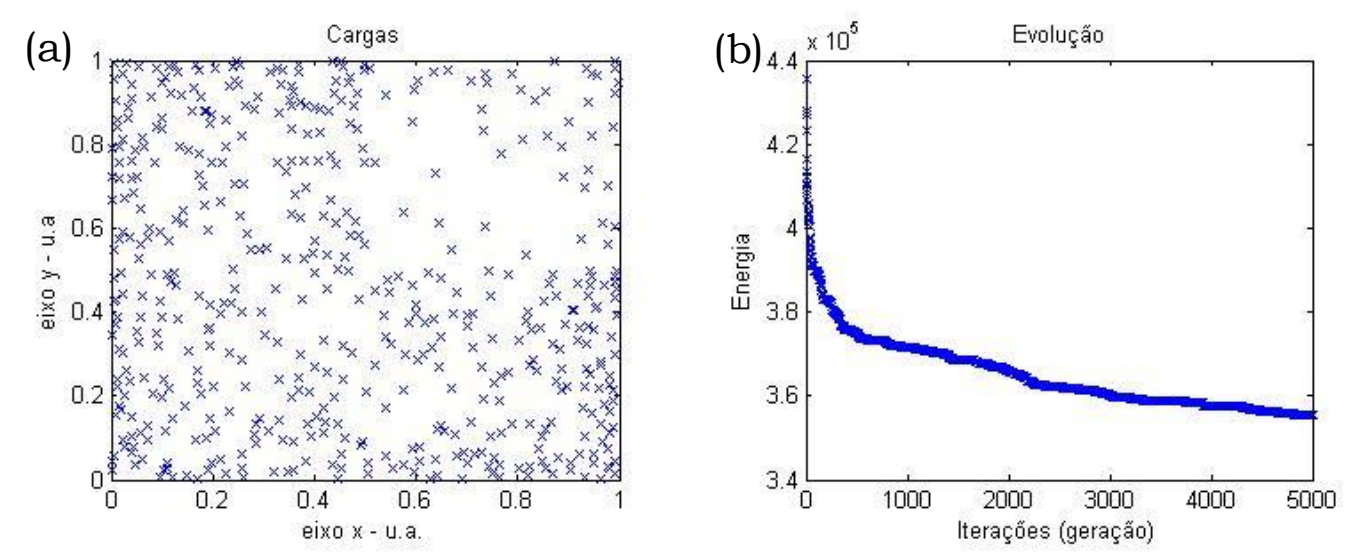

(c)

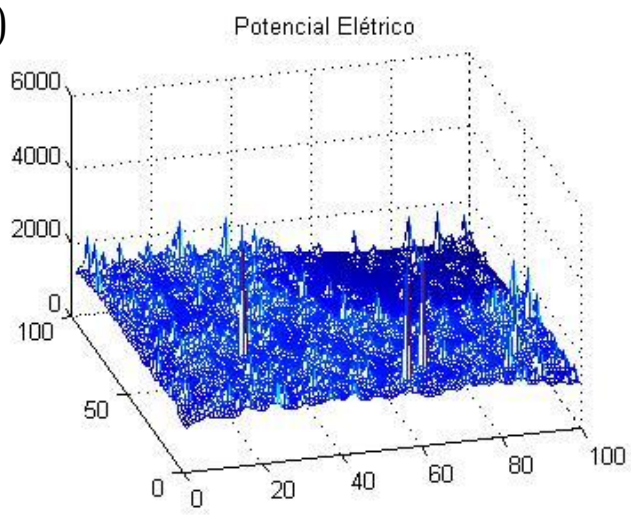

(d)

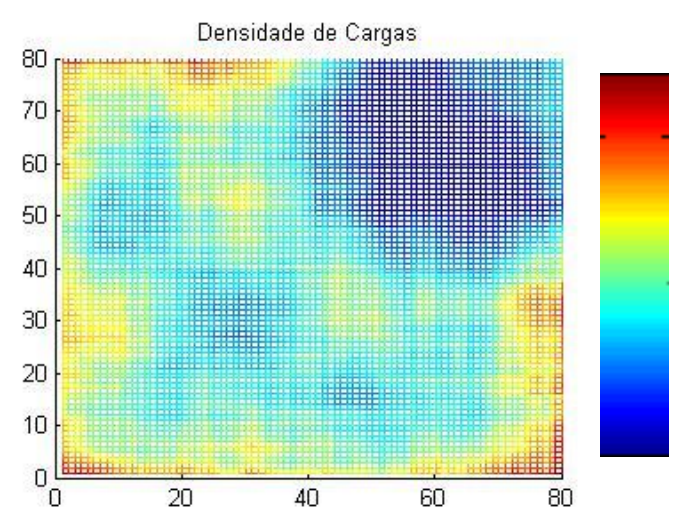

Figura $35-2$ constantes dielétricas, 50 indivíduos, 500 cargas, 5000 iterações. (a) Cargas na amostra. (b) Energia total do sistema em função do 
número de iterações. (c) Potencial elétrico na amostra. (d) Densidade de cargas na amostra.

O resultado mostra que a área de menor constante dielétrica apresenta uma menor concentração de cargas em comparação com as outras regiões (d). O mesmo é válido para o potencial elétrico (c). Este resultado mostra que o efeito corona é sensivel a variações nas propriedades de resistividade e permissividade elétrica no material. Assim como o modelo feito por Arnold, Harker e Bauchot (2000), é possivel então relacionar a medida elétrica com alterações biológicas.

Para efeito de comparação, a simulação descrita acima foi comparada com o efeito corona em uma pera que apresentava uma região mais escura com marcas de batida, figura 36.

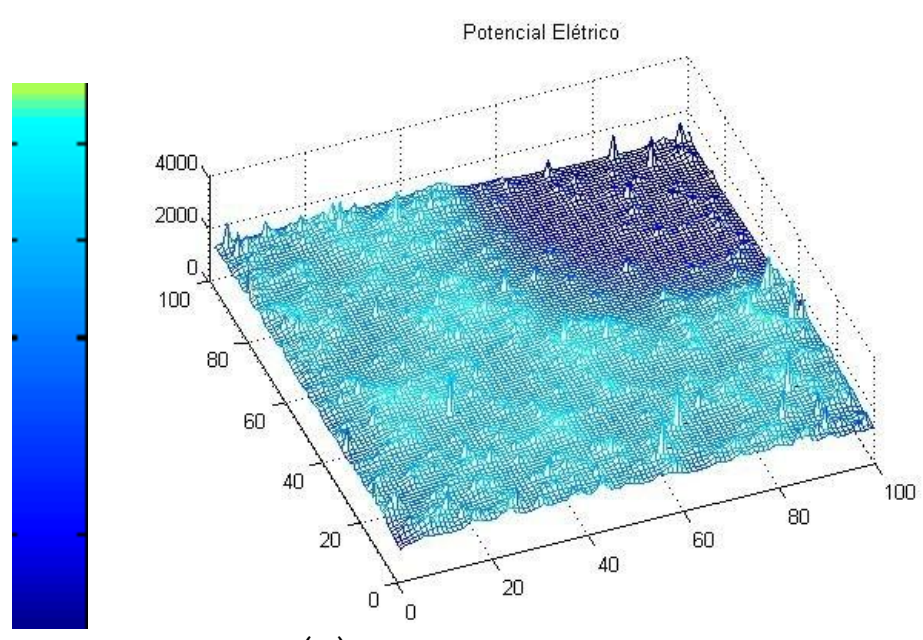

(a)

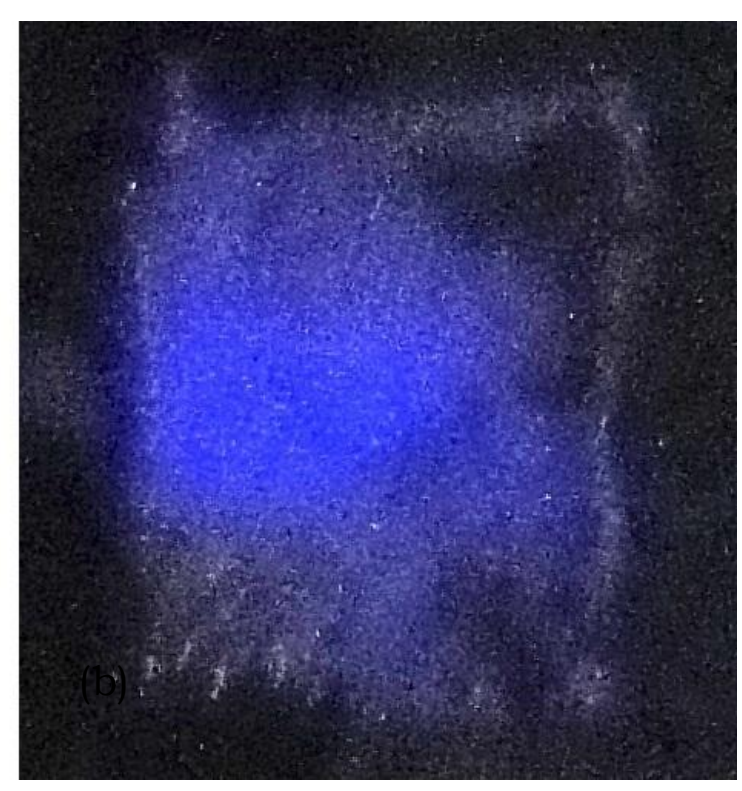

Figura 36 - Comparação entre o Potencial elétrico simulado com 2 constantes dielétricas (a) e efeito corona em uma pera com poupa escura na parte superior (b).

O tempo de processamento em cada etapa e linha de comando do algoritmo foi monitorado pelo utilitário 'Profiler' do matlab, que acompanha o processamento e emite um relatório permitindo que se trabalhe para a otimização do software, diminuindo o tempo de processamento. Após várias alterações o programa chegou em sua ultima versão (apêndice C). 


\section{Conclusões}

Conclui-se que o equipamento desenvolvido é capaz de captar o efeito corona em alimentos e que as imagens obtidas contêm informações das características físico-químicas do alimento. O software desenvolvido foi capaz de controlar o sistema, processar e salvar os dados recebidos. As simulações do efeito corona mostraram que as imagens são alteradas com mudanças na geometria e na constante dielétrica da amostra, indicando que as modificações observadas nas imagens das amostras podem ser provenientes tanto de variações na constante dielétrica como pela geometria. 


\section{Referências}

Arnold, W. M.; HARKER, F. R.; BAUCHOT, A. D. The use of electrical impedance spectroscopy to assess the physiological condition of kiwifruit. Postharvest Biology and Technology. Vol. 18, p. 9 -18. 2000.

BHATT, C.M.; NAGARAJU, J. Studies on glass transition and starch recrystallization in wheat bread during staling using electrical impedance spectroscopy. Innovative Food Science \& Emerging Technologies, Índia, v.10, n.2, p. 241-245. Abr. 2009.

BILYY, O. I.; YAREMYK, R.Y.; KOTSYUMBAS, I.Y.; KOTSYUMBAS, H.I. Impedance spectroscopy of food mycotoxins. Disponivel em:<http:// proceedings.spiedigitallibrary.org/proceeding.aspx?articleid=127 5342>. Acesso em: 10 out. 2012.

BOYERS, D. G.; TILLIER, W. A. Corona discharge photography. Journal Of Applied Physics, Califórnia, v. 44, n. 7, p. 3102-3112. Jul. 1973.

BRASIL. Resolução RDC n ${ }^{\circ}$ 275, de 21 de outubro de 2002. Legislação de Boas Práticas de Fabricação. Diário Oficial da União, Brasília, DF, 2002.

BUNDZEN, P.V.; KOROTOV, K.G.; UNESTAHL, L.E. Altered States of Consciousness: Review of Experimental Data Obtained with a Multiple Technique Approach. The Journal of alternative and complementary medicine, v. 8, n.2, p.153-165. 2002.

CALLOW, E.H. The electrical resistance of muscular tissue and its relation to curing. Annual Report of Food Investigations Board, HMSO, London, 1936.p. 57. 
CERF, O.; DONNAT, E. Application of hazard analysis - Critical control point (HACCP) principles to primary production: What is feasible and desirable? Food Control, França, v. 22, n. 12, p.1839-1843. Dez. 2011.

CRUZ, F. T.; SCHNEIDER, S. Qualidade dos alimentos, escalas de produção e valorização de produtos tradicionais. Revista Brasileira de Agroecologia, Rio Grande do Sul, v. 5, n. 2, p.22-38, 2010.

DALLAROSA, J. B. Estudo da formação e dispersão de ozônio troposférico em áreas de atividade de processamento de carvão aplicando modelos numéricos. 2005. 127 f. Dissertação (Mestrado) Departamento de Centro Estadual De Pesquisas Em Sensoriamento Remoto E Meteorologia, Universidade Federal Do Rio Grande Do Sul, Porto Alegre, 2005.

DUCROT, H.; THOMASSET, A.; JOLY, R.; JUNGERS, P.; EYRAUD, C.; LENOIR, J. Determination du volume des liquidesextracellulaires chezl'hommepar la mesure de l'impe'dancecorporelletotale. La Presse Me' dicale, v.78, n.51, p. 2269-2272. 1970.

EYLES, M.J.; ADAMS, R.F. Detection of microbial metabolites by gas chromatography in the examination of spoiled canned foods and related products. International Journal Of Food Microbiology, Austrália, v. 3, p.321-330. 10 jun. 1986.

FAUST, D. L.; KYLER, H. J.; PEHEK, J. O. Image modulation in corona discharge photography. Science, vol. 194, p. $263-270.1976$

FEYNMAN, R. P.; LEIGHTON, R.B.; SANDS, M. The Feynman Lectures On Physics. Narosa Publishing House, 2008.1372 p.

FILHO, R.J.; SANTOS, J.L.F. Controle de Qualidade de Alimentos e Saúde Pública. Disponivel em: 
<http:/ / 201.2.114.147/bds /BDS.nsf/D4EA53771568FD0603256FB6005EA D6F / \$File/NT000A4AB2.pdf> 2012.

FREITAS, E.I.; LEMOS, A.A.; MARIN, V.A. Validação de métodos alternativos qualitativos na detecção de patógenos alimentares. Ciência \& Saúde Coletiva, Rio de Janeiro, v. 4, n. 11, p.1073-1083. 2006.

HALTER, R.; HARVOT, A.; HEANEY, J.; PAULSEN, K.; SCHNED, A. Electrical impedance spectroscopy of the human prostate. IEEE Transactions on Biomedical Engineering, v. 54, n. 7, p. 1321-1327. Jul. 2007.

HARKER, R. F.; Maindonald, J. H. Ripening of Nectarine Fruit. Plant Physiology, vol. 106, p 165-171. 1994.

IBRAHIM, G.F.; FLEET, G.H. Detection of salmonella using accelerated method. International Journal Of Food Microbiology, Austrália, v. 2, p.259-272. 26 mai. 1985.

YOUNG, K. A Birdcage Model for the Chinese Meridian System: Part I. A Chanel as a Transmission Line. The American Journal of Chinese Medicine, Estados Unidos da América, Vol. 32, No 5, 815-828. 2004.

KONENKO, I. Machine Learning and GDV images. In: International Conference of Biology and Cognitive Science. v.20, p.217-225. 2000.

KONOMENKO, I. Machine learning for medical diagnosis: history, state of the art and perspective. Artificial Intelligence in Medicine, Ljubljana, v. 23, n.1, p.191-218. Ago. 1998.

KONOMENKO, I.; ZRIMEC, T.; SADIKOV, A.; MELE, K.; MILHARCIC, T. Machine learning and GDV images: current research and results. In: International Conference on Biology and Cognitive Sciences, 1999, Ljubljana. 
KOROTKOV, K.; WILLIAMS B.; WISNESKI, L.A. Assessing Biophysical Energy Transfer Mechanisms in Living Systems: The Basis of Life Processes. The Journal of Alternative and Complementary Medicine, Rússia, v.10, n.1, p.49-57. 2001.

LEPETIT, J.; ABOUELKARAM, S.; CLERJON, S.; DAMEZ, J. L. Beef meat electrical impedance spectroscopy and anisotropy sensing for non-invasive early assessment of meat ageing. Journal of food Engineering. França, vol. 85, p. 116-122. 2008;

LORENZO, A. D.; BOSAEUS I.; KYLE U. G. Bioelectrical Impedance analysis - part I: Review of principles and methods. Clinical Nitrition. Vol. 23, p. 1226-1243. 2004.

MARCHELLO, M.J.; SLANGER, W.D.; CARLSON, J.K. Bioelectrical impedance: Fat content of beef and pork from different size grinds. Journal of Animal Science, Estados Unidos, v.77, n.9, p.2464-2468. 1999.

MARTINEZ, M.B., TADEI., C.R. In: Microbiologia, TRABULSI, L.R., ALTERTHUM, F.4ª Ed, São Paulo: Atheneu, 2005, 718 p.

McGINTY, R.J.; POMERANZ, Y.; ROUSSER, R. Kirlian photography of corn fact or artifact? Cereal Foods World, v.20, n.6, p.280-281. 1975.

NORVING, P; RUSSEL, S. Artificial Inteligence: A modern Approach. Prentice Hall 2 edition. ISBN 013790352. 2002.

PINHEIRO, N.M.S.; FIGUEIREDO, E.A.T.; FIGUEIREDO, R.W.; MAIA, G.A.; SOUZA, P.H.M. Avaliação da qualidade microbiológica de frutos minimamente processados comercializados em supermercados de Fortaleza. Revista Brasileira de Fruticultura, Jaboticabal, v. 27, n. 1, p.153-156. Abr. 2005. 
PRABAKAR, K.; MALLIKARJUN RAO, S.P. Complex impedance spectroscopy studies on fatigued soft and hard PZT ceramics. Journal of Alloys and Compounds, Índia, v. 473, n. 1-2, p. 302-310. 28 jun 2007.

REITZ J. R.; MILFORD, F. J.; CHRISTY, R. W. Fundamentos da Teoria Eletromagnética. Editora Campus, $12^{\text {a }}$ Reimpressão. Rio de Janeiro 1982.

SHADURI, M. Secondary Holodiffractional radiation of biological systems. Kybernetes, v. 34, n.5, p. 660-680. 2005.

SILÓNIZ, M. I.; HERVÁS-MARTÍNEZ, C.; GARCÍA-GIMENO, R. M. Improving artificial neural networks with a pruning methodology and genetic algorithms for their application in microbial growth prediction in food. International Journal of Food Microbiology. Vol. 72. P. 19 - 30. 2002.

SILVA, M. C. Avaliação da qualidade microbiológica de alimentos com a utilização de metodologias convencionais e do sistema simplate. 2002. 75 f. Dissertação (Mestrado) - Curso de Ciência e Tecnologia de Alimentos, Escola Superior de Agricultura - Universidade de São Paulo, Piracicaba, 2002.

SKARJA, M. Influence of Ionic composition of water on the corona discharge around water drops. Journal of Applied Physics, v. 84, p. 2436-2442. 4 jun. 1998.

SKARJA, M.; BERDEN, M; JERMAN I. Instrumental measure of different homeopathic dilutions of potassium iodide in water. Europ PubMed Central, vol. 24, p. 29-44. (1999).

SLANGER, W.D.; MARCHELLO, M.J. Bioelectrical impedance can predict skeletal muscle and fat-free skeletal muscle of beef cows primal cuts. Journal of Animal Science, Estados Unidos, v.72, n.12, p.3124-3130. Dez 1994. 
VAINSHELBOIM, A.; MOMOH, K.S. Bioelectrographic Testing of Mineral Samples: A Comparison of Techniques. Journal of Alternative \& Complementary Medicine, v.11, n.2, p. 299-304. Abr. 2005.

VARNAMKHASTI, M. G.; MOHTASEBI, S. S.; SIADAT, M. Biomimetic-based odor and taste sensing systems to food quality and safety characterization: An overview on basic principles and recent achievements. Journal of Food Engineering, França, p. 377-387. Out. 2010.

VELUSAMY, V.; ARSHAK, K.; YANG, C.; YU, L.; KOROSTYNSKA, O.; OLIWASTASIAK, K.; ADLEY, C. Label-free detection of Bacillus cereus DNA hybridization using electrochemical impedance spectroscopy for food quality monitoring application. Disponivel em: <http:/ /ieeexplore.ieee.org/xpls /abs_all.jsp?arnumber=5439420\&tag=1>. Acesso em: 11 out. 2012 .

VOSE, J.D. The Application of Quantitative Risk Assessment to Microbial Food Safety Risks. Critical Reviews in Microbiology, Estados Unidos, v.22, n.4, p. 279-293. 1996.

ZOCCHE, F.; FRANÇA, R.C.; ALEIXO, J.A.G.; MOREIRA, A.N.; SILVA, W.P. Multiplex PCR for Detection of Enteroxigenic Staphylococcus aureus Isolated from Food of Animal Origin in South of Rio Grande do Sul, BRASIL. Interciência, Venezuela, v. 34, n. 7, p.487-491. Jul. 2009.

ZÖLLNER, P.; MAYER-HELM, B. Trace mycotoxin analysis in complex biological and food matrices by liquid chromatography-atmospheric pressure ionization mass spectrometry. Journal of Chromatography A, Alemanha, v. 2, n. 1136, p.123-169, 15 dez. 2006.

WEIBEL, F.; KONOMENKO, I.; SADIKOV, A. Analyzing Coronas of Fruits and Leaves. Measuring Energy Fields. USA, p. 143 - 156, 2004. 
WU, L.; OGAWA, Y.; TAGAWA, A. Electrical impedance spectroscopy analysis of eggplant pulp and effects of drying and freezing-thawing treatments on its impedance characteristics. Journal of Food Engineering, Japão, v.87, n.2, p. 274-280. Jul. 2008. 


\section{APÊNDICE A - Programa para o Microcontrolador PIC 16f628A}

\#use fixed_io(b_outputs=PIN_B2, PIN_B5,PIN_B6, PIN_B4)

int flag;

long int periodo;

void seta_pino();

void duty();

void main()

\{

setup_timer_O(RTCC_INTERNAL | RTCC_DIV_1);

setup_timer_1(T1_DISABLED);

setup_timer_2(T2_DISABLED, 0,1$)$;

setup_comparator(NC_NC_NC_NC);

setup_vref(FALSE);

int a, i;

long int tempo;

flag $=0$;

periodo $=0$;

tempo=1000;

output_high(pin_b2); // / seta o pino A0 em nivel baixo ou OV altereir para

high porque o transistor estava invertendo

for $(a=0 ; a<10 ; a++)$

\{

output_high(pin_b4); //seta o pino A0 em nivel alto acionando o

solenoide

delay_ms(70); // Aguarda $500 \mathrm{~ms}$

output_low(pin_b4); / / seta o pino A0 em nivel baixo desligando o solenoide

delay_ms(70); // Aguarda $500 \mathrm{~ms}$

output_high(pin_b5); //seta o pino A0 em nivel alto acionando o

solenoide

delay_ms(70); // Aguarda $500 \mathrm{~ms}$

output_low(pin_b5); / / seta o pino A0 em nivel baixo desligando o solenoide

delay_ms(70); // Aguarda $500 \mathrm{~ms}$

output_high(pin_b6); //seta o pino A0 em nivel alto acionando o solenoide

delay_ms(70); // Aguarda $500 \mathrm{~ms}$

output_low(pin_b6); / / seta o pino A0 em nivel baixo desligando o solenoide

delay_ms(70); // Aguarda $500 \mathrm{~ms}$

output_high(pin_a2); / / seta o pino AO em nivel alto acionando o solenoide

delay_ms(70); // Aguarda $500 \mathrm{~ms}$

output_low(pin_a2); //seta o pino A0 em nivel baixo desligando o solenoide

delay_ms(70); // Aguarda $500 \mathrm{~ms}$

\}

while(1) 


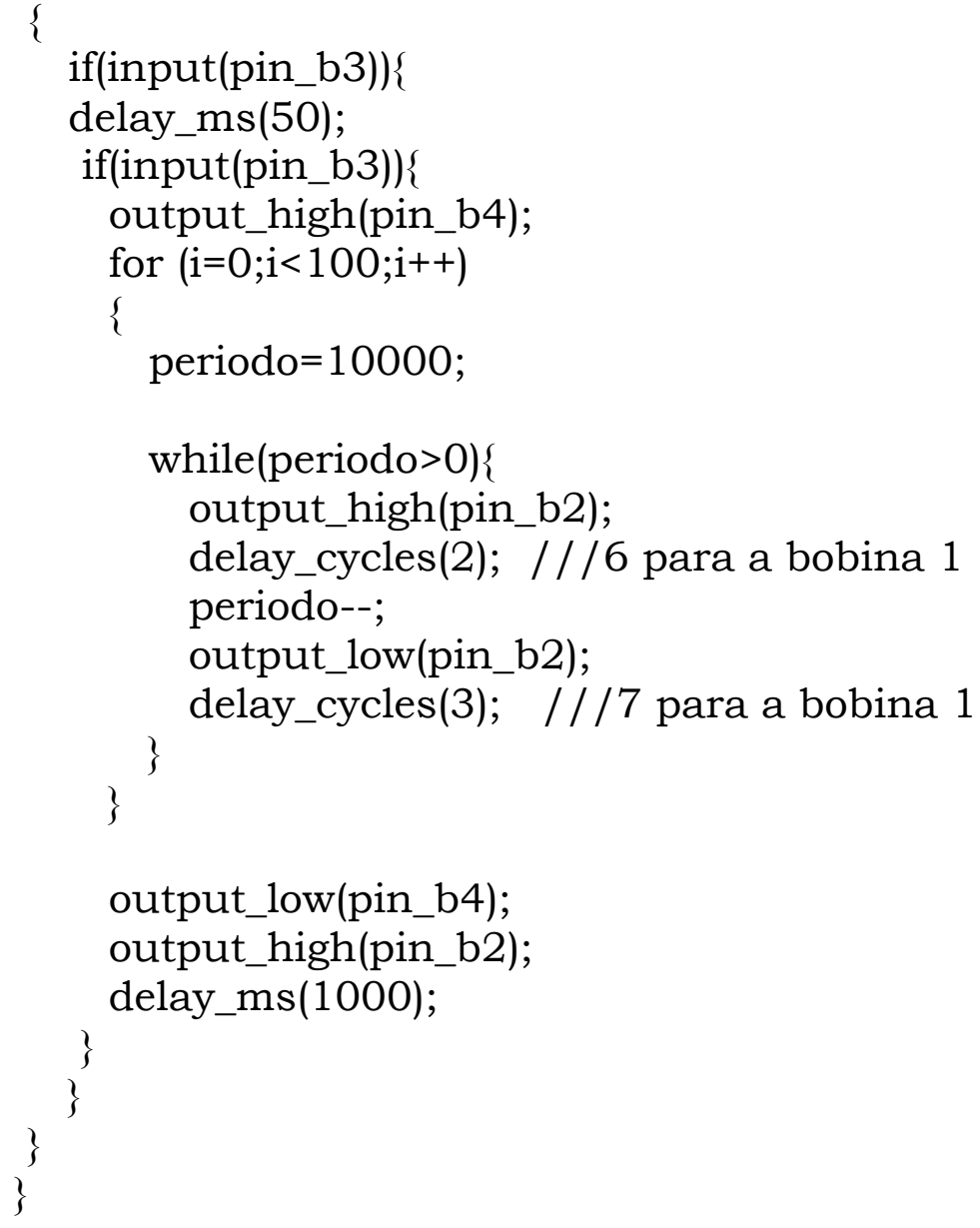




\section{APÊNDICE B - Programa e GUI em MATLAB® ${ }^{\circledR}$ responsável pela ativação do equipamento e aquisição de imagem}

function varargout $=$ controle_corona(varargin)

gui_Singleton $=1$;

gui_State $=$ struct('gui_Name', mfilename, ...

'gui_Singleton', gui_Singleton,...

'gui_OpeningFcn', @inicial_corona2_OpeningFcn,...

'gui_OutputFcn', @inicial_corona2_OutputFcn,...

'gui_LayoutFcn', [] , ...

'gui_Callback', []);

if nargin \&\& ischar(varargin $\{1\})$

gui_State.gui_Callback = str2func $(\operatorname{varargin}\{1\})$;

end

if nargout

[varargout $\{1$ :nargout $\}]=$ gui_mainfcn $($ gui_State, varargin $\{:\}) ;$

else

gui_mainfcn(gui_State, varargin $\{:\})$;

end

function inicial_corona2_OpeningFcn(hObject, , handles, varargin)

handles.output $=$ hObject;

guidata(hObject, handles);

clear all;

global a; // declara a como variável global

$\mathrm{a}=$ arduino('COM4'); // conecta o arduino a COM 4

a.pinMode(8,'output'); // seta o pino 8 como saída

a.pinMode(9,'output'); / / seta o pino 9 como saída

a.pinMode(13,'output'); // seta o pino 12 como saida

function varargout $=$ inicial_corona2_OutputFcn( , , handles $)$ varargout $\{1\}=$ handles.output; 
\% --- Executa ao pressionar o botão "Liga Camera"

function pushbutton1_Callback( , , )

\% Liga a camera

global vid; \% declara a variável como global

vid $=$ videoinput('winvideo', 1 ); \% recebe o winvideo 1 do windows

preview(vid); \% mostra a imagem em uma tela separada

\% --- Executa ao pressionar o botão 'Preview"

function pushbutton2_Callback(hObject, eventdata, handles)

\%Mostra o Preview no axes 1

global vid;

foto = getsnapshot(vid); \% tira um printscream do video

axes(handles.axes 1)\% chama o gráfico 1

image(foto); \% mostra a imagem no gráfico1

handles.img=foto; \% passa a variável foto por parâmetro handles

guidata(hObject, handles)

\% --- Executa ao pressionar o botão "salva Imagem"

function pushbutton3_Callback(hObject, eventdata, handles)

$\%$ botão Salva Imagem

im = handles.axes $1 ; \%$ chama os dados do gráfico 1

imsave $\quad \%$ salva a imagem

\% --- Executa ao pressionar o botão "Grava Imagem"

function pushbutton4_Callback(hObject, eventdata, handles)

global vid; \% recebe a variável globas aberda no botão 'liga camera'

vid = videoinput('winvideo', 1, 'RGB24_640x480'); \%configurações da camera

src $=$ getselectedsource(vid); \%configurações da camera

$\mathrm{a}=\operatorname{str} 2$ double(get(handles.edit1,'String'));\%recebe o numero de quadros

\%de gravação da caixa de texto

$\mathrm{a}=\mathrm{a}^{*} 15 ; \%$ tempo de gravação - 15 quadros por segundo

vid.FramesPerTrigger = a; \% número de quadros na gravação 
preview(vid); $\quad \%$ mostra o video sendo gravado

vid.LoggingMode = 'disk\&memory'; \% grava no disco e memória do matlab $\mathrm{b}=$ str2num(get(handles.edit2,'String')); \% recebe o nome do arquivo .avi diskLogger $=$ VideoWriter $(\mathrm{b}$, 'Uncompressed AVI'); \%salva o arquivo vid.DiskLogger = diskLogger; \%limpa a memódia do disklogger diskLogger. FrameRate $=15 ; \%$ quadros por segundo start(vid); \% inicia a gravação

\section{$\%$ Slider}

function togglebutton1_Callback(hObject, eventdata, handles) get(hObject, 'Value')

function edit1_Callback(hObject, eventdata, handles) function edit1_CreateFcn(hObject, eventdata, handles) if ispc \&\& isequal(get(hObject,'BackgroundColor'), get(0,'defaultUicontrolBackgroundColor')) set(hObject,'BackgroundColor','white'); end function edit2_Callback(hObject, eventdata, handles) function edit2_CreateFcn(hObject, eventdata, handles) if ispc \&\& isequal(get(hObject,'BackgroundColor'), get(0,'defaultUicontrolBackgroundColor')) set(hObject,'BackgroundColor','white'); end

function checkbox2_Callback(hObject, eventdata, handles) function pushbutton5_Callback(hObject, eventdata, handles)

\section{\% Liga a máquina}

function edit3_Callback(hObject, eventdata, handles) global a;

a.digitalWrite $(13,1)$; // acende o led do arduino sinalizando que o sinal foi // enviado para o equipamento 
a.digitalWrite $(9,1) ; / /$ envia sinal alto $(5 \mathrm{~V})$ para o pino que ativa o //equipamento

delay (5000); // aguarda 5 segundos

a.digitalWrite $(13,0)$;

a.digitalWrite $(8,0)$;

function edit3_CreateFcn(hObject, eventdata, handles)

if ispc $\& \&$ isequal(get(hObject,'BackgroundColor'), get(0,'defaultUicontrolBackgroundColor')) set(hObject,'BackgroundColor','white'); end function edit4_Callback(hObject, eventdata, handles) function edit4_CreateFcn(hObject, eventdata, handles) if ispc \&\& isequal(get(hObject,'BackgroundColor'), get(0,'defaultUicontrolBackgroundColor')) set(hObject,'BackgroundColor','white');

end

function edit5_Callback(hObject, eventdata, handles) function edit5_CreateFcn(hObject, eventdata, handles) if ispc \&\& isequal(get(hObject,'BackgroundColor'), get(0,'defaultUicontrolBackgroundColor')) set(hObject,'BackgroundColor','white'); end

\% --- Executa ao pressionar "Processamento de Imagem" function pushbutton6_Callback(hObject, eventdata, handles) \%Processamento da imagem para escala de cinza imagem = handles.img; \% recebe a imagem do grafico 1 gr = rgb2gray(imagem); \% converte para escala de cinza axes(handles.axes1) \% chama o gráfico1 
image(gr) \% mostra a imagem no grafico

colormap gray

gr = handles.img; \% disponibiliza a imagem tratada no handles

\%Executa ao alterar o a posição do Slider 2

function slider2_Callback(hObject, eventdata, handles)

$\%$ Filtro

$\mathrm{a}=\operatorname{get}($ handles.slider2,'Value'); \% recebe o valor do slider

imagen $=$ handles.img;

$a=1-\left(a^{*} 0.99\right) ; \%$ inverte os valores de a entre 0 e 1

imagen = imadjust(imagen, $[0$ a],[0 1]); \% aplica o filtro, com intensidade axes(handles.axes 1 ) $\%$ a

image(imagen)

imagen $=$ handles.img; $\quad \%$ disponibiliza a imagem pelo handles

function slider2_CreateFcn(hObject, eventdata, handles)

if isequal(get(hObject,'BackgroundColor'),

get(0,'defaultUicontrolBackgroundColor'))

set(hObject,'BackgroundColor',[.9 .9 .9]);

end

\%Executa ao alterar o a posição do Slider 3

function slider3_Callback(hObject, eventdata, handles)

$\%$ Contraste

$\mathrm{a}=\operatorname{get}($ handles.slider4,'Value'); \% recebe o valor do slider

imagen $=$ handles.img; $\quad \%$ chama a imagem no gráfico1

imagen = imadjust(imagen, stretchlim(imagen, a), [0 1]); \% aplica o

axes(handles.axes 1 )

$\%$ tratamento de contraste com valor 'a'

image(imagen)

imagen $=$ handles.img; $\quad \%$ disponibiliza a imagem pelo handles

function slider3_CreateFcn(hObject, eventdata, handles)

if isequal(get(hObject,'BackgroundColor'),

get(0,'defaultUicontrolBackgroundColor'))

set(hObject,'BackgroundColor',[.9 .9 .9]); 
end

\%Executa ao alterar o a posição do Slider 4

function slider4_Callback(hObject, eventdata, handles)

$\%$ Brilho

$\mathrm{a}=\operatorname{get}($ handles.slider4,'Value'); \% recebe o valor do slider

imagen $=$ handles.img; $\quad \%$ chama a imagem no gráfico 1

imagen = imadjust(imagen, [], [], a); \% aplica o tratamento de Brilho

axes(handles.axes 1)

image(imagen)

imagen $=$ handles.img; $\quad \%$ disponibiliza a imagem pelo handles

function slider4_CreateFcn(hObject, eventdata, handles)

if isequal(get(hObject,'BackgroundColor'),

get(0,'defaultUicontrolBackgroundColor'))

set(hObject,'BackgroundColor',[.9 .9 .9]);

end

function Untitled_1_Callback(hObject, eventdata, handles)

\%Executa ao pressionar o botão Diretório

function pushbutton7_Callback(hObject, eventdata, handles)

\% Diretório - Abre a busca de diratórios do windows

[nome local] = uigetfile('*.jpg','Abrir');

if nome $==0$

return

end

imagen = imread(fullfile(local,nome));

axes(handles.axes 1 )

image(imagen)

handles.img=imagen;

guidata(hObject, handles)

\% --- Executes during object creation, after setting all properties.

function axes1_CreateFcn(hObject, eventdata, handles) 


\section{APÊNDICE C - Programa em MATLAB ${ }^{\circledR}$ responsável pela simulação do potencial elétrico utilizando algoritmo genético}

\section{Principal}

\% Algoritmo genético p/ potencial elétrico

\% Tipo de superficie: Quadrada com condutividade constante

\% Calcula a melhor distribuição e retorna os gráficos da energia, cargas, \% densidade e evolução na figura 1.

clc; \%limpa a tela principal do matlab tam = input('digite o numero de Indivíduos: '); \%recebe o $\mathrm{n}^{\mathrm{a}}$ de indivíduos n = input('digite o número de cargas: '); \%recebe o número de cargas iter = input('digite o número de iterações (geração): '); \% recebe o

\%número de iterações

$\mathrm{Q}=\operatorname{rand}(\mathrm{n}, 2 * \operatorname{tam}) ; \quad \%$ Gera a População Inicial

yy $=\operatorname{zeros}(1$, iter $) ; \quad \%$ prelocate - inicializa o vetor com o tamanho for $\mathrm{xx}=1$ :iter $\quad \%$ correto reduzindo o tempo computacional $\mathrm{UQ}=\operatorname{DistQ}(\mathrm{Q}) ; \quad \quad \%$ Calcula a Energia de $\mathrm{Q}$ (individuo) $\mathrm{S}=$ selecao(UQ); $\quad$ \% seleciona os 4 melhores indivíduos (elitismo) $\mathrm{Q}=\operatorname{mutacao}(\mathrm{Q}, \mathrm{S}) ; \quad$ \% Realiza mutação

$\mathrm{UQ}=\operatorname{DistQ}(\mathrm{Q}) ; \quad \quad \%$ Calcula a Energia de Q (individuo) $\mathrm{S}=$ selecao(UQ); $\quad \%$ seleciona os 4 melhores indivíduos (elitismo) $\mathrm{Q}=\operatorname{random}(\mathrm{Q}, \mathrm{S}) ; \quad \quad \%$ Probabilidade, $20 \%$ de um indivíduo aleatório

$\mathrm{UQ}=\operatorname{DistQ}(\mathrm{Q}) ; \quad \quad \%$ Calcula a Energia de Q (individuo) $\mathrm{S}=$ selecao(UQ); $\quad \%$ seleciona os 4 melhores indivíduos (elitismo) $\mathrm{Q}=$ CrossOver $(\mathrm{Q}, \mathrm{S}) ; \quad \%$ Realiza CrossOver

$\mathrm{yy}(\mathrm{xx})=\min (\mathrm{UQ}) ; \quad \quad \quad \%$ Guarda o melhor caminho na iteração $\mathrm{xx}$ end $\mathrm{xx}=1$ :iter; $\quad \%$ pontos do eixo $\mathrm{x}$ para o subplot2 subplot $(2,2,2) \quad \%$ subplot 2 , mostra a menor energia em 


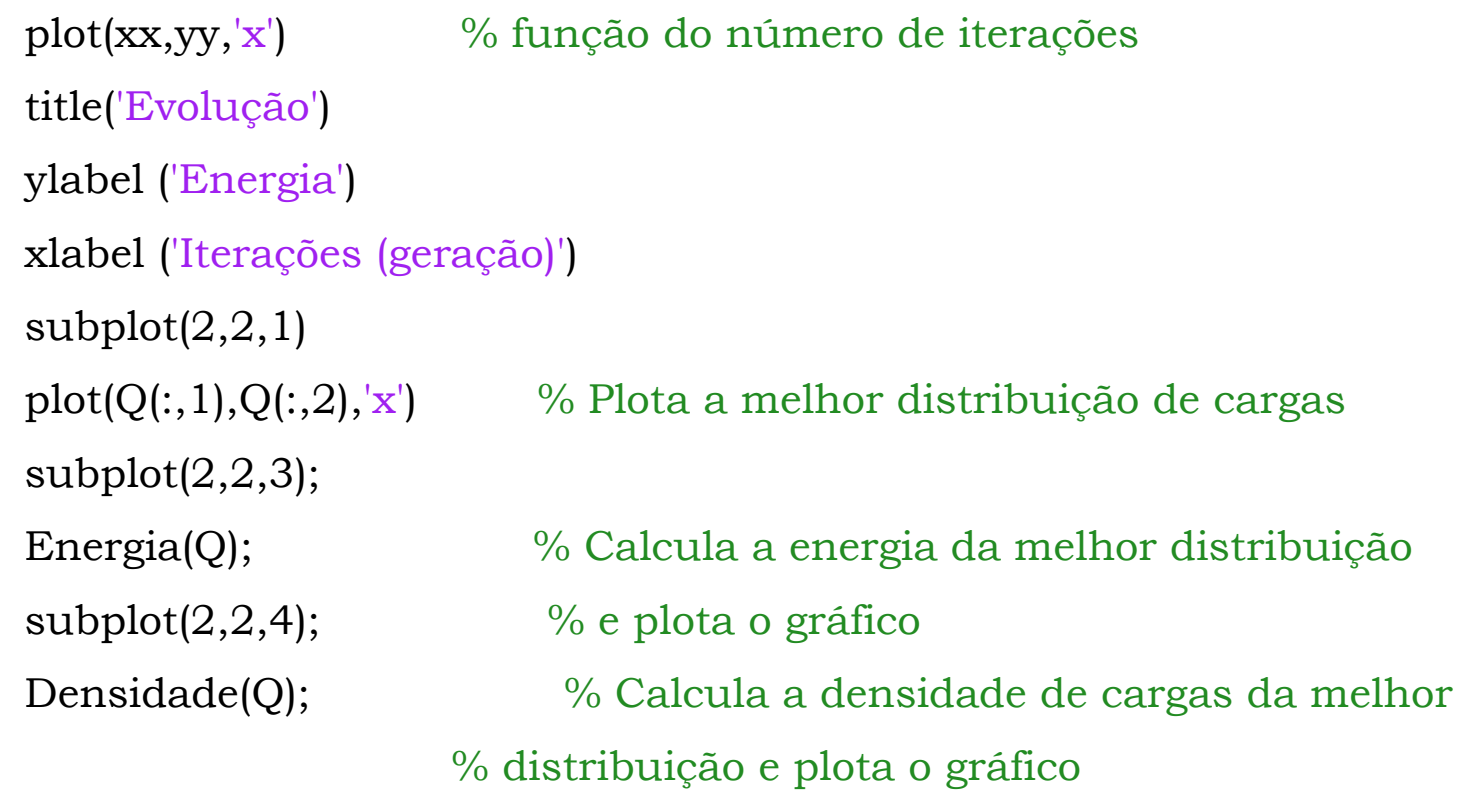

\section{Random}

function $[\mathrm{Q}]=\operatorname{random}(\mathrm{Q}, \mathrm{S})$

\% Mutação -> utiliza os gens vencedores S e gera as suas mutações em Q tam = size $(\mathrm{Q}) ; \%$ recebe o tamanho o número de cargas e indivíduos

$\mathrm{Q}(:, 1)=\mathrm{Q}(:, 2 * \mathrm{~S}(1,1)-1) ; \quad \%$ Repete $\mathrm{o} 1^{\circ}$ individuo vencedor (eixo $\left.\mathrm{x}\right)$ $\mathrm{Q}(:, 2)=\mathrm{Q}(:, 2 * \mathrm{~S}(1,1)) ; \quad \%$ Repete $\mathrm{o} 1^{\circ}$ individuo vencedor (eixo y) $\mathrm{Q}(:, 3)=\mathrm{Q}(:, 2 * \mathrm{~S}(1,2)-1) ; \quad \%$ Repete $\mathrm{o} 2^{\circ}$ individuo vencedor (eixo $\mathrm{x}$ ) $\mathrm{Q}(:, 4)=\mathrm{Q}(:, 2 * \mathrm{~S}(1,2)) ; \quad \%$ Repete o $2^{\circ}$ individuo vencedor (eixo y) $\mathrm{Q}(:, 5)=\mathrm{Q}(:, 2 * \mathrm{~S}(1,3)-1) ; \quad \%$ Repete $\mathrm{o} 3^{\circ}$ individuo vencedor (eixo $\mathrm{x}$ ) $\mathrm{Q}(:, 6)=\mathrm{Q}(:, 2 * \mathrm{~S}(1,3)) ; \quad \%$ Repete o $3^{\circ}$ individuo vencedor (eixo y) $\mathrm{Q}(:, 7)=\mathrm{Q}(:, 2 * \mathrm{~S}(1,4)-1) ; \quad \%$ Repete $\mathrm{o} 4^{\circ}$ individuo vencedor (eixo $\mathrm{x}$ ) $\mathrm{Q}(:, 8)=\mathrm{Q}(:, 2 * \mathrm{~S}(1,4)) ; \quad \%$ Repete o $4^{\circ}$ individuo vencedor (eixo y)

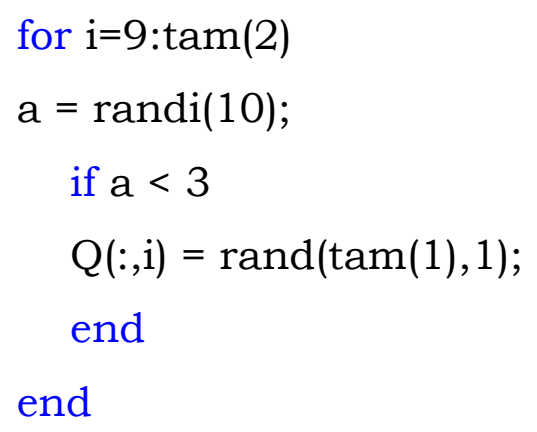




\section{População Inicial}

\%Gera uma população Inicial Aleatória

function $[Q]=$ PopulacaoInicial $(\mathrm{n}, \mathrm{tam})$

$\mathrm{Q}=\operatorname{zeros}(\mathrm{n}, \operatorname{tam})$;

for $1=1$ :tam $\%$ numero de Indivíduos

$\mathrm{Q}=\operatorname{rand}(\operatorname{tam}, 2)$

end

end

\section{Mutação}

function $[\mathrm{Q}]=\operatorname{mutacao}(\mathrm{Q}, \mathrm{S})$

\% Mutação -> utiliza os gens vencedores S e gera as suas mutações em Q tam $=\operatorname{size}(Q) ; \%$ recebe o tamanho o número de cargas e indivíduos

$\mathrm{Q}(:, 1)=\mathrm{Q}(:, 2 * \mathrm{~S}(1,1)-1) ; \quad \%$ Repete o $1^{\circ}$ individuo vencedor (eixo $\mathrm{x}$ )

$\mathrm{Q}(:, 2)=\mathrm{Q}(:, 2 * \mathrm{~S}(1,1)) ; \quad \%$ Repete o $1^{\circ}$ individuo vencedor (eixo y)

$\mathrm{Q}(:, 3)=\mathrm{Q}(:, 2 * \mathrm{~S}(1,2)-1) ; \quad \%$ Repete o $2^{\circ}$ individuo vencedor (eixo $\mathrm{x}$ )

$\mathrm{Q}(:, 4)=\mathrm{Q}(:, 2 * \mathrm{~S}(1,2)) ; \quad \%$ Repete o $2^{\circ}$ individuo vencedor (eixo y)

$\mathrm{Q}(:, 5)=\mathrm{Q}(:, 2 * \mathrm{~S}(1,3)-1) ; \quad \%$ Repete o $3^{\circ}$ individuo vencedor (eixo $\mathrm{x}$ )

$\mathrm{Q}(:, 6)=\mathrm{Q}(:, 2 * \mathrm{~S}(1,3)) ; \quad \%$ Repete o $3^{\circ}$ individuo vencedor (eixo y)

$\mathrm{Q}(:, 7)=\mathrm{Q}(:, 2 * \mathrm{~S}(1,4)-1) ; \quad \%$ Repete o $3^{\circ}$ individuo vencedor (eixo $\mathrm{x}$ )

$\mathrm{Q}(:, 8)=\mathrm{Q}(:, 2 * \mathrm{~S}(1,4)) ; \quad \%$ Repete o $3^{\circ}$ individuo vencedor (eixo y)

$\mathrm{a}=\mathrm{zeros}(1,2)$;

for $i=5: \operatorname{tam}(2)$

$\mathrm{a}(1)=\operatorname{randi}(\operatorname{tam}(1)-1) ; \quad \%$ gera 2 números aleatórios de 1 a \%tam(1)-1 (penultimo cromossomo)

$\mathrm{a}(2)=\operatorname{randi}([\mathrm{a}(1) \operatorname{tam}(1)]) ; \% \operatorname{tam}(1)$ é o número de cargas, o segundo \%número é gerado entre a(1) e tam(1)

$\mathrm{Q}(:, \mathrm{i})=\mathrm{Q}\left(:\right.$, randi $\left(\left[\begin{array}{ll}1 & 4\end{array}\right]\right) ; \quad \%$ Substitui o indivíduo perdedor por um \%dos 4 vencedores

for $\mathrm{k}=\mathrm{a}(1): \mathrm{a}(2) \quad \%$ elementos da linha $\mathrm{A}(1)$ até $\mathrm{a}(2)$ 


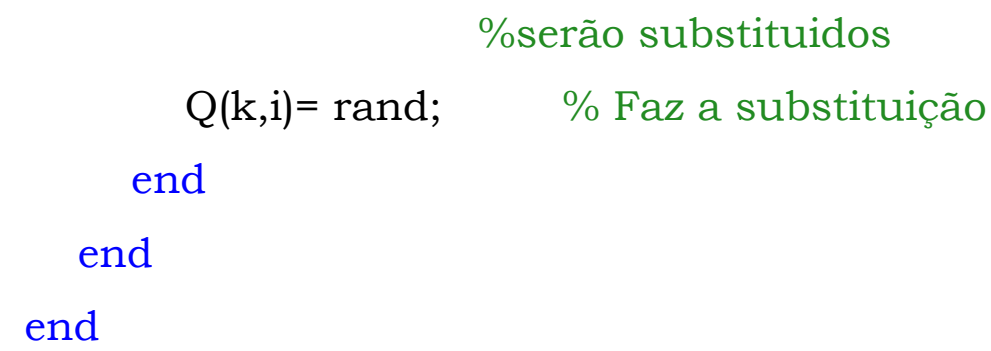

\section{DistQ}

\% Calcula a distância para cada Indivíduo da população P e retorna DG function [ UQ ] = DistQ(Q)

$\operatorname{dim}=\operatorname{size}(Q) ; \%$ pega o numero de cargas (cromossomos) e indivíduos $\mathrm{k}=\operatorname{dim}(1) ; \quad \%$ recebe o número de cargas (cromossomos)

$1=\operatorname{dim}(2) / 2 ; \quad \%$ recebe $\mathrm{o}$ número de indivíduos

$\mathrm{E} 1 \mathrm{Q}=0$

$\mathrm{UQ}=\operatorname{zeros}(1,1) ; \quad \%$ zera a matriz Energia dos indivíduos

for $\mathrm{a}=1: 2: 2 * 1 \quad \%$ anda nos individuos (passo 2 pois cada ind. tem 2 colunas)

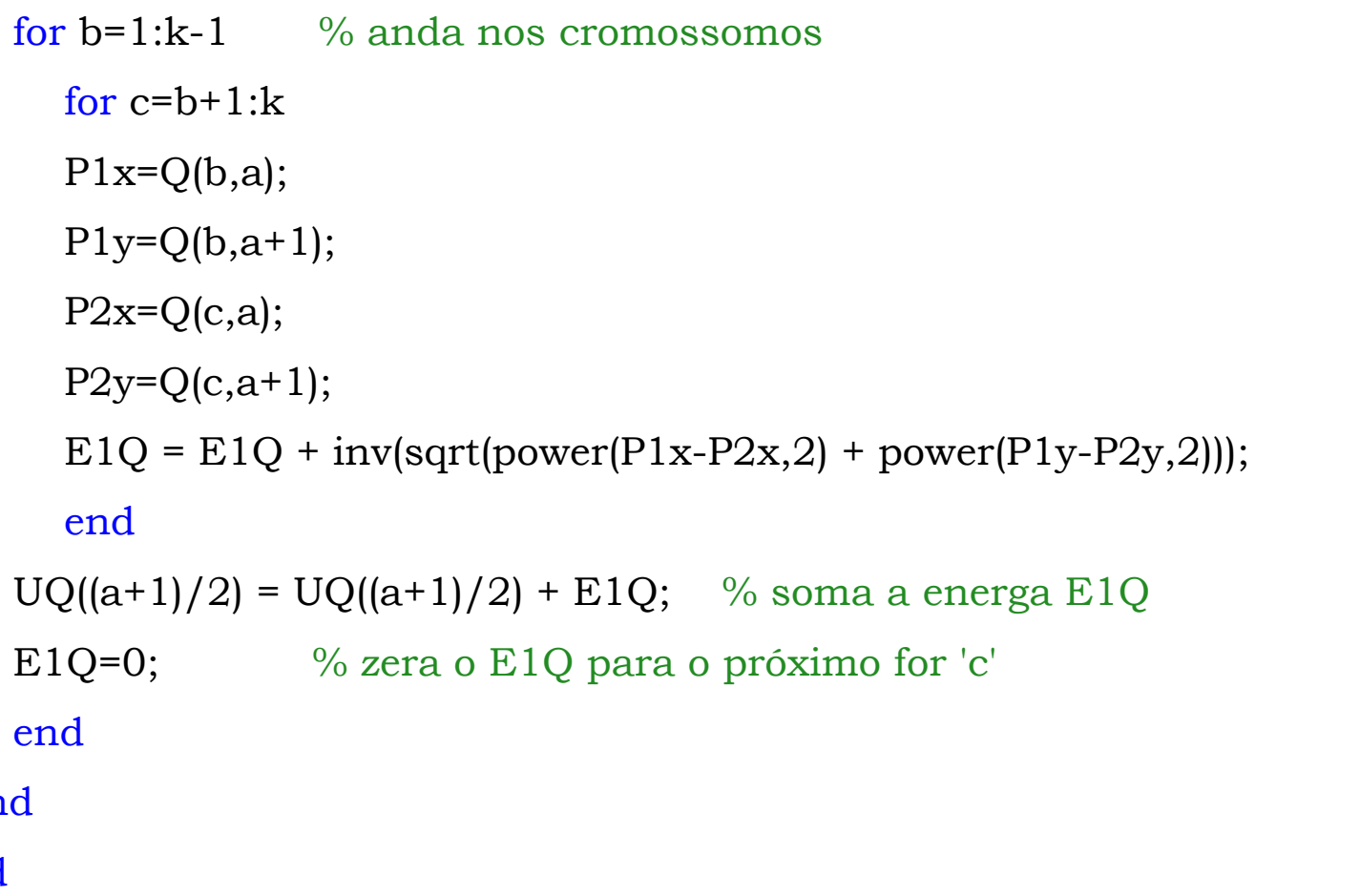

\section{CrossOver}

function $[\mathrm{Q}]=\operatorname{Cross} \operatorname{Over}(\mathrm{Q}, \mathrm{S})$

\% CrossOver -> retorna o cruzamento dos 2 melhores gens 
tam $=$ size $(Q) ; \%$ recebe o tamanho o número de cargas e indivíduos

$\mathrm{Q}(:, 1)=\mathrm{Q}(:, 2 * \mathrm{~S}(1,1)-1) ; \quad \%$ Repete o $1^{\circ}$ individuo vencedor (eixo $\mathrm{x}$ ) $\mathrm{Q}(:, 2)=\mathrm{Q}(:, 2 * \mathrm{~S}(1,1)) ; \quad \%$ Repete o $1^{\circ}$ individuo vencedor (eixo y) $\mathrm{Q}(:, 3)=\mathrm{Q}(:, 2 * \mathrm{~S}(1,2)-1) ; \quad \%$ Repete o $2^{\circ}$ individuo vencedor (eixo $\mathrm{x}$ ) $\mathrm{Q}(:, 4)=\mathrm{Q}(:, 2 * \mathrm{~S}(1,2)) ; \quad \%$ Repete o $2^{\circ}$ individuo vencedor (eixo y) $\mathrm{Q}(:, 5)=\mathrm{Q}(:, 2 * \mathrm{~S}(1,3)-1) ; \quad \%$ Repete o $3^{\circ}$ individuo vencedor (eixo $\mathrm{x}$ ) $\mathrm{Q}(:, 6)=\mathrm{Q}(:, 2 * \mathrm{~S}(1,3)) ; \quad \%$ Repete o $3^{\circ}$ individuo vencedor (eixo y) $\mathrm{Q}(:, 7)=\mathrm{Q}(:, 2 * \mathrm{~S}(1,4)-1) ; \quad \%$ Repete o $4^{\circ}$ individuo vencedor (eixo x) $\mathrm{Q}(:, 8)=\mathrm{Q}(:, 2 * \mathrm{~S}(1,4)) ; \quad \%$ Repete o $4^{\circ}$ individuo vencedor (eixo y)

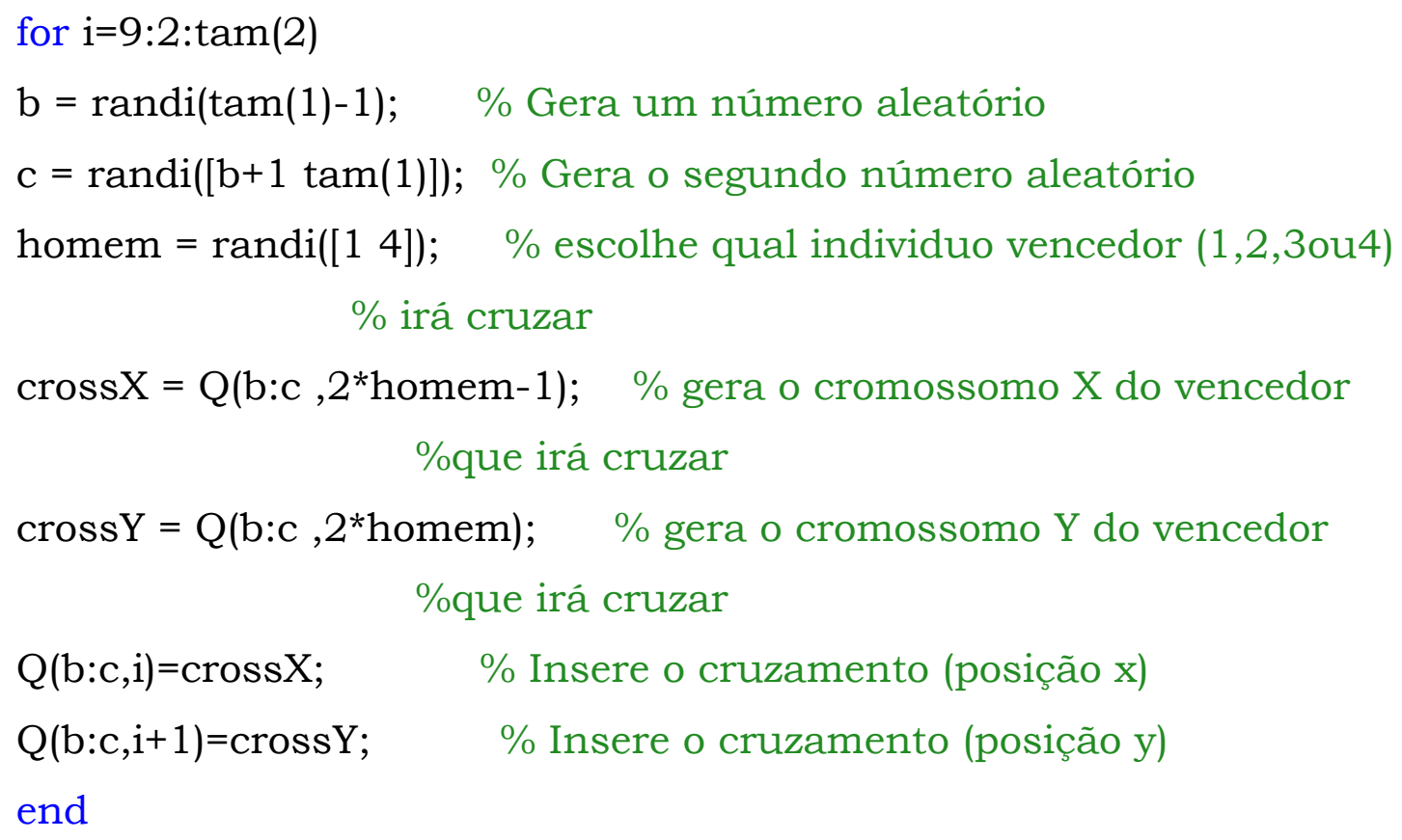

\section{Energia}

function $[\mathrm{E}]=$ Energia $(\mathrm{Q})$

\% Função que calcula e energia na placa para a melhor distribuição de Q $\mathrm{C}=\mathrm{Q}(:, 1) ; \quad \%$ eixo $\mathrm{x}$ do melhor indivíduo

$\mathrm{D}=\mathrm{Q}(:, 2) ; \quad \%$ eixo y do melhor indivíduo

$\mathrm{A}=[\mathrm{C}, \mathrm{D}] ; \quad \%$ Guarda na variável A o melhor indivícuo

$\mathrm{n}=\operatorname{size}(\mathrm{A}) ; \quad \%$ recebe o tamanho de A (melhor indivíduo)

$\mathrm{E}=$ zeros(100); \% pre-aloca a matriz com valor igual a zero 
for $x=1: 100$

for $\mathrm{y}=1: 100$

for $\mathrm{k}=1: \mathrm{n}(1) \%$ para cada carga $\mathrm{k}$, soma-se todas as energias até $\mathrm{n}(1)$ $\mathrm{E}(\mathrm{x}, \mathrm{y})=\mathrm{E}(\mathrm{x}, \mathrm{y})+1 /(\operatorname{sqrt}(\operatorname{power}((\mathrm{x} / 100)-\mathrm{A}(\mathrm{k}, 1), 2)+\operatorname{power}(\mathrm{y} / 100)-$ $\mathrm{A}(\mathrm{k}, 2), 2))$;

\% Calcula a energia na posição x,y como a soma da energia de todas as $\%$ outras cargas

end if $(\mathrm{E}(\mathrm{x}, \mathrm{y})>10 * \mathrm{n}(1))$ \% limite máximo para o plot (saturação)

$\mathrm{E}(\mathrm{x}, \mathrm{y})=10 * \mathrm{n}(1) ; \quad \%$ devido a posição muito próxima de uma carga end

end

end

$\mathrm{x}=1: 100$

$\mathrm{y}=1: 100$;

$[\mathrm{x}, \mathrm{y}]=\operatorname{mesh} \operatorname{mrid}(\mathrm{x}, \mathrm{y})$;

$\operatorname{mesh}(\mathrm{x}, \mathrm{y}, \mathrm{E}) ; \quad$ \% plota o gráfico da energia

\section{Seleção}

function $[\mathrm{S}]=\operatorname{selecao}(\mathrm{UQ})$

\% Seleção -> Retorna os 4 melhores indivíduos de da população P

$[\mathrm{E} 1, \mathrm{p} 1]=\min (\mathrm{UQ}) ;$ \%Acha o valor e aposição da menor energia

$\mathrm{UQ}(1, \mathrm{p} 1)=1000 * \mathrm{E} 1 ; \%$ atribui um valor alto para o caminho para procuar \% o segundo melhor caminho

$[\mathrm{E} 2, \mathrm{p} 2]=\min (\mathrm{UQ})$; \%Acha o valor e aposição da segunda menor energia $\mathrm{UQ}(1, \mathrm{p} 2)=1000 * \mathrm{E} 2$;

$[\mathrm{E} 3, \mathrm{p} 3]=\min (\mathrm{UQ})$; \%Acha o valor e aposição da terceira menor energia $\mathrm{UQ}(1, \mathrm{p} 3)=1000 * \mathrm{E} 3$;

$[\mathrm{E} 4, \mathrm{p} 4]=\min (\mathrm{UQ}) ; \%$ Acha o valor e aposição da quarta menor energia

$\mathrm{S}=[\mathrm{p} 1 \mathrm{p} 2$ p3 p4;E1 E2 E3 E4];

End

\section{Densidade}


function $[\mathrm{C}]=$ Densidade $(\mathrm{Q})$

\% Calcula e mostra a densidade de cargas da melhor distribuição de cargas

$\%$ de Q na figura1, subplot 4

$\mathrm{A}=[\mathrm{Q}(:, 1), \mathrm{Q}(:, 2)] ; \%$ guarda o melhor indivíduo de $\mathrm{Q}$

[B ] = hist3(A,[100 100]); \%B recebe a matriz 100x100 com o número

$\%$ de cargas em cada posição

$\mathrm{C}=$ zeros(80); $\quad$ \% Prealoca a matriz C 80x80 com valores zero

for $\mathrm{a}=1: 80 \quad \%$ eixo $\mathrm{x}$ da matriz densidade

for $b=1: 80 \quad \%$ enxi y da matriz densidade

for $c=(a):(a+20)$

for $d=(b):(b+20)$

$\mathrm{C}(\mathrm{a}, \mathrm{b})=\mathrm{C}(\mathrm{a}, \mathrm{b})+\mathrm{B}(\mathrm{c}, \mathrm{d}) ; \%$ soma os valores ao redor do

$\%$ ponto a,b para a matriz densidade

end

end

end

end

$x=1: 80$;

$\mathrm{y}=1: 80$;

$[\mathrm{x}, \mathrm{y}]=\operatorname{meshgrid}(\mathrm{x}, \mathrm{y})$;

mesh $(\mathrm{x}, \mathrm{y}, \mathrm{C}) ; \quad$ \% Plota o gráfico com a densidade

\section{DistQ2 \%diferentes constantes dielétricas}

function [ UQ ] = DistQ(Q)

\% Calcula a distância para cada Indivíduo da população P e retorna DG

$\operatorname{dim}=\operatorname{size}(\mathrm{Q}) ; \%$ pega o numero de cargas (cromossomos) e indivíduos

$\mathrm{k}=\operatorname{dim}(1) ; \quad \%$ recebe o número de cargas (cromossomos)

$1=\operatorname{dim}(2) / 2 ; \quad \%$ recebe o número de indivíduos

$\mathrm{E} 1 \mathrm{Q}=0$;

$\mathrm{UQ}=\operatorname{zeros}(1,1) ; \quad \%$ zera a matriz Energia dos indivíduos 
for $\mathrm{a}=1: 2: 2 * 1 \%$ anda nos indivíduos (passo 2 pois cada ind. tem 2 colunas) for $\mathrm{b}=1: \mathrm{k}-1 \quad \%$ anda nos cromossomos

for $\mathrm{c}=\mathrm{b}+1: \mathrm{k}$

if $(\mathrm{Q}(\mathrm{b}, \mathrm{a})>0.5) \& \&(\mathrm{Q}(\mathrm{b}, \mathrm{a}+1)>0.5) \%$ verifica se

\% a carga está na área de maior constante dielétrica

$\mathrm{E} 1 \mathrm{Q}=\mathrm{E} 1 \mathrm{Q}+2 /(\operatorname{sqrt}(\operatorname{power}(\mathrm{Q}(\mathrm{b}, \mathrm{a})-\mathrm{Q}(\mathrm{c}, \mathrm{a}), 2)+\operatorname{power}(\mathrm{Q}(\mathrm{b}, \mathrm{a}+1)-$ $\mathrm{Q}(\mathrm{c}, \mathrm{a}+1), 2)))$;

\% multiplica a energia por 2 (dobro da constande diel.

else \% área de menor constante dielétrica

$\mathrm{E} 1 \mathrm{Q}=\mathrm{E} 1 \mathrm{Q}+1 /(\operatorname{sqrt}(\operatorname{power}(\mathrm{Q}(\mathrm{b}, \mathrm{a})-\mathrm{Q}(\mathrm{c}, \mathrm{a}), 2)+\operatorname{power}(\mathrm{Q}(\mathrm{b}, \mathrm{a}+1)-$ $\mathrm{Q}(\mathrm{c}, \mathrm{a}+1), 2)))$;

\% Calculo normal da energia

end

end

$\mathrm{UQ}((\mathrm{a}+1) / 2)=\mathrm{UQ}((\mathrm{a}+1) / 2)+\mathrm{E} 1 \mathrm{Q} ; \quad \%$ soma a energa E1Q

$\mathrm{E} 1 \mathrm{Q}=0 ; \quad$ \% zera o $\mathrm{E} 1 \mathrm{Q}$ para o próximo for ' $\mathrm{c}$ '

end

end

end 


\section{APÊNDICE D - Programa para o Microcontrolador Atmega - placa}

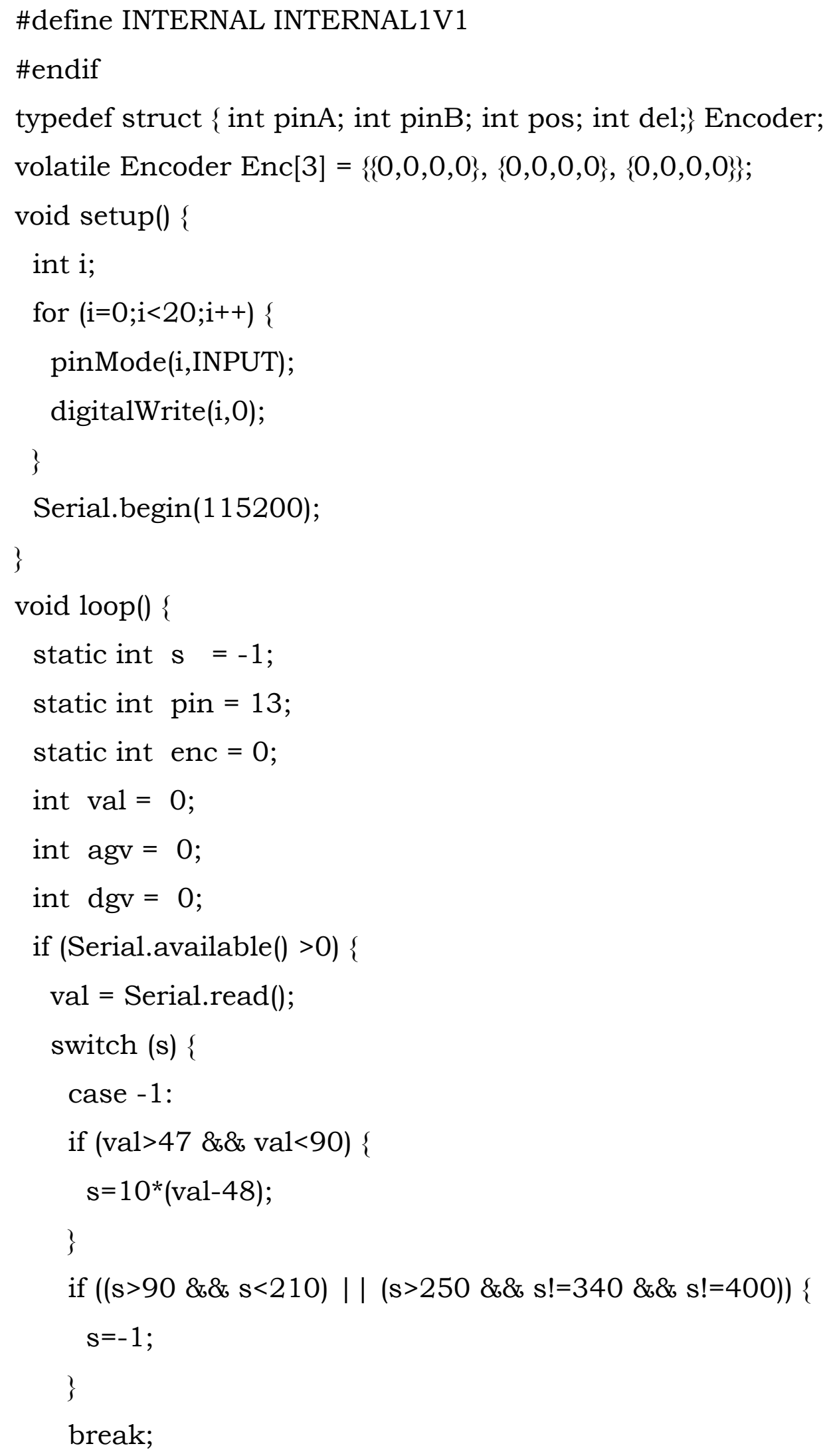




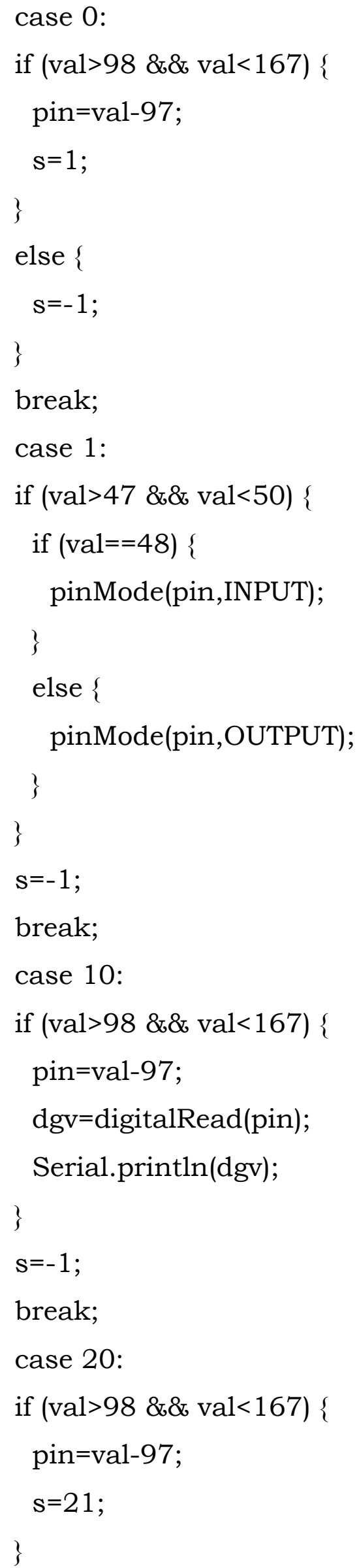




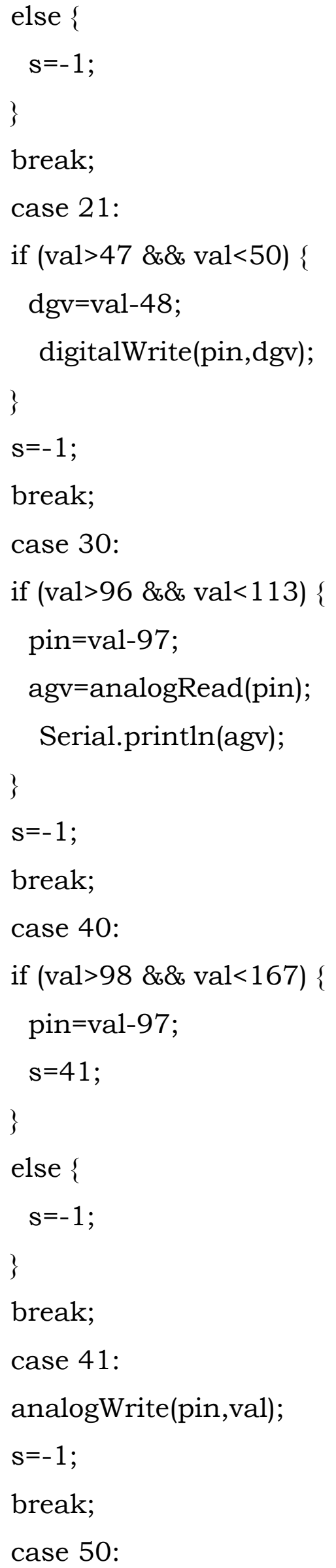




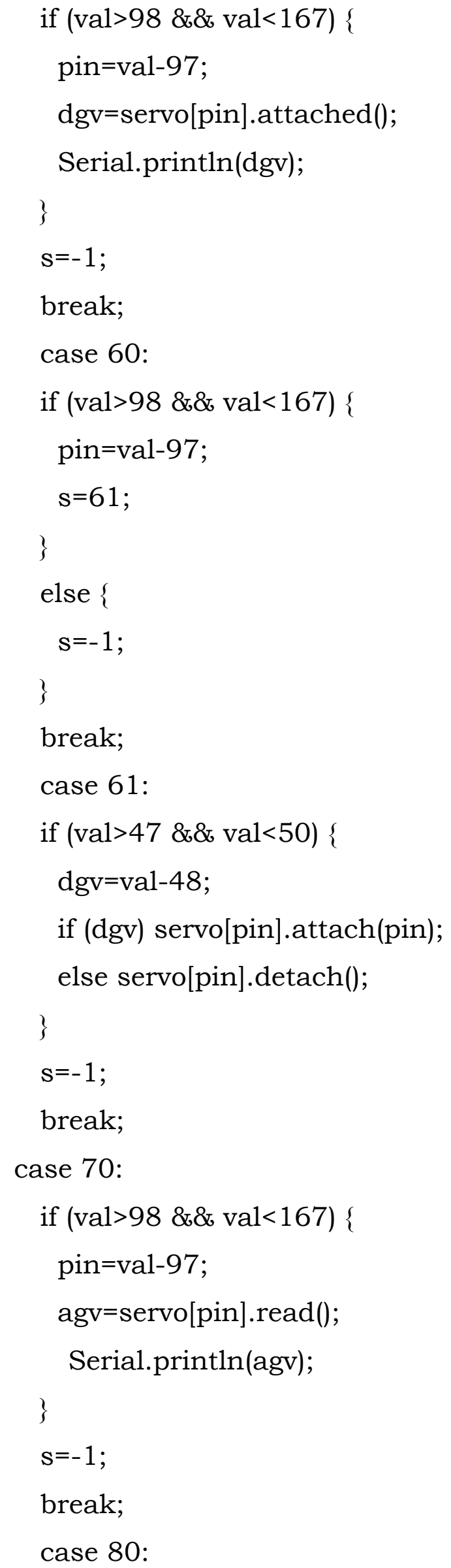




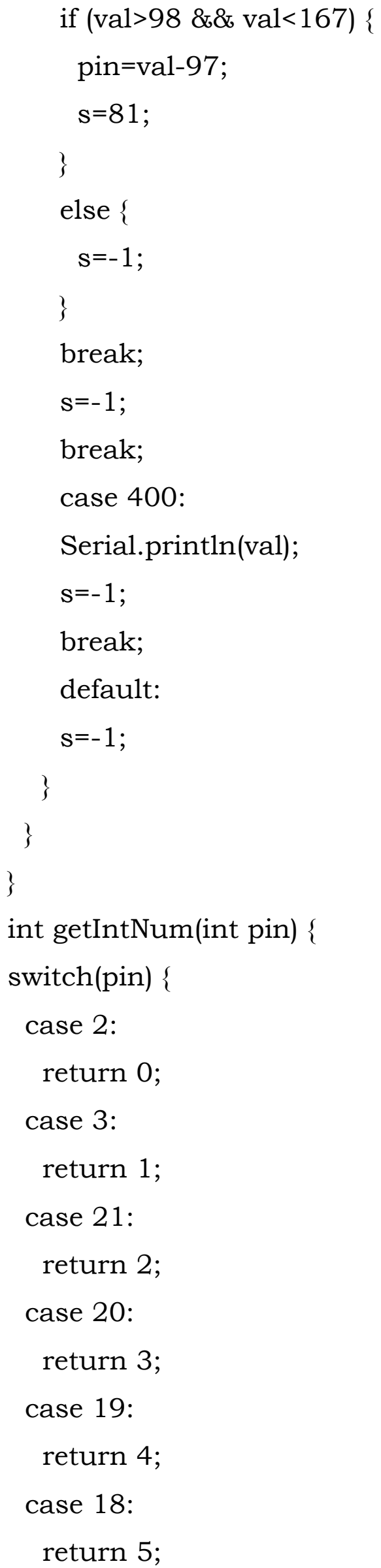




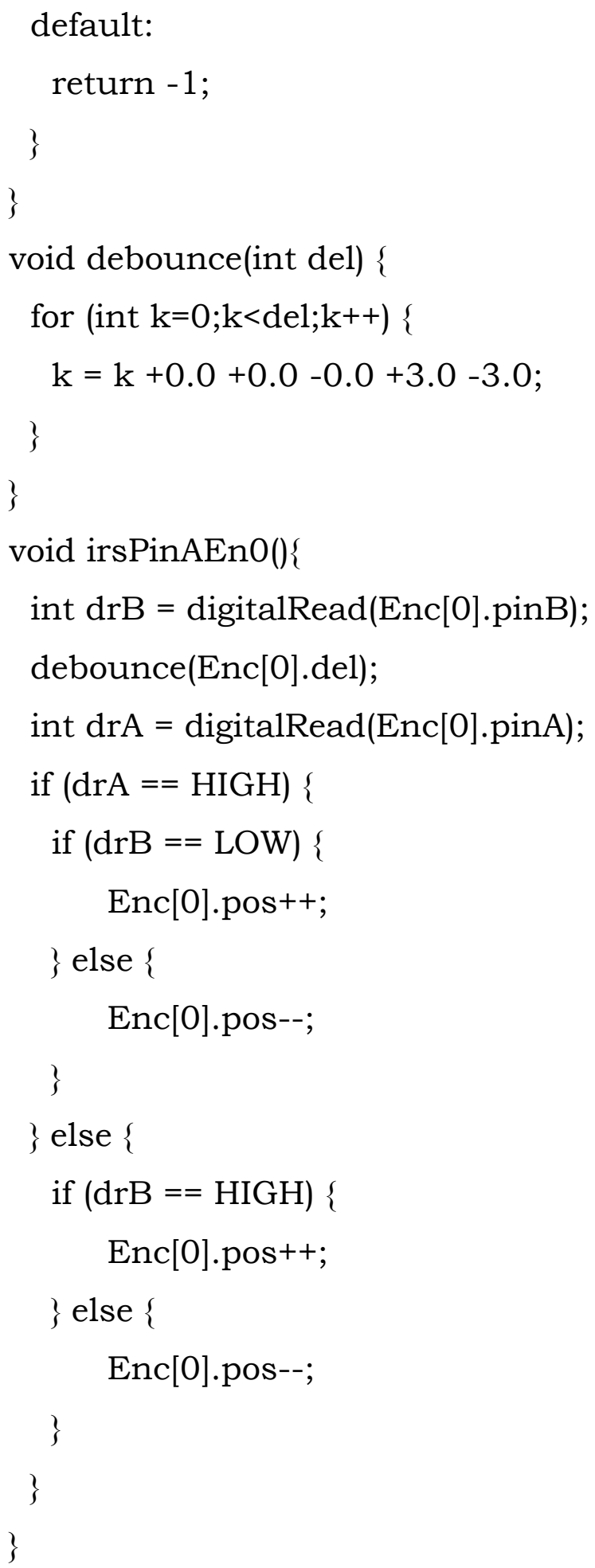




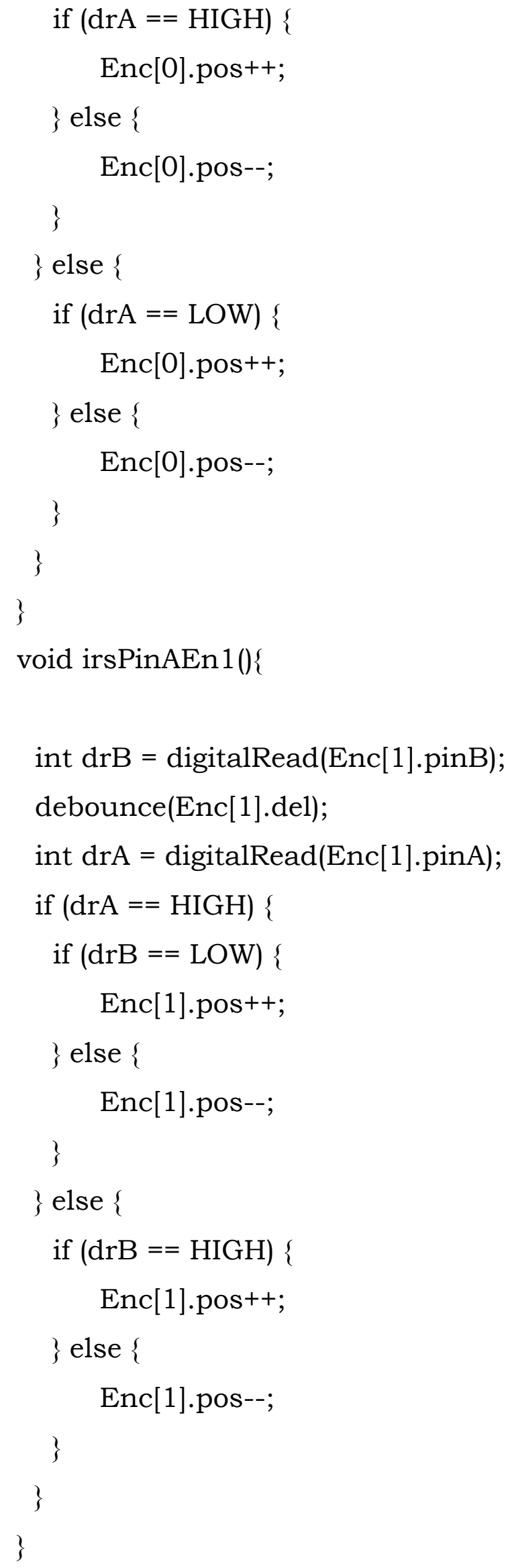




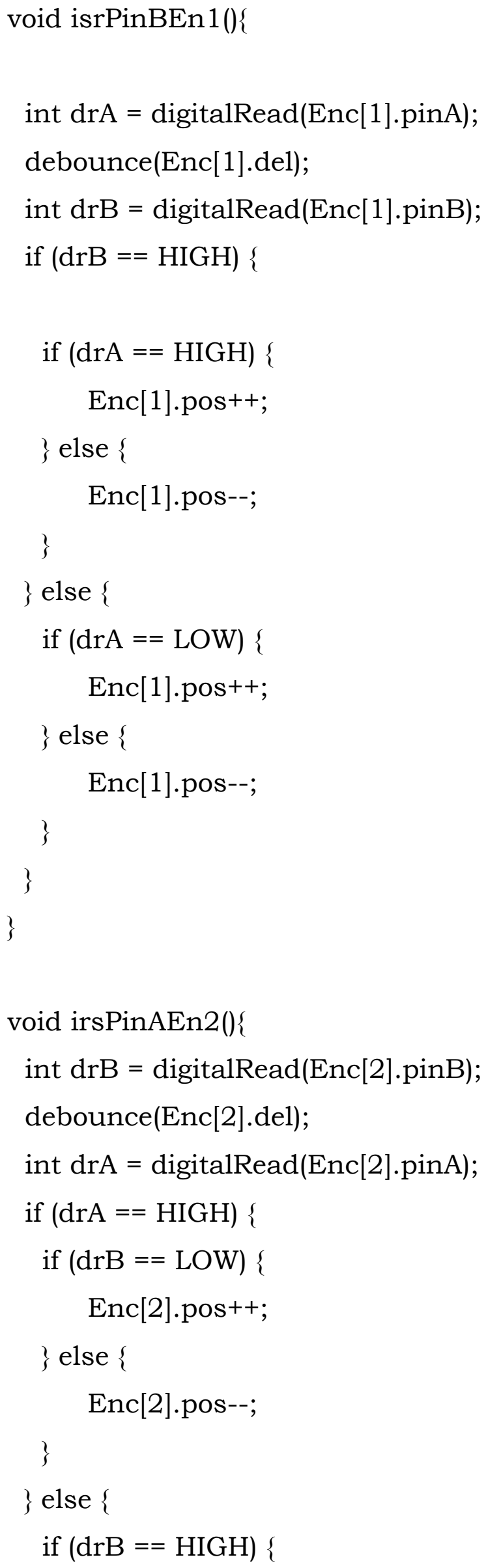




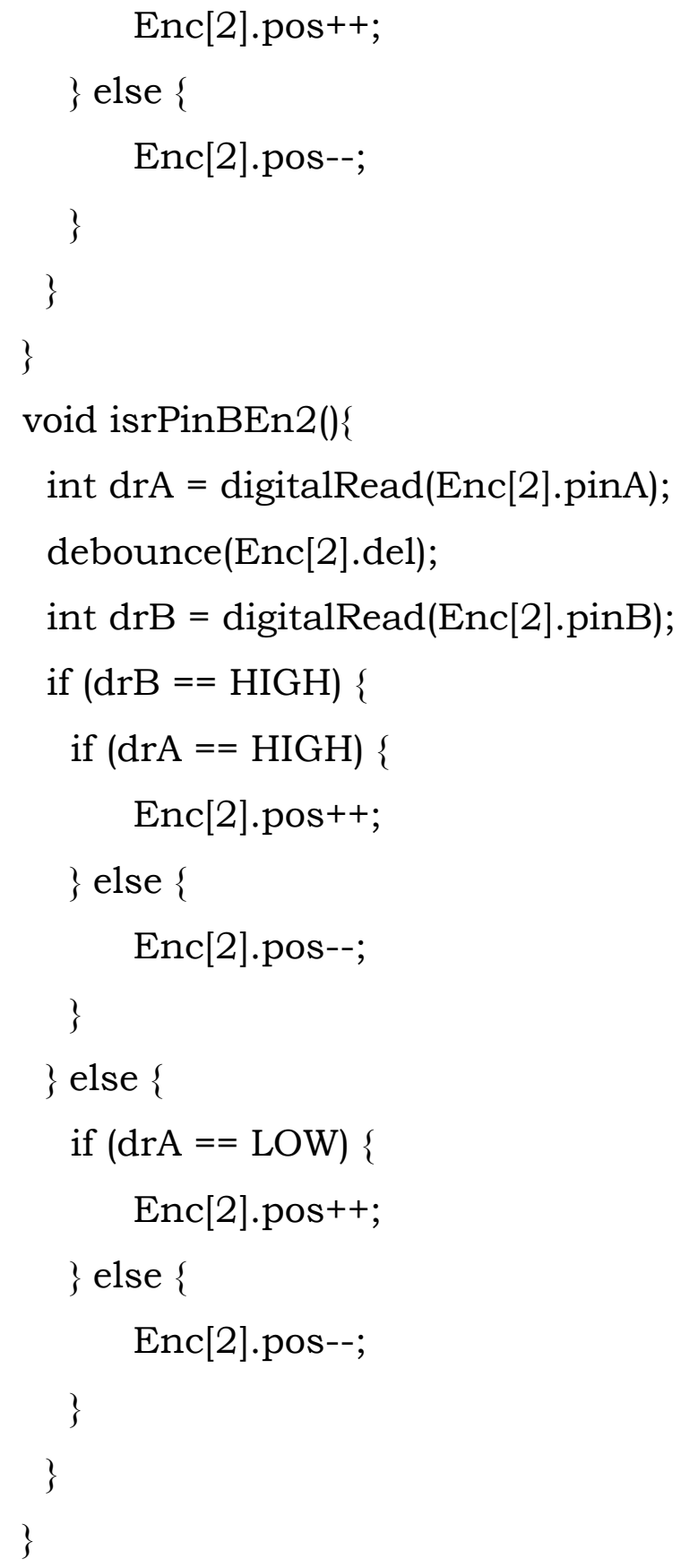

